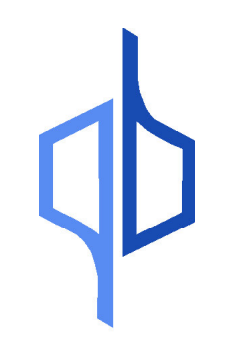

Universidade de São Paulo

Instituto de Química

\title{
COMPÓSITOS FORMADOS POR POLIETILENO MODIFICADO E CELULOSE: OBTENÇÃO E CARACTERIZAÇÃO
}

Romeu Casarano

Tese de Mestrado

Profa. Dra. Denise Freitas Siqueira Petri

Orientadora

São Paulo - SP

2004 
Agradeço aos meus pais, Ettore Casarano e Iracema Tagliari Casarano, às minhas irmãs, Isabel Cristina Casarano e Sonia Maria Casarano (in memoriam) e aos meus sobrinhos, Erico Vinicius Casarano Moraes e Patrícia Monteiro, pelo apoio, carinho e incentivo. 


\section{Agradecimentos}

À Profa. Dra. Denise Freitas Siqueira Petri, pela oportunidade e confiança prestada a mim na execução deste trabalho.

À Profa. Dra. Daisy de Brito Rezende, pela oportunidade que me foi dada de iniciar o Mestrado nesta instituição.

Aos colegas de Laboratório, nomeadamente, Alliny, André, Arlete, Caio, Juliana, Karina, Lizandra, Sabrina e, em especial, ao Paulo Guilherme e à Priscila, pelos bons momentos desfrutados e pelas colaborações dadas.

À Profa. Dra. Nicole Raymonde Demarquette e aos seus técnicos, nomeadamente, Juliana, Sendy, Rafael e Roger, EPMT-USP, pelas contribuições dadas à realização desta Tese.

Aos Profs. Drs. Josef Wilhelm Baader e Luiz Henrique Catalani, assim como aos seus respectivos alunos e ao técnico Luiz, pelas contribuições dadas para a realização desta Dissertação.

Ao Prof. Dr. Yoshio Kawano, ao Laércio e ao Luiz, pelas contribuições dadas para a realização desta Dissertação.

Ao Dr. Arnaldo Antonio Couto e ao Mariano, IPEN, por permitirem a realização dos ensaios de tração.

À Selma e ao Nelson, IPT, por emprestarem o cunho para cortar os corpos de provas para os ensaios de tração.

À Profa. Dra. Márcia Carvalho de Abreu Fantini, IFUSP, pela realização dos ensaios de $\mathrm{XRD}$.

À Profa. Dra. Patrícia Helena Lara dos Santos Matai e aos técnicos Antonio Carlos e Marcelo, EPQI, por possibilitarem a realização dos ensaios de MFI.

Ao Eng. Sérgio D. Almeida, Politeno-SP, pelo fornecimento das amostras de polietileno.

Às agências de fomento à pesquisa, Capes, pela bolsa de estudo, e Fapesp, pela verba indireta.

Ao Prof. Dr. Jivaldo do Rosário Matos e aos seus alunos, pela realização dos ensaios de TG e DSC.

Aos Profs. que ministraram as disciplinas de Pós-Graduação, pela dedicação. 


\section{Índice}

RESUMO

ABSTRACT

LISTA DE SÍMBOLOS E ABREVIATURAS iii

1. INTRODUÇÃO 1

1.1. Compósito e funcionalização 1

1.2. Polietileno 2

1.3. Celulose e acetato-butirato de celulose 6

1.4. Reações envolvendo radicais livres 8

1.5. Técnicas 10

1.5.1. Espectroscopia no infravermelho com transformada de Fourier (FTIR) 10

1.5.2. Cromatografia gasosa acoplada à espectrometria de massas (GC-MS) 12

1.5.3. Calorimetria exploratória diferencial (DSC) 13

1.5.4. Termogravimetria (TG) e termogravimetria derivada (DTG) 14

1.5.5. Índice de fluidez no fundido (MFI) 16

1.5.6. Medidas de ângulo de contato 16

$\begin{array}{ll}\text { 1.5.7. Difração de raios X (XRD) } & 18\end{array}$

1.5.8. Microscopia eletrônica de varredura (SEM) 22

1.5.9. Ensaios mecânicos de tração 23

2. OBJETIVOS 25

3. EXPERIMENTAL 26

3.1. Materiais 26

3.1.1. Matriz polimérica 26

3.1.2. Agentes funcionalizantes $\quad 27$

3.1.3. Agentes iniciadores $\quad 29$

3.1.4. Polissacarídeos 31

3.1.5. Solventes 33

3.2. Métodos 33

3.2.1. Funcionalização por processamento reativo 33

3.2.2. Obtenção de compósitos (e blendas)

3.2.3. Funcionalização em solução 36

3.2.4. Funcionalização superficial por radiação ultravioleta (UV) 37

3.2.5. Purificação das amostras funcionalizadas 37

3.2.6. Obtenção de filme por evaporação do solvente ("casting") 38

3.2.7. FTIR e curvas de calibração 39

3.2.8. GC-MS 43

3.2.9. Análise elementar 44

3.2.10. DSC 44

3.2.11. TG e DTG

3.2.12. MFI 45

3.2.13. Obtenção de placas por prensagem $\quad 46$

3.2.14. Medidas de ângulo de contato $\quad 47$

3.2.15. XRD 47 
3.2.16. SEM 48

3.2.17. Ensaios mecânicos de tração 48

4. RESULTADOS e DISCUSSÃO 50

4.1. Funcionalização em solução 50

4.1.1. Reatividade do alil glicidil éter (AGE) na ausência de polietileno (PE) em tolueno $\left(93^{\circ} \mathrm{C}\right)$

4.1.2. Funcionalização em clorobenzeno $\left(93^{\circ} \mathrm{C}\right.$ e $\left.121^{\circ} \mathrm{C}\right)$ e xileno $\left(121^{\circ} \mathrm{C}\right) \quad 53$

4.1.2.1. Determinação do grau de funcionalização (GF) por FTIR 54

4.1.2.2. Mecanismo na funcionalização em solução $\quad 57$

4.2. Funcionalização superficial por radiação UV 60

4.2.1. Caracterização das superfícies por medidas de ângulo de contato 61

4.2.2. Mecanismo na funcionalização superficial por radiação UV 64

4.3. Funcionalização por processamento reativo 67

4.3.1. Determinação do GF por FTIR $\quad 70$

4.3.2. Mecanismo na funcionalização por processamento reativo 73

4.3.3. Confirmação da funcionalização por meio de outras técnicas $\quad 76$

4.3.3.1. Análise elementar 76

4.3.3.2. Análise térmica por TG e DTG 77

4.3.3.3. Análise térmica por DSC 79

$\begin{array}{ll}\text { 4.3.3.4. Análise por XRD } & 82\end{array}$

4.3.4. Determinação do MFI $\quad 86$

4.4. Obtenção de compósitos (e blendas)

4.4.1. Efeito da funcionalização e do processamento nas propriedades mecânicas do PE $\quad 89$

4.4.2. Compósitos obtidos com celulose fibra curta 93

4.4.3. Compósitos obtidos com celuloses fibras média e longa 99

4.4.4. Blendas obtidas com acetato-butirato de celulose 103

4.4.5. Caracterização por SEM 105

4.4.6. Extração em xileno sob refluxo 108

5. CONCLUSÃO 111

6. REFERÊNCIAS BIBLIOGRÁFICAS 113

$\begin{array}{ll}\text { 7. CURRICULUM VITAE } & 120\end{array}$ 


\section{RESUMO}

A primeira parte desta Tese incluiu a funcionalização em solução de polietileno linear de média densidade (LMDPE) com alil glicidil éter (AGE), na presença de peróxido de benzoíla (BPO) como iniciador de reações radicalares. A caracterização foi feita por espectroscopia no infravermelho com transformada de Fourier (FTIR) e o grau de funcionalização (GF) foi estimado por meio de duas curvas de calibração. Foi observado efeito do tipo de solvente sobre o GF.

A segunda parte consistiu na funcionalização superficial por radiação ultravioleta (UV). Como monômeros foram usados AGE, anidrido maléico (MAH) e anidrido tetraidroftálico (THFAH). Como iniciadores, BPO e benzofenona (BP). A caracterização das superfícies foi realizada por medidas de ângulo de contato. THFAH apresentou a melhor performance.

A terceira tratou da funcionalização por processamento reativo do LMDPE com AGE, na presença de BPO. A caracterização se deu por FTIR e o GF foi estimado conforme descrito acima. A funcionalização foi confirmada (indiretamente) por calorimetria diferencial exploratória, que evidenciou a diminuição do grau de cristalinidade com a funcionalização. Não foi possível confirmar a funcionalização por meio de análise elementar, termogravimetria e difração de raios $X$. A fragmentação das cadeias do LMDPE funcionalizado do ensaio 13 (e 13A) foi evidenciada por decréscimo no torque e nas propriedades mecânicas. Contudo, o índice de fluidez, surpreendentemente, diminuiu. Os valores relativamente superiores de resistência à tração e módulo de Young dos compósitos e blendas obtidos com LMDPE funcionalizado, contra os obtidos com LMDPE virgem, evidenciaram a interação favorável entre os grupos epóxidos inseridos nas cadeias do LMDPE e os grupos hidroxilas presentes no polissacarídeo. $O$ aumento da adesão entre a matriz polimérica e as fibras de celulose foi confirmado por microscopia eletrônica de varredura e, qualitativamente, por quantidades relativamente maiores de resíduos remanescentes após extração em xileno sob refluxo. 


\section{ABSTRACT}

The first part of this work included the functionalization in solution of linear medium density polyethylene (LMDPE) with allyl glycidyl ether (AGE), in the presence of benzoyl peroxide (BPO) as free radical reaction initiator. The characterization was made by Fourier transform infrared spectroscopy (FTIR) and the degree of functionalization was estimated by means of two calibration curves. The type of solvent influenced the DF.

The second part comprised the surface functionalization by ultraviolet (UV) radiation. AGE, maleic anhydride $(\mathrm{MAH})$ and tetrahydrophthalic anhydride (THFAH) were used as monomers and BPO and benzophenone (BP) as initiators. Contact angle measurements were used to characterize the surfaces. THFAH showed the best performance.

The third part dealt with the functionalization by reactive processing of LMDPE with AGE, in the presence of BPO. FTIR was used to characterize the samples and the degree of functionalization was estimated as described above. The functionalization was (indirectly) confirmed by differential scanning calorimetry. The degree of crystallinity decreased with the functionalization. The functionalization couldn't be confirmed by elemental analysis, thermogravimetry and X-ray diffraction. The chain scissions of the chemical modified LMDPE of trial 13 (and 13A) were evidenced by reduction of torque and mechanical properties. However, the melt flow index diminished. The favorable interaction between epoxide groups inserted on LMDPE chains and hydroxyl groups present in polysaccharide caused the increase in tensile strength and Young's modulus values for composites and blends in relation to those obtained with virgin LMDPE. The increase in adhesion between the polymeric matrix and cellulose fibers was also confirmed by scanning electron microscopy and, qualitatively, by relatively large amounts of remaining residues after extraction in refluxing xylene. 


\section{LISTA DE SÍMBOLOS E ABREVIATURAS}

AGE: Alil glicidil éter.

AIBN: Azo-bis-isobutironitrilo.

ASTM: American Society for Testing Materials.

BP: Benzofenona.

BPO: Peróxido de benzoíla.

BUT-CEL: Acetato-butirato de celulose.

DSC: Calorimetria exploratória diferencial.

DTG: Termogravimetria derivada.

E: Módulo de Young.

EF: Eficiência da funcionalização.

El: Impacto eletrônico.

FTIR: Espectroscopia no infravermelho com transformada de Fourier.

GC-MS: Cromatografia gasosa acoplada à espectrometria de massas.

GF: Grau de funcionalização.

HDPE: Polietileno de alta densidade.

IPEN: Instituto de Pesquisas Energéticas e Nucleares de São Paulo.

IPT: Instituto de Pesquisas Tecnológicas de São Paulo.

LDPE: Polietileno de baixa densidade.

LF-CEL: Polpa de celulose Kraft branqueada de pinus Elliotti e Taeda, fibra longa.

LLDPE: Polietileno linear de baixa densidade.

LMDPE: Polietileno linear de média densidade, poli(etileno-co-1-buteno).

LMDPE : Polietileno linear de média densidade virgem. 
LMDPE$E_{x}$ : Polietileno linear de média densidade funcionalizado, onde $x$ refere-se ao número do ensaio da amostra funcionalizada por processamento reativo.

MAH: Anidrido maléico.

MF-CEL: Polpa de celulose Kraft branqueada de eucalipto, considerada como fibra média.

MFI: Índice de fluidez no fundido.

$\boldsymbol{m} / \boldsymbol{m}$ : Relação massa sobre massa.

PE: Polietileno.

Ph-: Grupo fenila.

SEM: Microscopia eletrônica de varredura.

SF-CEL: Celulose fibrosa em pó, considerada como fibra curta.

$\boldsymbol{T}_{f:}$ Temperatura de fusão.

$T_{g}$ : Temperatura de transição vítrea.

TG: Termogravimetria.

THFAH: Anidrido tetraidroftálico.

ULF-CEL: Polpa de celulose Kraft não branqueada de pinus Radiata, fibra longa.

UV: Ultravioleta.

XRD: Difração de raios $\mathrm{X}$.

$\beta$ : Razão de aquecimento.

$\varepsilon$ : Elongação.

$\varepsilon_{y}$ : Elongação no ponto de escoamento ("yield point").

$\varepsilon_{b}$ : Resistência à tração na ruptura.

$\Delta \theta$ : Histerese do ângulo (de contato). 
$\Delta \boldsymbol{H}_{\boldsymbol{f}}$ : Variação da entalpia de fusão.

$\theta$ : ângulo de contato.

$\boldsymbol{\theta}_{\boldsymbol{x}}$ : Ângulo formado entre a direção dos raios $\mathrm{X}$ e o plano do retículo cristalino.

$\boldsymbol{\theta}_{\text {avanço: }}$ Ângulo de contato de avanço.

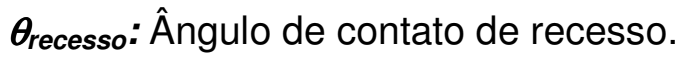

$\lambda$ : Comprimento de onda.

$\boldsymbol{\sigma}$ : Tensão.

$\sigma_{y}$ : Resistência à tração no ponto de escoamento ("yield point").

$\sigma_{m}:$ Resistência à tração máxima.

$\sigma_{b}$ : Resistência à tração na ruptura.

$\chi_{c}$ : Grau de cristalinidade. 


\section{INTRODUÇÃO}

\subsection{Compósito e funcionalização}

Compósito é um material formado por duas fases, uma matriz polimérica contínua (que possui propriedades mecânicas inferiores às da fase descontínua) e uma fase dispersa de reforço (cargas como fibras, óxidos, negro de fumo, argilas). Entretanto, um dos problemas associados à utilização de fibras naturais como reforço em compósitos poliméricos é a elevada higroscopicidade destas fibras e sua fraca adesão com a matriz polimérica (principalmente, apolar), por causa da sua hidrofilicidade. A modificação química das fibras ou de matrizes poliméricas é uma das soluções que tem sido empregada para contornar estes problemas. Nesse sentido, os polissacarídeos (polares, hidrofílicos), como quitosana e celulose, podem ser utilizados como carga de reforço sem modificação prévia (para matrizes poliméricas polares), pois as suas estruturas originais já apresentam grupos reativos. ${ }^{1,2}$ Poliolefinas (apolares, hidrofóbicas) são polímeros sintéticos de baixo custo e fácil processabilidade. ${ }^{3 a}$ Entretanto, a baixa energia superficial e baixa reatividade das poliolefinas impedem a adesão delas a outros substratos polares. ${ }^{4}$ Por essa razão, as cadeias das poliolefinas são modificadas com monômeros bifuncionais, normalmente contendo uma ligação dupla (que se liga à cadeia polimérica, por meio de reação radicalar) e um grupo polar, como anidridos, ácidos carboxílicos, ésteres ou epóxidos (que interage física ou quimicamente com a carga polar). A modificação das poliolefinas por inserção de grupos funcionais específicos pode se dar em solução (reações químicas em solução) ou por processamento reativo (reações químicas envolvendo a poliolefina fundida) em misturadores mecânicos (como reômetro de torque). Uma boa adesão interfacial ou compatibilidade entre a matriz polimérica e a carga fibrosa é essencial para a dispersão da celulose e transferência de tensão da matriz polimérica para as fibras e, assim, obter compósitos com melhores resistências mecânicas. ${ }^{5,6}$ 
Pode-se destacar alguns dos monômeros normalmente empregados na funcionalização de poliolefinas, tais como anidrido maléico ${ }^{7-10}$ (inclusive, estas poliolefinas modificadas já são empregadas comercialmente), ${ }^{11}$ ácido acrílico, ${ }^{12}$ metacrilato de etil dimetilamino, ${ }^{13}$ ácido itacônico, ${ }^{14}$ metacrilato fosfonatado, ${ }^{15}$ anidrido tetraidroftálico ${ }^{16}$ e metacrilato de glicidil ${ }^{17-19}$ (também já há emprego comercial destas poliolefinas funcionalizadas). ${ }^{20} \mathrm{O}$ alil glicidil éter, nos trabalhos correlatos citados na literatura, foi utilizado na funcionalização de celulose, ${ }^{21,22}$ mas não na de poliolefinas. Na literatura há trabalhos que reportam blendas de poliolefinas modificadas com metacrilato de glicidil (que possui um grupo epóxido na molécula, como o alil glicidil éter) com poli(tereftalato de butileno), ${ }^{23}$ ou com borracha nitrílica modificada com ácido acrílico ${ }^{24}$ ou com poliéster, ${ }^{25}$ mas não há de compósitos de poliolefinas modificadas com metacrilato de glicidil e celulose.

\subsection{Polietileno}

A primeira conversão de eteno em polímeros de altas massas molares foi realizada em 1933 por Fawcett e Gibson das industrias Imperial Chemical (Reino Unido), durante uma investigação da reação entre eteno e benzaldeído, em um processo de alta pressão. A primeira planta comercial para a produção de polietileno de baixa densidade (LDPE), pelo processo de alta pressão, foi inaugurada em 1939 e até 1955 todos os polietilenos comerciais eram produzidos por processos de alta pressão. Em 1953, o pesquisador Ziegler, na Alemanha, e as empresas Phillips Petroleum Co. e Standard Oil Co., nos Estados Unidos da América, quase simultaneamente, descobriram métodos, por meio dos quais, as altas pressões (e as altas temperaturas) podiam ser evitadas, na obtenção do assim chamado polietileno de alta densidade (HDPE). A primeira planta usando o processo Ziegler iniciou sua operação em 1955 (Farbwerke Hoechst A.G.), enquanto que, as primeiras usando os processos Phillips e Standard Oil, iniciaram as suas produções em 1957 e 1961, respectivamente. ${ }^{26 a}$ No final dos anos de 1970, o polietileno linear de baixa ou média densidade (LLDPE ou LMDPE) começou a despertar considerável interesse, o qual possui propriedades e 
estruturas intermediárias entre HDPE e LDPE. O polietileno de muito baixa densidade (VLDPE) foi desenvolvido pela Union Carbide em $1985 .^{27}$

As poliolefinas são comercialmente produzidas usando iniciadores radicalares (processo de alta pressão), catalisadores tipo Phillips, tipo Ziegler-Natta e, mais recentemente, à base de metalocenos. ${ }^{28}$ Os processos industriais que usam os catalisadores tipo Ziegler-Natta são os mais importantes, em virtude da grande extensão de aplicações dos produtos obtidos pelo uso desses tipos de catalisadores. No processo Ziegler, a pressão varia de $2 \mathrm{~atm}$ a 4 atm e a temperatura de $70^{\circ} \mathrm{C}$ a $100^{\circ} \mathrm{C}$. Os catalisadores usados são derivados de metais dos Grupos IV-VIII B mais os dos Grupos I-III A, por exemplo, Ti[Cl] $]_{4}-\left[\mathrm{CH}_{3} \mathrm{CH}_{2}\right]_{3} \mathrm{Al}$. O mecanismo de reação é do tipo coordenação-inserção, ou seja, o monômero é coordenado com o metal de transição e a extremidade da cadeia em propagação, seguido de inserção do monômero entre o catalisador e a extremidade da cadeia em propagação. ${ }^{27}$ No processo Phillips, a pressão varia de 14 atm a 34 atm e a temperatura de $130^{\circ} \mathrm{C}$ a $160^{\circ} \mathrm{C}$. Os catalisadores usados são preparados a partir da mistura de $5 \%$ de óxidos de cromo, principalmente, trióxido de cromo, e 95\% de alumina-sílica, a qual serve de suporte e é constituída de $75 \%$ a $90 \%$ de sílica. ${ }^{27}$ No processo Standard Oil, a pressão varia de $40 \mathrm{~atm}$ a $80 \mathrm{~atm}$ e a temperatura de $230^{\circ} \mathrm{C}$ a $270^{\circ} \mathrm{C}$. O catalisador usado é o óxido de molibdênio suportado em alumina, em dióxido de titânio ou em dióxido de zircônio. ${ }^{27}$

O LDPE contém muitas ramificações de cadeia curta e longa, originadas de forma aleatória. Apresenta densidade de $0,915 \mathrm{~g} \mathrm{~cm}^{-3}$ a $0,930 \mathrm{~g} \mathrm{~cm}^{-3}$ e grau de cristalinidade de $45 \%$ a $55 \%$. ${ }^{3 a}$ É produzido em condições de alta pressão (1000 atm a $3000 \mathrm{~atm})$ e alta temperatura (80ํ $\mathrm{C}$ $300^{\circ} \mathrm{C}$ ), usando iniciadores radicalares (como peróxido de benzoíla e oxigênio). ${ }^{27}$ É usado predominantemente para produção de filmes. O HDPE tem pouca, ou nenhuma, ramificação de cadeia curta (em homopolímeros) e não contém ramificação de cadeia longa. Apresenta densidade de 
$0,940 \mathrm{~g} \mathrm{~cm}^{-3}$ a $0,970 \mathrm{~g} \mathrm{~cm}^{-3}$ e grau de cristalinidade de $70 \%$ a $90 \%$. $^{3 \mathrm{a}} \mathrm{E}$ produzido pelos processos Ziegler, Phillips e Standard Oil. É usado em aplicações estruturais, por causa de sua maior rigidez. O LLDPE (ou LMDPE) contém (de forma proposital e controlada) ramificações de cadeia curta (com 1, 2, 4 ou 6 átomos de carbono) como conseqüência da copolimerização de eteno com outra $\alpha$-olefina (1-propeno, 1-buteno, 1-hexeno ou 1-octeno). ${ }^{3 a}$ Essas ramificações são introduzidas de forma ordenada e, variando-se a quantidade e tipo de $\alpha$-olefina, tipo de catalisador e condições de copolimerização, pode-se produzir várias classes de copolímeros para se adequar às demandas específicas de mercado. Não contém ramificações de cadeia longa, sendo por isso referido como "linear", para diferenciá-lo do LDPE. Apresenta densidade de $0,915 \mathrm{~g} \mathrm{~cm}^{-3}$ a $0,940 \mathrm{~g} \mathrm{~cm}^{-3}$ e grau de cristalinidade intermediário entre HDPE e LDPE. ${ }^{3 a}$ É produzido em condições de baixa pressão $(\sim 20 \mathrm{~atm})$ e baixa temperatura $\left(\sim 100^{\circ} \mathrm{C}\right) \cdot{ }^{27}$ Os catalisadores usados são os dos processos Ziegler $\mathrm{e}$ Phillips. É usado predominantemente para produção de filmes.

As amostras de polímeros podem ser encontradas em diversos graus de organização de suas cadeias. Uma amostra na qual as cadeias encontram-se totalmente desorganizadas é denominada amorfa. Se as cadeias pudessem estar totalmente organizadas, a amostra seria denominada totalmente cristalina. Os polímeros que tendem a apresentar cadeias distribuídas em regiões amorfas e cristalinas organizadas entre si são denominados semicristalinos, como no caso o polietileno. Dependendo de fatores tais como estereorregularidade, simetria, entre outros, os polímeros irão apresentar maior ou menor tendência a cristalizar. ${ }^{29 a}$ Quando amostras de polietileno são cristalizadas a partir de soluções extremamente diluídas, elas formam cristais únicos de forma lamelar. As lamelas têm espessura de $10 \mathrm{~nm}$ a $20 \mathrm{~nm}$, implicando que as cadeias do polietileno estão dobradas, pois o comprimento de contorno das cadeias é de $\sim 200 \mathrm{~nm}{ }^{30}$ Quando as amostras de polietileno são cristalizadas a partir do "bulk", isto é, a partir do material fundido, elas formam esferulitos, que são estruturas 
cristalinas (cristalitos) de forma esférica. Os esferulitos são constituídos de várias lamelas individuais. ${ }^{30} \mathrm{Na}$ Figura 1 é mostrada uma imagem ampliada da superfície do esferulito, onde se podem ver as estruturas lamelares do polietileno, que é um polímero semicristalino. Observam-se as regiões cristalinas (formadas por cadeias paralelas umas em relações as outras) e regiões amorfas (entre as lamelas e as dobras das cadeias), que são ricas em substâncias, tais como, polímeros atáticos, materiais de massa molar baixa ou impurezas de vários tipos. Também são mostradas as moléculas de ligação ("tie molecules"), situadas parcialmente em um cristalito e parcialmente em outro, que mantêm as lamelas individuais no esferulito unidas entre si.

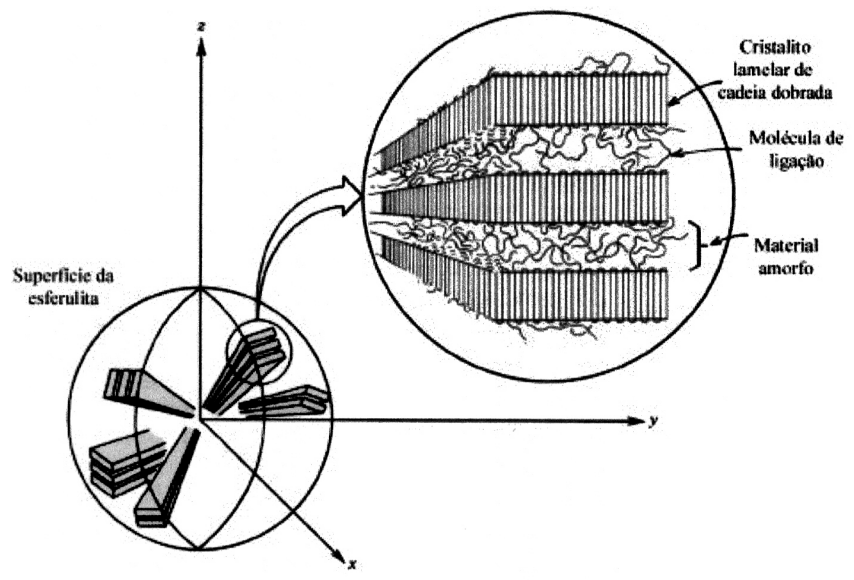

Figura 1 - Representação da estrutura de um polímero semicristalino, como o polietileno.

A cela unitária é definida como a menor porção do retículo cristalino que, deslocada de uma distância igual a suas dimensões, reproduz todo o retículo cristalino. A Figura 2 mostra a cela unitária ortorrômbica do polietileno com as dimensões $\mathrm{a}$, b e c. ${ }^{31} \mathrm{O}$ polietileno apresenta polimorfismo (mais de uma forma cristalina). A outra forma cristalina, menos comum, é a monoclínica. 


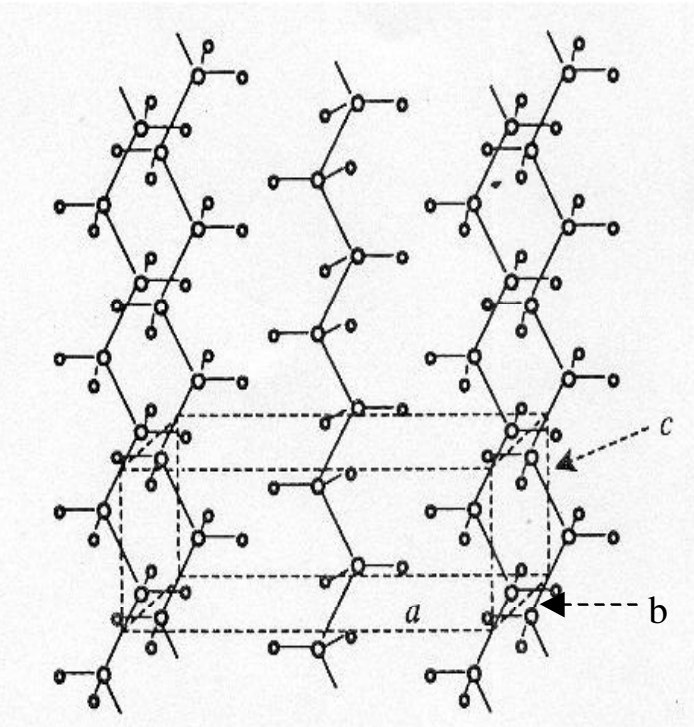

Figura 2 - Secção com 5 cadeias do retículo cristalino ortorrômbico do polietileno em vista lateral.

\subsection{Celulose e acetato-butirato de celulose}

A celulose (polissacarídeo de forma fibrosa) é o polímero natural mais abundante. Entretanto, as fontes comerciais de celulose se limitam à polpa de madeira e ao "linter" de algodão (forma mais pura de celulose natural). ${ }^{32 a}$ Há dois processos de polpação alcalina da madeira, o Soda $(\mathrm{NaOH})$ e Kraft $\left(\mathrm{NaOH}+\mathrm{Na}_{2} \mathrm{~S}\right)$. O objetivo da polpação é cindir um número suficiente de ligações éter na lignina, para produzir fragmentos menores que podem, assim, serem dissolvidos mais facilmente no meio reacional. ${ }^{33} \mathrm{~A}$ pasta celulósica pode ser obtida pelos processos mecânico, químico "pasta para papel", químico "pasta para dissolução", mecanoquímico e semiquímico, nos rendimentos de $90 \%$ a $97 \%, 40 \%$ a $60 \%, 30 \%$ a $45 \%, 85 \%$ a $95 \%$ e $60 \%$ a $85 \%$, respectivamente. ${ }^{32 \mathrm{~b}} \mathrm{~A}$ composição das polpas de madeira (materiais lignocelulósicos) é de $\sim 50 \%$ de celulose (um polissacarídeo linear, constituído por um único tipo de unidade de açúcar, a $\beta$-D-glicose, que são unidas por ligações 1,4- $\beta$ ), 20\% de hemicelulose (um polissacarídeo ramificado e de cadeia mais curta, constituído de vários tipos de unidades de 
açúcar), 15\% a 35\% de lignina (uma macromolécula tridimensional, de composição complexa, que confere firmeza e resistência à compressão, cuja unidade básica é o fenilpropano) e $\sim 10 \%$ de constituintes menores, formados por compostos orgânicos e inorgânicos. ${ }^{32 c} O$ novelo de algodão é composto de fios fibrosos longos e curtos unidos à semente de algodão. As fibras mais longas (> $10 \mathrm{~mm}$ ) são denominadas como fibras de "lint" de algodão, ou algodão principal, e são usadas para produzir fibras têxteis. As fibras mais curtas $(<10 \mathrm{~mm}$ ) são denominadas como fibras de "linter" de algodão e são matérias primas básicas para a modificação química. $O$ linter de algodão cru contém de $65 \%$ a $80 \%$, em massa, de celulose. ${ }^{3 \mathrm{~b}} \mathrm{~A}$ celulose de algodão com alta pureza é designada como "algodão químico".

Os resíduos de glicose na celulose contêm três grupos funcionais hidroxilas (três por anel), um primário, ligado ao C-6, e dois secundários, ligados ao C-2 e C-3, como mostrado na Figura 3(a) ${ }^{3 b}$ Essas hidroxilas servem como sítios para a obtenção de derivados de celulose, tais como ésteres orgânicos de celulose (como acetato de celulose e acetato-butirato de celulose), ésteres inorgânicos de celulose (como nitrato de celulose), éteres de celulose (como etil celulose), fibras regeneradas de celulose (como rayon) e filmes (materiais tipo celofane). ${ }^{34 a} \mathrm{~A}$ abundância das três hidroxilas leva à formação de um arranjo complexo de ligações de hidrogênio intermolecular e intramolecular durante a biossíntese. As ligações de hidrogênio intramoleculares entre os anéis adjacentes de glicose aumentam a integridade das cadeias poliméricas. Essas ligações de hidrogênio intramoleculares não somente afetam a rigidez da cadeia, mas também a reatividade dos grupos hidroxilas. Particularmente, as hidroxilas ligadas ao C-3, as quais formam ligações de hidrogênio com os átomos de oxigênio adjacentes que constituem os anéis de glicose, como mostrado na Figura 3(b). ${ }^{3 b}$ Ésteres de celulose de quase qualquer tipo de ácido orgânico podem ser preparados, mas por causa de limitações de ordem prática, ésteres de ácidos contendo mais que quatro átomos de carbono não obtiveram importância comercial. ${ }^{3 b} \mathrm{O}$ acetato-butirato de celulose, uma 
mistura de ésteres, é obtido pela reação de celulose (de "linter" de algodão ou polpa de madeira) com os ácidos acético e butírico, ou seus respectivos anidridos, na presença de ácido sulfúrico (catalisador) e ácido acético (solvente) ou na de ácido perclórico (catalisador) e cloreto de metileno, $\mathrm{CH}_{2} \mathrm{Cl}_{2}$, (solvente). ${ }^{3 \mathrm{~b}}$

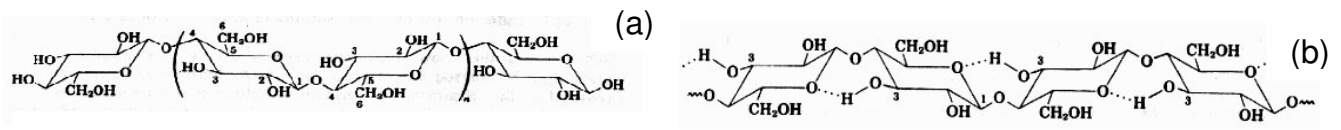

Figura 3 - Representação da estrutura química da celulose (a) sem ilustrar e (b) ilustrando as ligações de hidrogênio intramoleculares entre os átomos de $\mathrm{C}-3$ e os adjacentes de $\mathrm{O}$.

\subsection{Reações envolvendo radicais livres}

Os fatores envolvidos na estabilidade de radicais são o impedimento estérico, força da ligação, polaridade e estabilização eletrônica (por deslocalização de elétron). ${ }^{35} \mathrm{Na}$ estabilização eletrônica, tem-se o efeito de substituinte, quer por grupos aceptores de elétrons, quer por grupos doadores de elétrons, através de efeitos indutivos e/ou mesomêricos (de ressonância). ${ }^{36 a}$ Uma simples descrição de radicais (não separação de carga) pode parecer que eles não estão sujeitos aos mesmos tipos de influências polares que afetam as reações de espécies com carga e, conseqüentemente, não seriam influenciados pela natureza eletrônica dos reagentes. Freqüentemente este é o caso, mas, algumas vezes, as reações de radicais mostram efeitos pronunciados em conseqüência da influência da polaridade. ${ }^{37}$ Uma explicação para isso tem sido baseada na idéia de que há algum caráter polar no estado de transição em virtude de diferenças de eletronegatividade dos átomos envolvidos na reação, normalmente na presença de átomos de halogênio. Nas reações de abstração de átomos de hidrogênio, por exemplo, a energia de dissociação da ligação C-H está sujeita aos efeitos de substituinte. Uma interpretação bem sucedida de reações radicalares, portanto, requer a consideração de fatores como a 
eletronegatividade e a polarizabilidade dos radicais e a energia de ligação das ligações $\mathrm{C}-\mathrm{H}$ envolvidas na reação. ${ }^{38} \mathrm{~A}$ importância relativa desses efeitos pode variar de sistema para sistema. Como conseqüência, em reações radicalares, o efeito de substituinte tende a ser mais complicado do que aqueles envolvendo reações heterolíticas, para as quais os efeitos de substituinte são usualmente predominados pela capacidade de doar ou receber elétrons dos substituintes. ${ }^{38}$ As principais reações dos radicais estão representadas nas reações de (1) a (7).

$\checkmark$ Combinação

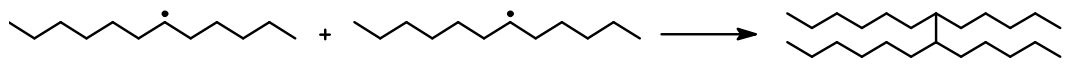

$\checkmark$ Desproporção

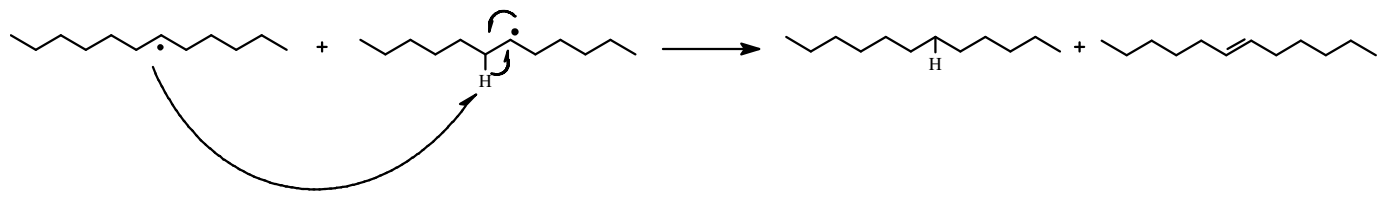

$\checkmark$ Abstração de hidrogênio (exemplo de transferência de cadeia)

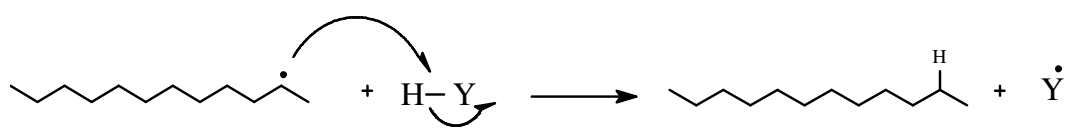

$\checkmark$ Adição à moléculas de oxigênio (um tripleto no estado fundamental)

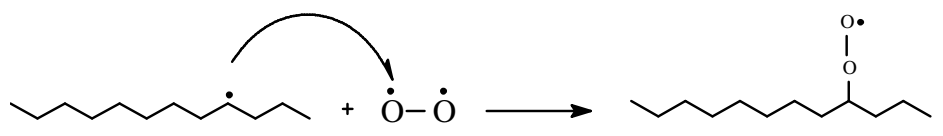


$\checkmark$ Adição à compostos insaturados

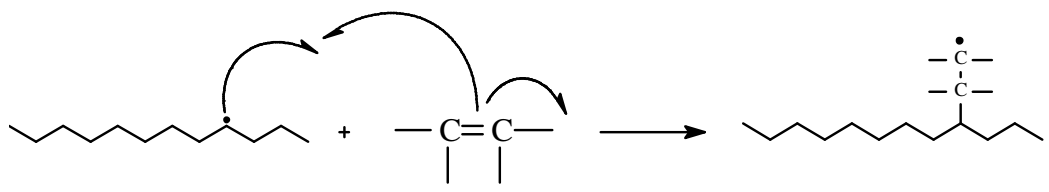

$\checkmark$ Reações de fragmentação ( $\beta$-cisão)

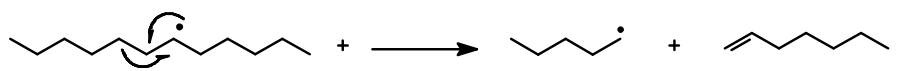

$\checkmark$ Reações de acoplamento entre dois anéis aromáticos ${ }^{36 a}$

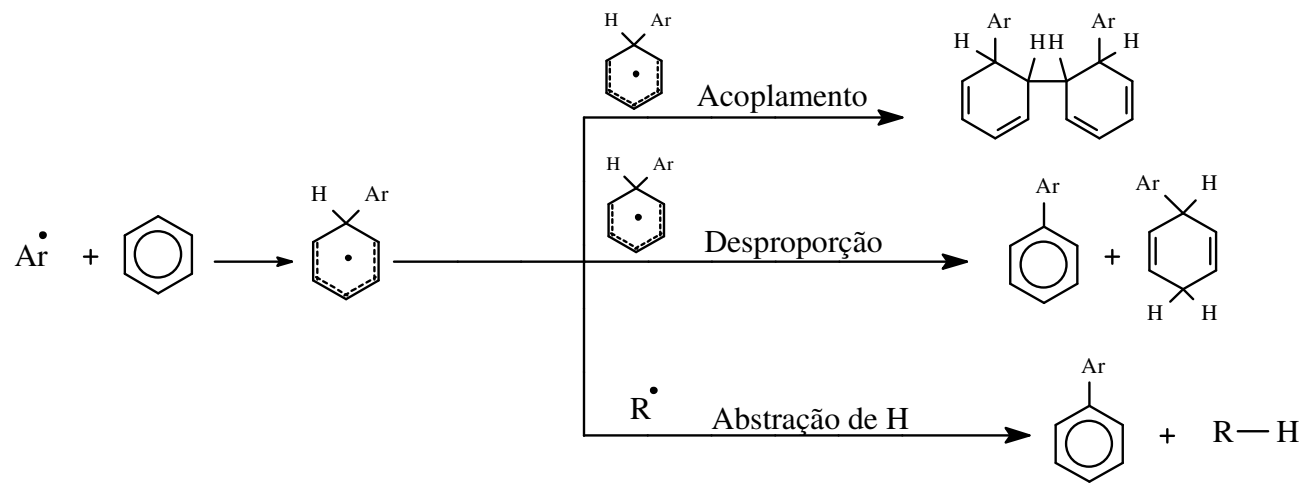

\subsection{Técnicas}

\subsubsection{Espectroscopia no infravermelho com transformada de Fourier} (FTIR)

A absorção de radiação infravermelha está muito restrita a espécies moleculares que têm diferenças de energia pequenas entre vários estados vibracionais e rotacionais. Para absorver radiação infravermelha, uma molécula precisa sofrer uma variação no momento de dipolo como conseqüência do movimento vibracional e rotacional. Apenas nessas circunstâncias o campo elétrico alternado da radiação pode interagir com a molécula e causar variações na amplitude de um de seus movimentos. ${ }^{39 a} \mathrm{O}$ 
momento de dipolo é determinado pela magnitude da diferença de carga e a distância entre os dois centros de carga. Quando uma molécula de cloreto de hidrogênio (polar), por exemplo, vibra, uma variação regular no momento dipolar ocorre e surge um campo que pode interagir com o campo elétrico associado à radiação. Se a freqüência da radiação coincidir exatamente com a freqüência vibracional natural da molécula, ocorre uma transferência de energia efetiva e resulta em uma variação da amplitude da vibração molecular; a absorção de radiação é a conseqüência. Do mesmo modo, a rotação de moléculas assimétricas em torno dos seus centros de massa resulta em uma variação periódica do dipolo que pode interagir com a radiação. ${ }^{39 a}$ Uma vibração de estiramento envolve uma variação contínua na distância interatômica ao longo do eixo da ligação entre dois átomos, podendo ser simétrica $\left(v_{\mathrm{s}}\right)$ ou assimétrica $\left(v_{\mathrm{as}}\right)$. As vibrações de deformação angular são caracterizadas pela variação do ângulo entre duas ligações e são de quatro tipos: deformação angular simétrica no plano ("scissoring"), $\delta_{s}$; deformação angular simétrica fora do plano ("wagging"), $\omega$; deformação angular assimétrica fora do plano ("twisting"), $\tau$, e deformação angular assimétrica no plano ("rocking"), $\rho .{ }^{40}$ Além disso, interação ou acoplamento de vibrações pode ocorrer se as vibrações envolvem ligações de um mesmo átomo central. O resultado de um acoplamento leva a uma variação nas características das vibrações envolvidas. Assim, a energia de uma vibração e, portanto, o comprimento de onda de sua banda de absorção, pode ser influenciada por (ou acoplada com) outros vibradores na molécula. ${ }^{39 a} \mathrm{~A}$ espectroscopia quantitativa no infravermelho baseia-se na lei de Beer, mas ocorrem desvios aparentes desta, quer de origem química quer de origem instrumental. O método da linha base consiste em escolher uma banda de absorção do composto a determinar que não seja muito próximo das bandas devidas a outros componentes da matriz. ${ }^{41}$ Mede-se a altura ou área da banda, sendo o último especialmente vantajoso quando a largura da banda ou a forma dela altera-se (usualmente alarga-se) com o aumento da concentração do composto a determinar. 


\subsubsection{Cromatografia gasosa acoplada à espectrometria de massas (GC-MS)}

Gases ou substâncias volatilizáveis podem ser separados utilizandose a técnica denominada cromatografia gasosa (GC). Esta técnica pode ser empregada na análise de substâncias voláteis e estáveis termicamente. A separação baseia-se na diferença de afinidade das substâncias da amostra em relação à fase estacionária (sólida ou líquida, a qual é um filme líquido que recobre um material sólido) e à fase móvel (gasosa, que é inerte). Os processos cromatográficos consistem em repetidas adsorções e dessorções ou partições durante o movimento dos componentes da amostra ao longo da fase estacionária, obtendo-se a separação graças às diferenças de coeficientes de distribuição dos componentes da amostra. ${ }^{42} \mathrm{~A}$ amostra, através de um sistema de injeção, é introduzida em uma coluna contendo a fase estacionária. O uso de temperaturas convenientes no local de injeção da amostra e na coluna possibilita a vaporização destas substâncias que, de acordo com suas propriedades e as da fase estacionária, são retidas por tempos determinados e chegam à saída da coluna em tempos diferentes. $\mathrm{O}$ uso de um detector adequado (por condutividade térmica, por ionização de chama, por captura de elétrons ou termiônicos) na saída da coluna torna possível a detecção e quantificação destas substâncias. ${ }^{42} \mathrm{~A}$ espectrometria de massas (MS) é iniciada por meio da ionização da amostra e os íons resultantes são separados e detectados. Então, os sinais são plotados como abundância relativa (\%) versus a razão massa/carga $(\mathrm{m} / \mathrm{z})$. A técnica mais comum para produzir íons é a de impacto eletrônico (EI). Na técnica El as moléculas $[\mathrm{M}]$ na fase vapor são bombardeadas com um feixe de elétrons de alta energia (25 eV a $80 \mathrm{eV})$, ocasionando a ejeção de um elétron de valência da molécula, que produz o íon molecular cátion-radical $[\mathrm{M}]^{+\bullet}$. O íon molecular, por sua vez, produz uma série de fragmentos ionizados. Os processos de fragmentação, que produzem esses fragmentos (observados na forma de picos), são característicos de diferentes grupos funcionais e tipos de esqueletos carbônicos. Ademais, a fragmentação pode produzir fragmentos iônicos ou neutros, no entanto, o analisador de massas somente 
pode detectar os fragmentos ionizados. ${ }^{43}$ Os analisadores (setor magnético, eletrostático, "time of flight", "ion trap" ou "quadrupole mass filter") são responsáveis pela resolução dos fragmentos com diferentes massas. $\mathrm{O}$ detector de massas ("Faraday cup", transdutor com cintilação e fotomultiplicadora ou multiplicadores de elétrons), operando em alto vácuo, detecta os íons resolvidos. A GC-MS combina o método cromatográfico com o método espectrométrico. A cromatografia separa os componentes da amostra em frações "puras", e estas são introduzidas no MS pela interface, sendo então ionizadas (por exemplo, por El a $70 \mathrm{eV}$ ). Os fragmentos iônicos passam pelo analisador e, depois de resolvidos, são detectados pelo detector de massas. A análise por GC-MS fornece, além do espectro de massas, o "total íon chromatogram" (TIC), que proporciona informações similares aos cromatogramas obtidos com outros detectores, sendo a área ou altura dos picos proporcional a concentração. Cada ponto no TIC corresponde a um espectro de massas adquirido e a resposta de cada ponto é a soma das abundâncias de todo o espectro de massas correspondente. A principal vantagem do GC-MS sobre as outras técnicas acopladas é a existência de um grande número de informações espectrais, como bibliotecas eletrônicas (NIST, Wiley e Pfleger).

\subsubsection{Calorimetria exploratória diferencial (DSC)}

DSC é uma técnica na qual mede-se a diferença de energia fornecida à substância e a um material de referência, em função da temperatura enquanto a substância e o material são submetidos a uma programação controlada de temperatura. ${ }^{44} \mathrm{De}$ acordo com o método utilizado, há duas modalidades, a calorimetria diferencial com compensação de potência (DSC com compensação de potência) e a calorimetria exploratória diferencial com fluxo de calor (DSC com fluxo de calor). DSC possibilita acompanhar e obter dados quanto às alterações físicas ou químicas da amostra, tais como mudança de estado físico (fusão e cristalização, por exemplo), transições de fase (modificações na estrutura cristalina) ou reações de desidratação, de decomposição e de oxi-redução. ${ }^{44}$ No caso do processo de fusão, a 
temperatura "onset" (início extrapolado) corresponde ao ponto de fusão para substâncias simples e puras. Porém, para substâncias complexas, substâncias simples impuras e polímeros, a temperatura no máximo do pico é a que corresponde ao ponto de fusão. Polímeros semicristalinos possuem cristalitos de diferentes tamanhos, causando alargamento do pico. Pela ASTM, a razão de aquecimento $(\beta)$ para o ensaio de polímeros é de $10^{\circ} \mathrm{C} \min ^{-1},{ }^{29 a}$ segundo a norma ASTM D-3418-82. A relação entre a região amorfa e cristalina de uma amostra de polímero é expressa em termos de grau de cristalinidade. A variação no grau de cristalinidade irá afetar diretamente diversas propriedades do material. A temperatura de fusão, a variação da entalpia de fusão e o grau de cristalinidade de um polímero podem ser determinados por DSC. Se um maior teor da amostra apresentase na forma de arranjo organizado (mais regiões cristalinas ou maior grau de cristalinidade), então uma maior quantidade de calor será absorvida. O oposto é observado para amostras com pequena porcentagem de regiões cristalinas. O conhecimento do grau de cristalinidade dos polímeros é importante, tendo em vista que praticamente todas as propriedades mecânicas e físicas dos polímeros são afetadas por ele. ${ }^{29 a}$ Grupos laterais (ramificações) dispostos aleatoriamente na cadeia polimérica não conseguem se acomodar adequadamente no retículo cristalino do polímero. Desse modo, o polímero apresenta temperatura de fusão, calor de fusão, grau de cristalinidade e densidade reduzidos.

\subsubsection{Termogravimetria (TG) e termogravimetria derivada (DTG)}

TG é uma técnica na qual a variação de massa de uma substância é medida em função da temperatura, enquanto a substância é submetida a uma programação controlada de temperatura. O registro é a curva TG ou termogravimétrica. A massa deve ser colocada em ordenadas, com valores decrescentes de cima para baixo e o tempo (t) ou a temperatura (T) em abscissas, com valores crescentes da esquerda para a direita. ${ }^{44}$ As curvas TG são características de um dado composto ou sistema, devido ao caráter específico da seqüência das reações físico-químicas que ocorrem ao longo 
de um intervalo definido de temperaturas, a velocidades que são uma função da estrutura molecular. As variações de massa resultam da ruptura e/ou formação de diferentes ligações químicas, a elevadas temperaturas, as quais conduzem à libertação de produtos voláteis ou à formação de produtos de reação mais pesados. A partir dessas curvas, obtêm-se dados sobre a termodinâmica e a cinética das diversas reações químicas, mecanismos de reação e produtos de reação, finais e intermediários. ${ }^{45}$ TG é uma técnica quantitativa apenas para medir a variação de massa. Porém, é qualitativa para temperatura, por isso é expressa em termos de temperatura de decomposição experimental. DTG é uma técnica que fornece a derivada primeira da curva termogravimétrica, em função do tempo ou da temperatura. A curva é a curva termogravimétrica derivada ou curva DTG. A derivada deve ser colocada em ordenadas, com as perdas de massa voltadas para baixo e t ou $\mathrm{T}$ em abscissas, com valores crescentes da esquerda para a direita. ${ }^{44}$ Polímeros diferentes devem gerar produtos voláteis diferentes, em concentrações variadas, quando submetidos a determinadas variações de temperatura. As etapas químicas envolvidas na formação dos produtos voláteis podem diferir em natureza eletrônica, via radicais livres ou iônica. De acordo com os tipos de produtos voláteis gerados, os materiais poliméricos podem ser classificados em polímeros que despolimerizam, não despolimerizam ou sofrem reações intramoleculares e intermoleculares. ${ }^{29 b}$ As poliolefinas, como o PE, são exemplos de polímeros que não despolimerizam, para os quais a degradação ocorre por meio da clivagem aleatória da cadeia, seguida por outras clivagens ao acaso, que levam a uma produção de monômeros (eteno) baixa e a um rápido decréscimo da massa molar. A estabilidade térmica do polietileno está relacionada ao grau e natureza das ramificações. O HDPE, que praticamente não possui ramificações, é termicamente mais estável que o LDPE, que possui um grau de ramificações significativo quando comparado ao HDPE. O mecanismo principal de degradação é a cisão homolítica da cadeia e as reações de transferência ocorrem mais rapidamente nos átomos ligados a átomos de carbono terciários. A cisão inicial envolve ligações C-C, 
pontos de ramificação ou outras ligações fracas que podem ter sido formadas durante o processo de polimerização, ou, como no presente caso, também durante o processo de funcionalização. Assim, átomos de carbono terciários e quartenários na cadeia introduzem pontos fracos na estrutura do polímero. Do mesmo modo, a introdução de oxigênio na cadeia hidrocarbônica do polímero reduz a estabilidade térmica, porque a ligação $\mathrm{C}-\mathrm{O}$ é mais fraca que a ligação C-C. ${ }^{29 b}$

\subsection{5. Índice de fluidez no fundido (MFI)}

MFI é expresso em termos da massa de material em gramas "extrudado" em 10 min, obtido de acordo com a norma ASTM D-1238. Quanto maior for a massa molar média ponderal do polímero, menor será o valor de MFI. Portanto, dados de MFI também podem ser usados para estimar a massa molar média ponderal de polímeros, contudo o resultado é muito influenciado pelo número e tamanho das ramificações presentes nas cadeias poliméricas. Quando se ensaia termoplásticos, o ponto de interesse é, em geral, o comportamento do polímero à fusão quando obrigado a passar através de um orifício sob pressão. ${ }^{46} \mathrm{O}$ aparelho é operado a $190^{\circ} \mathrm{C}$ para polietileno e $230^{\circ} \mathrm{C}$ para polipropileno. Um pistão tipo extrusão opera sobre o material em condições de peso morto $(2,16 \mathrm{~kg})$.

\subsubsection{Medidas de ângulo de contato}

O ângulo de contato é definido como o ângulo $(\theta)$ entre um substrato plano e a superfície livre de uma gota de líquido na linha de contato com o substrato. ${ }^{3 \mathrm{c}} \mathrm{O}$ grau com que um líquido molha (molhamento é definido como o processo no qual um líquido espontaneamente adere e se espalha sobre uma superfície sólida ${ }^{3 c}$ uma superfície sólida é medido por meio do ângulo de contato, como ilustrado na Figura 4. Quando $\theta=0^{0}$, o líquido espalha-se livremente sobre a superfície e se diz que ele a molha completamente. Molhamento completo ocorre quando as atrações moleculares entre as 
moléculas do líquido e as do sólido são maiores que as entre as moléculas iguais do líquido. ${ }^{3 c}$

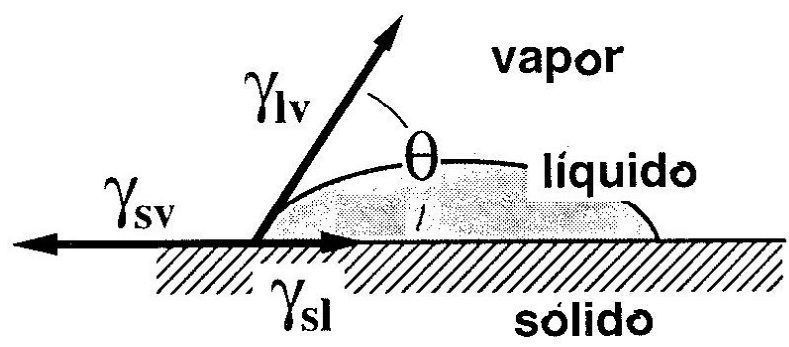

Figura 4 - Ângulo de contato $\theta$ de uma gota de líquido sobre uma superfície plana sólida.

As tensões superficiais se relacionam com o ângulo de contato $\theta$ através da equação de Young, representada na eq. (8).

$$
\gamma_{s v}=\gamma_{s l}+\gamma_{l v} \cos \theta
$$

onde $\gamma_{\mathrm{sv}}$ é a tensão superficial sólido-vapor, $\gamma_{\mathrm{sl}}$ é a tensão superficial sólidolíquido e $\gamma_{\mathrm{lv}}$ é a tensão superficial líquido-vapor. $\mathrm{O}$ ângulo $\theta$ formado entre 0 sólido e líquido é resultado do equilíbrio entre os três tensores mostrados na Figura 4.

O ângulo de contato de avanço ( $\left.\theta_{\text {avanço }}\right)$ é obtido no avanço lento da delimitação de uma gota de um líquido situada em cima de uma superfície sólida. Reflete a interface entre o sólido em equilíbrio com o meio gasoso (freqüentemente, o ar, que é apolar), e o líquido do ensaio, ou seja, correspondendo à interação do líquido do ensaio com os componentes de baixa energia da superfície. ${ }^{47 a, b} \mathrm{O}$ ângulo de contato de recesso ( $\theta_{\text {recesso }}$ ) é obtido no recesso lento da delimitação de uma gota de um líquido situada em cima de uma superfície sólida. Reflete a interface entre o sólido e o líquido do ensaio, ou seja, correspondendo à interação do líquido do ensaio 
com os componentes de mais alta energia da superfície (mais "polar"). ${ }^{47 a, b}$. A histerese do ângulo $(\Delta \theta)$ de contato informa sobre a homogeneidade química e rugosidade da superfície. Quanto maior for o valor de $\Delta \theta$, mais rugosa e/ou mais heterogênea será a superfície. ${ }^{48}$

\subsubsection{Difração de raios $X(X R D)$}

Os raios $\mathrm{X}$ constituem uma radiação eletromagnética de comprimento de onda curto produzida pela aceleração ou desaceleração de elétrons de alta energia ou pelas transições de elétrons dos orbitais internos dos átomos. O intervalo de comprimentos de onda dos raios $X$ vai de $10^{-6} \mathrm{~nm}$ até $10 \mathrm{~nm} \cdot{ }^{39 b}$ Os raios $X$ podem ser obtidos pelo bombardeamento de um alvo metálico (como cobre, cromo, ou molibdênio) com um feixe de elétrons de alta energia provenientes do cátodo aquecido (do tubo de raios $\mathrm{X}$ ou tubo de Coolidge), produzindo tanto um espectro de linha como um contínuo. Os espectros de linhas de raios $X$ são marcantemente simples e constituem de duas séries de linhas, a série $\mathrm{K}$ e série $\mathrm{L}$. $\mathrm{O}$ espectro de linhas de raios $\mathrm{X}$ é resultado de transições eletrônicas que envolvem os orbitais atômicos mais internos. Para todos os elementos, menos os mais leves, os comprimentos de onda das linhas características de raios $X$ são independentes do estado físico e químico do elemento, porque as transições responsáveis por essas linhas envolvem elétrons que não tomam parte na ligação química. As diferenças de energia entre as transições denominadas $\alpha_{1}$ e $\alpha_{2}$, bem como as entre $\beta_{1}$ e $\beta_{2}$, são tão pequenas que somente são observadas linhas únicas em todos os espectrômetros, exceto nos de mais alta resolução. ${ }^{39 b}$ Da mesma forma que para as outras radiações eletromagnéticas, as interações entre o vetor campo elétrico da radiação de raios $X$ e os elétrons da matéria que a radiação atravessa resulta no espalhamento. Quando os raios X são espalhados pelo ambiente ordenado de um cristal (os planos cristalinos), ocorre a interferência entre os raios espalhados (tanto construtiva como destrutiva) porque as distâncias entre os centros espalhadores (os átomos do cristal) são da mesma ordem de grandeza que 
o comprimento de onda da radiação. O resultado é a difração. ${ }^{39 b}$ Sempre que a diferença de fase entre duas ondas for zero, um comprimento de onda, dois comprimentos de onda, ou seja, um número inteiro, as ondas interferem construtivamente e suas amplitudes se somam. Mas, se a diferença de fase for de meio comprimento de onda, três meios comprimentos de onda etc., elas interferem destrutivamente e suas amplitudes se subtraem. Existem várias "famílias" de planos cristalinos. A Figura 5 mostra algumas como exemplo, onde $d_{1}, d_{2}$ e $d_{3}$ são as distâncias interplanares do retículo cristalino. ${ }^{49}$ Para cada uma dessas famílias poderá haver uma direção, pelo menos, de feixe difratado resultando em um ponto no filme. Usando essas fotografias pode-se determinar como são esses planos e obter-se a estrutura cristalina do cristal.

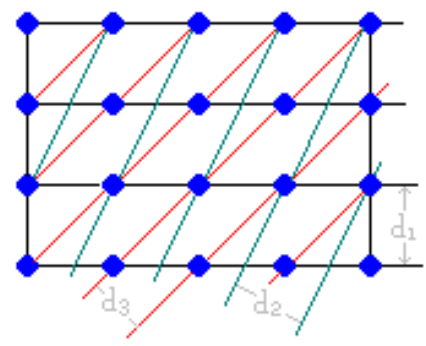

Figura 5 - Representação esquemática de três famílias de planos cristalinos, nas cores preta $\left(d_{1}\right)$, verde $\left(d_{2}\right)$ e vermelha $\left(d_{3}\right)$.

A condição para o máximo na intensidade de difração é dada pela equação de Bragg, mostrada na eq. (9), ${ }^{31}$ conforme ilustrado na Figura $6,{ }^{49}$ utilizando uma estrutura cristalina como rede de difração tridimensional.

$$
n \lambda=d_{h k l} 2 \operatorname{sen} \theta_{X}
$$

onde $d_{h k l}$ é a distância entre os planos cristalinos, n é a ordem (dos máximos de intensidade) de difração, sendo um número inteiro, e para a difração de 
raios $\mathrm{X}$ é igual a $1, \lambda$ é o comprimento de onda do feixe monocromático de raios $X$ (no presente caso, é $0,154 \mathrm{~nm}$ ) e $\theta_{X}$ é o ângulo formado entre a direção dos raios $\mathrm{X}$ e o plano do retículo cristalino.

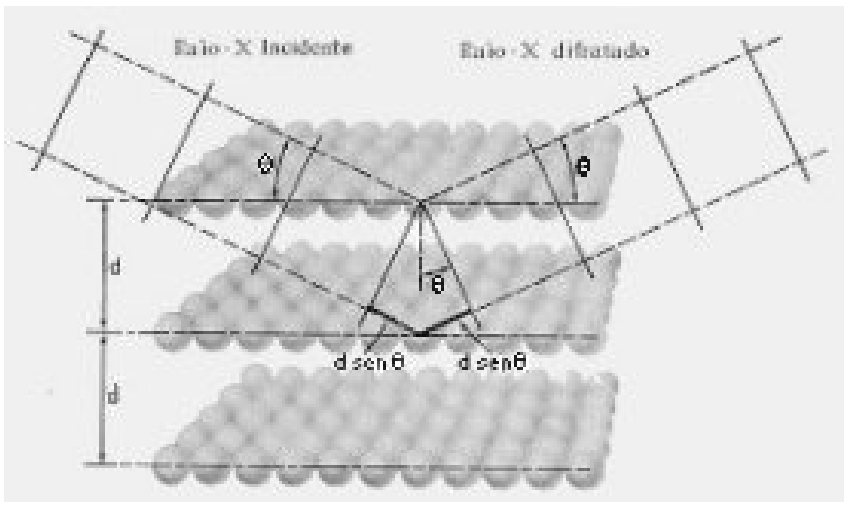

Figura 6 - Ilustração da equação de Bragg, mostrada na eq. (9).

Para polímeros, a difração de raios $\mathrm{X}$ propicia uma determinação direta da ordem tridimensional, mas medições de cristalinidade absoluta exigem métodos bem rigorosos. Outras técnicas, como DSC, medem propriedades relacionadas ao grau de cristalinidade e, portanto, são técnicas relativas ou indiretas. Para muitos fins, as cristalinidades relativas são suficientes, e um número de métodos aproximados de raios $\mathrm{X}$ estão disponíveis e são utilizados. ${ }^{3 \mathrm{~d}}$ Para polímeros, a determinação do grau de cristalinidade relativo exige materiais $100 \%$ cristalinos ou $100 \%$ amorfos. Em 1848, Bravais demonstrou que todos os possíveis retículos cristalinos poderiam ser agrupados em 14 tipos, entre eles, aquele que forma a cela unitária ortorrômbica. ${ }^{50}$ Por estes retículos cristalinos podem-se passar uma série de planos que são caracterizados por índices chamados de Miller e são representados pelas letras $\mathrm{h}, \mathrm{k}$ e I. Para ilustração, os planos (110), (200) e (002) cortando a cela unitária ortorrômbica do polietileno são mostrados na Figura 7. Por exemplo, no caso do plano (110), os índices de Miller são $\mathrm{h}=$ $1, \mathrm{k}=1 \mathrm{el}=0$. 

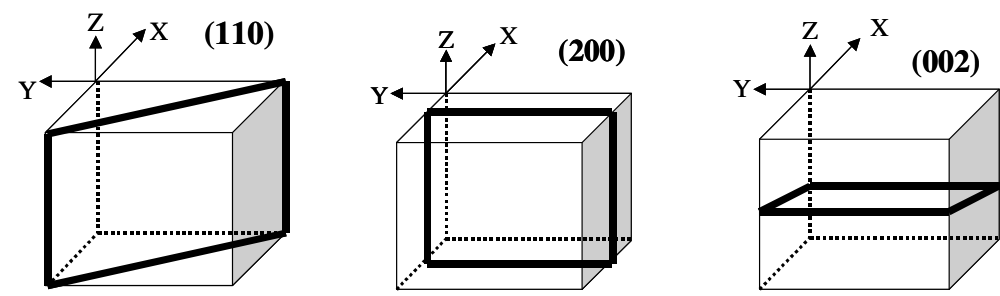

Figura 7 - Planos cristalinos (110), (200) e (002) passando pela cela unitária ortorrômbica do polietileno.

A distância entre os planos cristalinos, os índices de Miller e as dimensões de uma cela unitária ortorrômbica estão relacionados por meio da eq. (10). ${ }^{51}$

$$
\frac{1}{d_{h k l^{2}}}=\frac{h^{2}}{a^{2}}+\frac{k^{2}}{b^{2}}+\frac{l^{2}}{c^{2}}
$$

onde $d_{h k l}$ é a distância entre os planos cristalinos, h, k e I são os índices de Miller e a, b e c são as dimensões da cela unitária ortorrômbica.

Um material amorfo produz um espalhamento (o termo difração é geralmente preferido quando o espécime sob estudo tem uma regularidade na sua estrutura de maneira que os raios $X$ detectados exibam um máximo de intensidade bem definido) difuso e largo, com a intensidade centrada no assim chamado halo amorfo. Um material cristalino perfeito, por outro lado, produz difração somente nos ângulos definidos por Bragg, gerando picos estreitos. Na verdade, a ordem cristalina nos polímeros nunca é perfeita e é perturbada, por exemplo, pela presença de imperfeições no retículo cristalino ou regiões cristalinas de tamanho finito e, como conseqüência, as difrações nos ângulos de Bragg podem apresentar picos alargados. Apesar disso, os padrões de difração que se obtêm das regiões cristalinas e amorfas são em geral claramente distinguíveis. ${ }^{3 d}$ 


\subsubsection{Microscopia eletrônica de varredura (SEM)}

SEM é largamente usada no campo da ciência de polímeros para estudos morfológicos. Quando um feixe de elétrons atinge a amostra, pode passar livremente ou interagir com ela. As interações entre o feixe de elétrons e a amostra fornecem informações sobre a forma, a composição, a estrutura cristalina e a estrutura eletrônica, e podem ser elásticas ou inelásticas. As interações elásticas afetam a trajetória do feixe, sem alterar significativamente a sua energia. As interações inelásticas resultam numa transferência de energia para a amostra. Em um microscópio eletrônico, a superfície de uma amostra sólida é varrida com um padrão de rastreamento com um feixe de elétrons energéticos, produzindo vários sinais, como, por exemplo, elétrons secundários, raios $X$ e elétrons retroespalhados ("backscattered electrons"), em conseqüência da interação do feixe de elétrons com a superfície sólida. ${ }^{39 c}$ Os dois sinais mais freqüentemente usados para produzir imagens por SEM são os elétrons secundários (para estudo de topografia) e os elétrons retroespalhados (para estudo de heterogeneidade química). Para suprimir o carregamento (elétrico) de espécimes isolantes (o carregamento introduz artefatos no contraste da imagem) e/ou para aumentar a velocidade de emissão secundária, metais pesados, como ouro, são usados para cobrir a superfície do espécime, por exemplo, usando um "sputter coater". ${ }^{2 a}$ Porém, uma liga de 60\% Au - 40\% $\mathrm{Pd}$ é recomendada, visto apresentar uma menor granulometria, tendo a desvantagem de ser mais cara. O revestimento metálico é freqüentemente adotado para aumentar a condutividade elétrica do espécime. Revestindo o espécime com uma fina camada $(\sim 20 \mathrm{~nm}$ a $50 \mathrm{~nm})$ de metal traz o benefício adicional de diminuir os danos causados pela radiação. $O$ detector (cintilador) reconhece ponto a ponto as regiões de protuberância ou cavidade, quando o feixe de elétrons é varrido ao longo da superfície fraturada, como resultado da diferença de intensidade do sinal que 0 atinge. A resolução da imagem obtida varia com a tensão aplicada, isto é, quanto maior a tensão, menor é o comprimento de onda do feixe e, portanto, maior 
a resolução da imagem. Materiais moles e elastômeros devem ser resfriados abaixo da temperatura de transição vítrea $\left(T_{g}\right)$ para proporcionar uma fratura frágil. ${ }^{53}$ Fraturas são um meio efetivo de revelar a estrutura interna de compósitos, como avaliar a adesão entre a fase dispersa e a matriz polimérica.

\subsubsection{Ensaios mecânicos de tração}

Fratura é a ruptura de um material submetido a uma tensão, separando-o em duas ou mais partes. A maneira como ocorre a fratura depende do tipo de material e das condições ambientais em que ele sofre o ensaio mecânico. Uma fratura é dúctil se for precedida por uma apreciável deformação plástica e redução localizada na área transversal do corpo de prova. Por outro lado, uma fratura é frágil ou semifrágil quando ocorre abruptamente, sem redução na área transversal e com pouco ou nenhuma deformação plástica. Na Figura 8 são ilustradas três curvas típicas da tensão $(\sigma)$ em função da elongação $(\varepsilon)$. A curva (a) mostra um comportamento típico de fratura frágil, $\sigma$ aumenta de forma aproximadamente linear com $\varepsilon$, até 0 ponto de ruptura. Já a curva (b) mostra um comportamento típico de fratura dúctil, onde se observa um ponto de máximo, no presente caso, correspondendo ao ponto de escoamento ("yield point"), que é o ponto-limite de uma deformação reversível, e $\sigma$ cai antes da fratura. Enquanto que, a curva (c) mostra um outro comportamento típico de fratura dúctil, onde se observa 0 ponto de escoamento seguido de queda de $\sigma$, com 0 aparecimento de um pescoço ("necking", redução da área transversal do espécime sob ensaio), como ilustrado na Figura $9(\mathrm{a}),{ }^{52 b}$ e início do estiramento a frio ("cold drawing") e propagação do pescoço, seguido de aumento de $\sigma$ antes da ruptura. Esse aumento de $\sigma$ antes da ruptura é devido a reorganização das cadeias do polímero, onde os esferulitos são pertubados e as cadeias do polímero tornam-se orientadas na direção do estiramento, conforme ilustrado na Figura $9(b) .{ }^{30}$ 
(a)

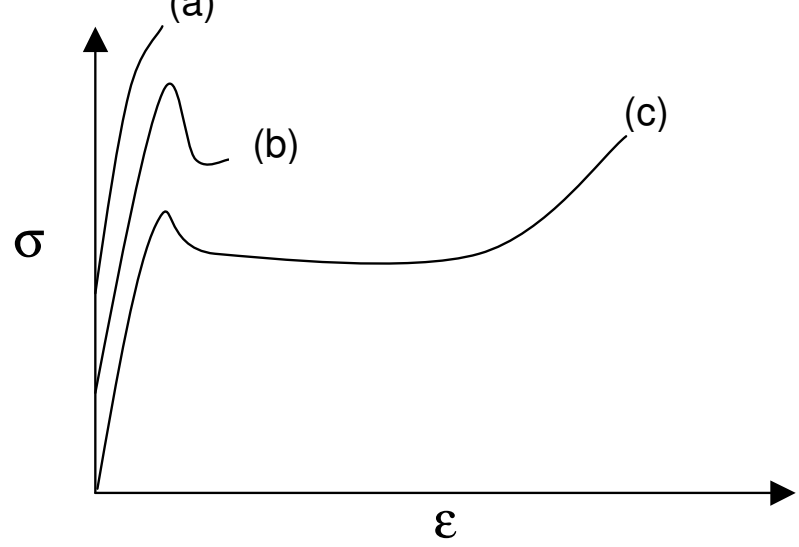

Figura 8 - Curvas típicas da tensão $\sigma$ em função da elongação $\varepsilon$.

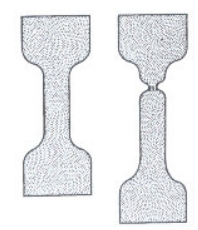

(a)
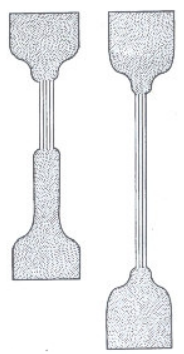

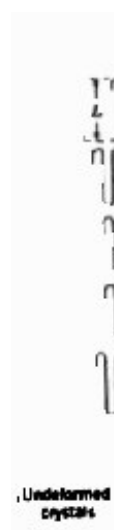

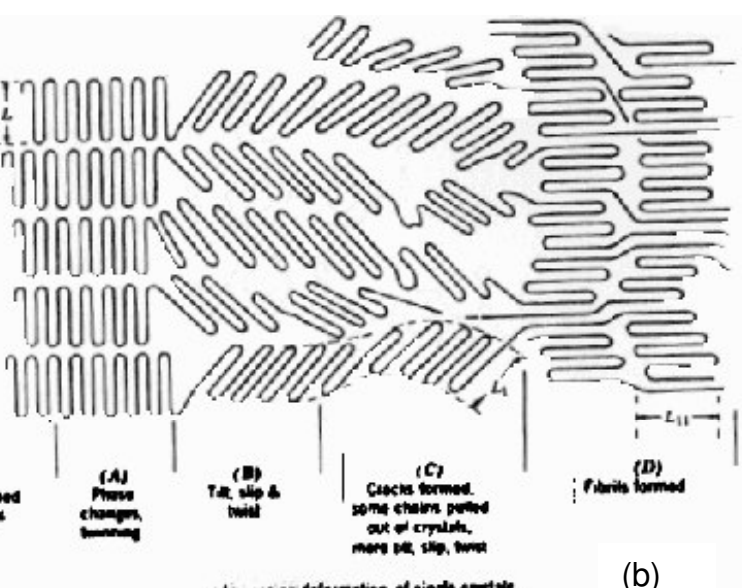

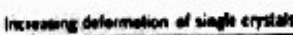

(b)

Figura 9 - llustração de (a) formação de pescoço e (b) reorganização cristalina durante o estiramento a frio (propagação do pescoço na direção do estiramento).

O módulo de Young, ou módulo de elasticidade, que é um indicativo da rigidez do material (quanto maior o valor do módulo de Young, maior a rigidez do material), é uma propriedade que pode ser obtida a partir das curvas de $\sigma$ em função de $\varepsilon$. Corresponde à inclinação (coeficiente angular) da parte da curva que apresenta um aumento da $\sigma$ de forma aproximadamente linear com a $\varepsilon$. 


\section{OBJETIVOS}

O principal objetivo deste trabalho consistiu na obtenção de compósitos (ou blendas) de LMDPE funcionalizado (por processamento reativo com AGE, na presença de BPO) e celulose (ou acetato-butirato de celulose), em um reômetro de torque. Avaliando as influências das quantidades de AGE e BPO no grau de funcionalização e as das proporções de celulose (ou acetato-butirato de celulose), comprimentos das fibras de celulose e presença de lignina (na celulose) nas propriedades mecânicas dos compósitos.

O segundo objetivo visou a funcionalização do LMDPE em solução com AGE, na presença de BPO, avaliando as influências no grau de funcionalização das quantidades de AGE e BPO, do tipo de iniciador (azobis-isobutironitrilo versus BPO), do tempo e temperatura de reação e de solventes bons e maus doadores de átomos de hidrogênio.

O objetivo terciário contemplou a funcionalização superficial de placas de LMDPE por radiação UV com AGE, MAH e THFAH, na presença de BPO (ou BP). 


\section{EXPERIMENTAL}

\subsection{Materiais}

\subsubsection{Matriz polimérica}

Polietileno linear de média densidade, com comonômero 1-buteno (LMDPE), é uma amostra comercial (FP 33) com índice de fluidez de 1,70 \pm $0,04 \mathrm{~g}$ (10 min) ${ }^{-1}$ (ASTM D-1238) e densidade de $0,93 \mathrm{~g} \mathrm{~cm}^{-3}$ (medida por picnometria, a partir de uma suspensão em água a 10\%), foi gentilmente cedido pela Politeno e foi usado tal qual recebido. Segundo o fabricante, a proporção inicial (no reator) de 1-buteno é de $8 \%$ a 10\%. A Figura 10 mostra a estrutura química do LMDPE.

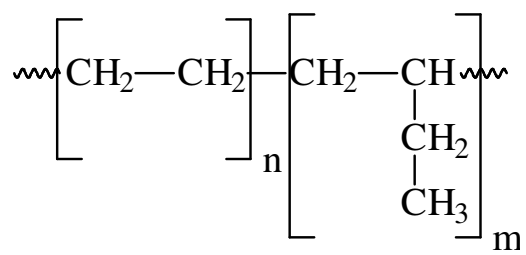

Figura 10 - Representação da estrutura química do LMDPE.

A Figura 11 mostra o espectro no FTIR do LMDPE. Pode-se atribuir as seguintes bandas para o LMDPE: $2913 \mathrm{~cm}^{-1}$, estiramento assimétrico da ligação $\mathrm{C}-\mathrm{H}\left(v_{\text {as }} \mathrm{CH}_{3}\right) ; 2850 \mathrm{~cm}^{-1}$, estiramento simétrico da ligação $\mathrm{C}-\mathrm{H}$ $\left(v_{\mathbf{s}} \mathrm{CH}_{3}\right) ; 1472 \mathrm{~cm}^{-1}$ e $1463 \mathrm{~cm}^{-1}$, deformação angular simétrica no plano da ligação $\mathrm{C}-\mathrm{H}\left(\boldsymbol{\delta}_{\mathbf{s}} \mathrm{CH}_{2}\right) ; 730 \mathrm{~cm}^{-1}$ e $720 \mathrm{~cm}^{-1}$, deformação angular assimétrica no plano da ligação $\mathrm{C}-\mathrm{H}\left(\rho \mathrm{CH}_{2}\right) \cdot{ }^{40}$ Os dubletos clássicos no polietileno $\left(1475 / 1460 \mathrm{~cm}^{-1}\right.$ e 733/721 $\left.\mathrm{cm}^{-1}\right)$ são exemplos de desdobramentos de banda causados pelo retículo cristalino, no caso, pela forma ortorrômbica do polietileno, a qual possui duas unidades de repetição por cela unitária. ${ }^{3 e} \mathrm{~A}$ outra forma cristalina, a monoclínica, contém apenas uma unidade de 
repetição (por cela unitária) e não são observados aqueles pares de dubletos.

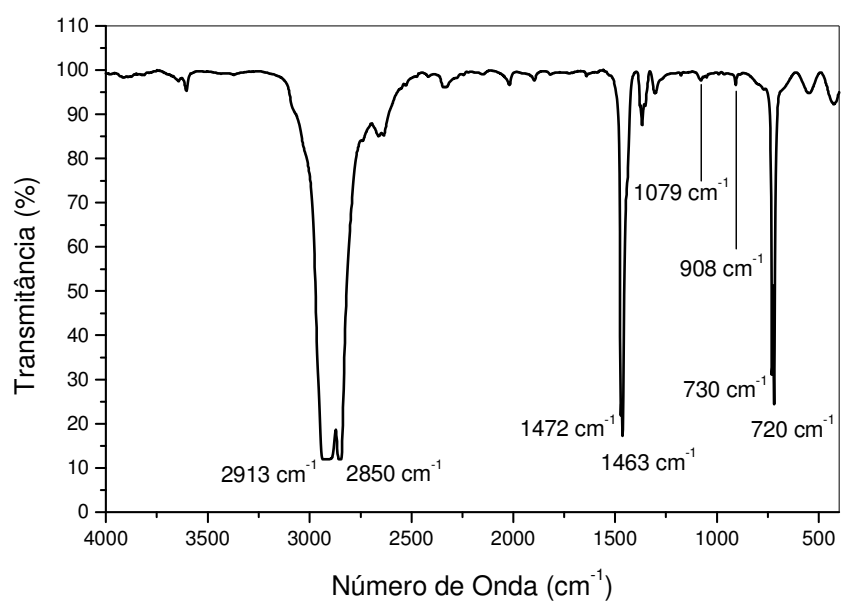

Figura 11 - Espectro no FTIR do LMDPE.

\subsubsection{Agentes funcionalizantes}

Alil glicidil éter (AGE), adquirido da Sigma-Aldrich, com ponto de ebulição de $154^{\circ} \mathrm{C}$ e densidade $0,96 \mathrm{~g} \mathrm{~cm}^{-3}$, foi usado tal qual recebido. A Figura 12 mostra a estrutura química do AGE.<smiles>C=CCOCC1CO1</smiles>

Figura 12 - Representação da estrutura química do AGE.

A Figura 13 mostra o espectro no FTIR do AGE. Pode-se atribuir as seguintes bandas para o AGE: $2998 \mathrm{~cm}^{-1}$, estiramento da ligação $\mathrm{C}-\mathrm{H}$, do grupo metino, de anéis epóxidos; $1254 \mathrm{~cm}^{-1}$, estiramento simétrico de anéis epóxidos; $1100 \mathrm{~cm}^{-1}$, estiramento assimétrico de C-O-C em éteres alifáticos (entre $1150 \mathrm{~cm}^{-1}$ e $1085 \mathrm{~cm}^{-1}$ ); $920 \mathrm{~cm}^{-1}$, estiramento assimétrico de anéis epóxidos (entre $950 \mathrm{~cm}^{-1}$ e $810 \mathrm{~cm}^{-1}$ ); $851 \mathrm{~cm}^{-1}$, característica de anéis 
epóxidos, chamada, às vezes, "banda de 12 mícrons" (entre $840 \mathrm{~cm}^{-1} \mathrm{e}$ $\left.750 \mathrm{~cm}^{-1}\right) \cdot{ }^{54}$

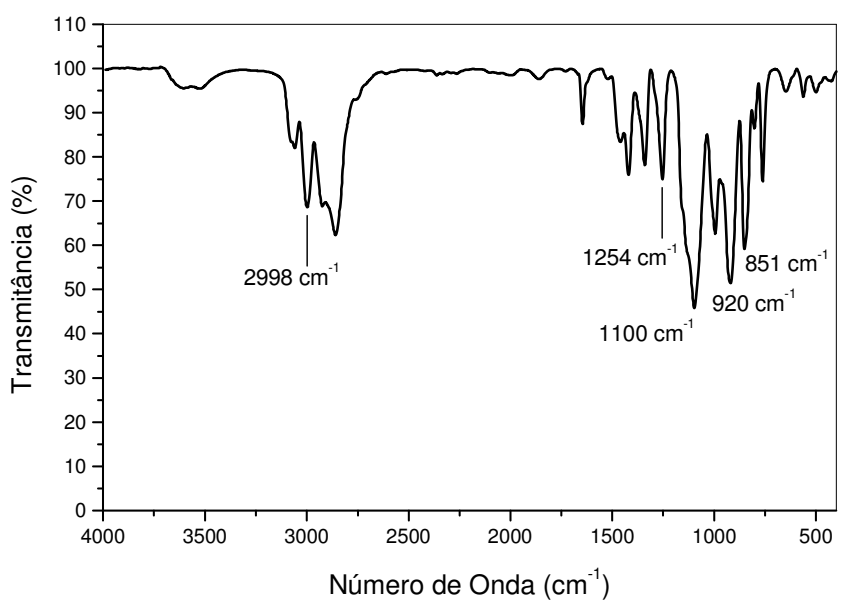

Figura 13 - Espectro no FTIR do AGE.

A Figura 14(a) ilustra o cromatograma e a Figura 14(b) mostra o espectrograma de massas do pico número 1 do cromatograma (Figura 14a), do AGE, obtidos GC-MS.
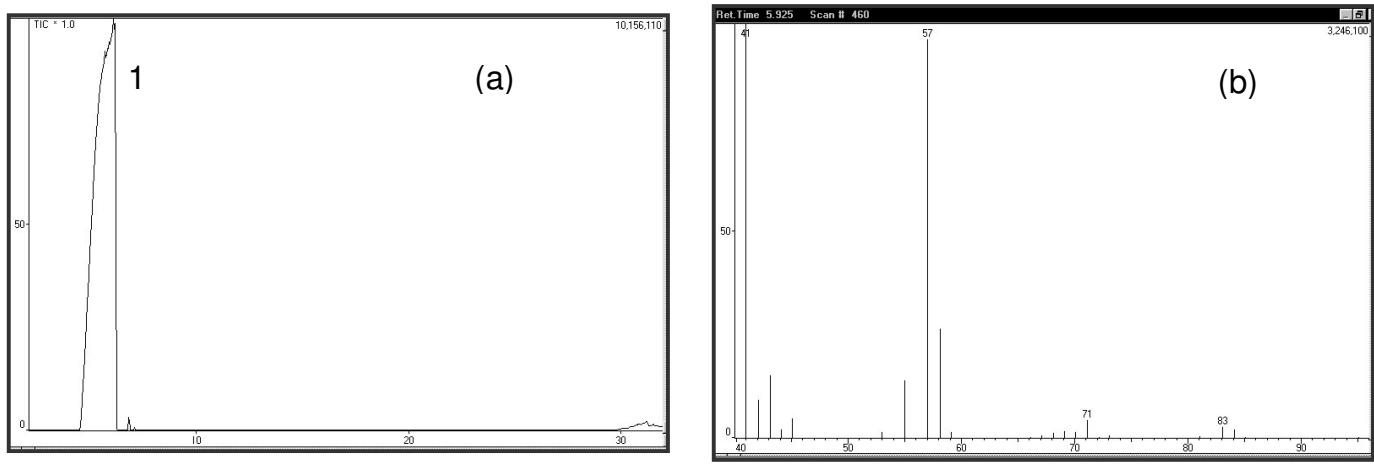

Figura 14 - (a) Cromatograma e (b) espectrograma de massas do pico número 1, do AGE, obtidos por GC-MS. 
A área do pico número 1 (Figura 14a), corresponde a mais de 99\% da soma das áreas de todos os picos, podendo ser usado como indicativo da pureza da amostra. De acordo com o fabricante, a pureza é maior que 99\%. Já o espectrograma de massas (Figura 14b) está de acordo com obtido para o AGE na literatura. ${ }^{55}$

Anidrido maléico (MAH), adquirido da Vetec, com ponto de fusão de $53^{\circ} \mathrm{C},{ }^{56}$ foi usado tal qual recebido. A estrutura química do MAH é mostrada na Figura 15.

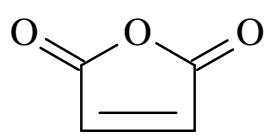

Figura 15 - Representação da estrutura química do MAH.

Anidrido tetraidroftálico (THFAH) foi gentilmente cedido pela Schenectady Brasil LTDA e usado tal qual recebido. A estrutura química do THFAH é mostrada na Figura 16.<smiles>O=C1OC(=O)C2CC=CCC12</smiles>

Figura 16 - Representação da estrutura química do THFAH.

\subsubsection{Agentes iniciadores}

Peróxido de benzoíla (BPO), com ponto de fusão de $103^{\circ} \mathrm{C}$ a $106^{\circ} \mathrm{C},{ }^{56}$ foi adquirido da Vetec e usado tal qual recebido. A estrutura química do BPO é mostrada na Figura 17. Os dados de tempo de meia-vida do BPO variam 
com a fonte bibliográfica. Em uma referência os valores são $438 \min \left(70^{\circ} \mathrm{C}\right)$, $84 \min \left(85^{\circ} \mathrm{C}\right)$ e $19,8 \mathrm{~min}\left(100^{\circ} \mathrm{C}\right)$, usando benzeno ou tolueno como solvente. ${ }^{57 a} \mathrm{Na}$ outra, os valores são $29 \min \left(100^{\circ} \mathrm{C}\right), 0,38 \mathrm{~min}\left(150^{\circ} \mathrm{C}\right) \mathrm{e}$ $0,013 \min \left(200^{\circ} \mathrm{C}\right)$, o solvente usado foi omitido. ${ }^{58}$

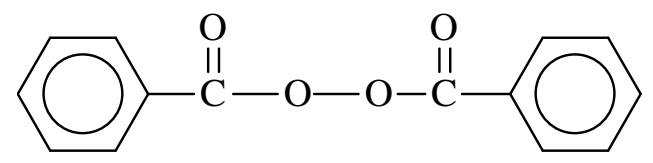

Figura 17 - Representação da estrutura química do BPO.

Azo-bis-isobutironitrilo (AIBN) foi gentilmente cedido pelo Professor Dr. Luiz Henrique Catalani e usado tal qual recebido. A estrutura química do AIBN é mostrada na Figura 18. Os dados de tempo de meia-vida do AIBN são $4440 \min \left(50^{\circ} \mathrm{C}\right), 288 \min \left(70^{\circ} \mathrm{C}\right)$ e $7,2 \min \left(100^{\circ} \mathrm{C}\right)$, usando benzeno ou tolueno como solvente. ${ }^{57 a}$<smiles>CC(C)(C#N)N=NC(C)(C)C#N</smiles>

Figura 18 - Representação da estrutura química do AIBN.

Benzofenona (BP), com ponto de fusão de $48^{\circ} \mathrm{C},{ }^{56}$ foi gentilmente cedida pela Professora Dra. Liliana Marzorati e usada tal qual recebida. A estrutura química da BP é mostrada na Figura 19.

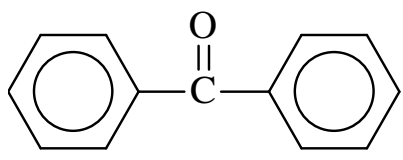

Figura 19 - Representação da estrutura química da BP. 


\subsubsection{Polissacarídeos}

Celulose fibrosa em pó, considerada como fibra curta (SF-CEL), foi adquirida da Fluka. Polpa de celulose Kraft branqueada de eucalipto, considerada como fibra média (MF-CEL), foi gentilmente cedida pela Cia. Suzano de Papel e Celulose (Brasil). Polpa de celulose Kraft branqueada de pinus Elliotti e Taeda, fibra longa (LF-CEL), foi gentilmente cedida pela Cia. Alto do Parana (Argentina). Polpa de celulose Kraft não-branqueada de pinus Radiata, fibra longa (ULF-CEL), com conteúdo de lignina de $33 \pm 2$, expresso em termos de número Kappa, que equivale a $\sim 5 \%$ de lignina, ${ }^{32 d}$ foi gentilmente cedida pela Cia. Celulosa Arauco Y Constitución (Chile). O número Kappa (método para determinar a branqueabilidade ou grau de deslignificação da celulose) é o número de mililitros de uma solução de $\mathrm{KMnO}_{4}$ 0,1 $\mathrm{N}$ consumido por uma grama de celulose absolutamente seca, sob condições específicas. Os resultados são corrigidos para dar um consumo relativo de $50 \%$ de permanganato. ${ }^{32 e}$ A temperatura de degradação da celulose é de $\sim 200^{\circ} C^{59}$.

Acetato-butirato de celulose (BUT-CEL), gentilmente doado pela Eastman, com temperatura de fusão $\left(T_{f}\right)$ de $155^{\circ} \mathrm{C}$ a $165^{\circ} \mathrm{C}, \mathrm{T}_{\mathrm{g}}$ de $130^{\circ} \mathrm{C}$ e conteúdos em massa de acetil, butiril e hidroxil de 13\%, 37\% e 1,5\%, respectivamente. Os graus de substituição, em termos da razão entre os grupos ésteres e resíduos de glicose, equivalem a $\sim 1$ (como acetato) e $\sim$ 1,6 (como butirato). ${ }^{26 b} \mathrm{O}$ produto final da mistura de LMDPE e acetatobutirato de celulose, processada no reômetro de torque, é uma blenda, que é um composto formado pela mistura física de dois termoplásticos diferentes fundidos. ${ }^{34 b}$

Esses polissacarídeos foram usados sem purificação prévia. A estrutura química da celulose e do BUT-CEL é mostrada na Figura 20. 


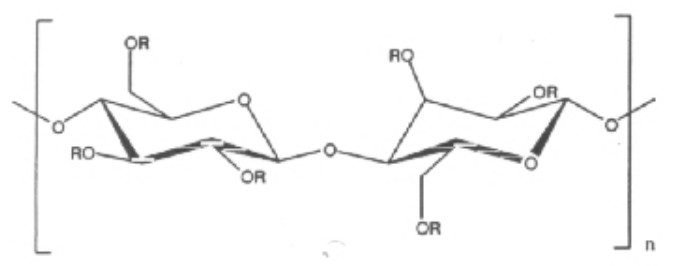

Figura 20 - Representação da estrutura química da celulose $[R=H]$ e BUT$\mathrm{CEL}\left[\mathrm{R}=\mathrm{H}\right.$ ou $\mathrm{CH}_{3} \mathrm{C}(\mathrm{O})$ - ou $\left.\mathrm{CH}_{3} \mathrm{CH}_{2} \mathrm{CH}_{2} \mathrm{C}(\mathrm{O})-\right]$.

As celuloses MF-CEL, LF-CEL e ULF-CEL foram submetidas a um processo de desagregação e corte em um liquidificador antes de serem usadas na obtenção de compósitos. Os comprimentos e diâmetros das fibras de celulose, bem como o diâmetro do BUT-CEL (pó), foram medidos em um microscópio óptico (Carl Zeiss, modelo Axioplan2, com analisador de imagens Leica Q 550 IW) e os valores médios obtidos, junto com os respectivos desvios padrões, são mostrados na Tabela 1.

Tabela 1 - Valores de comprimento e diâmetro obtidos para os polissacarídeos.

\begin{tabular}{cccc}
\hline Polissacarídeo & $\begin{array}{c}\mathbf{L} \\
\text { Comprimento }(\mathrm{mm})\end{array}$ & $\begin{array}{c}\mathbf{D} \\
\text { Diâmetro }(\mathrm{mm})\end{array}$ & $\mathbf{L}^{\mathbf{a}}$ \\
\hline SF-CEL & $0,13 \pm 0,07$ & $0,030 \pm 0,008$ & 4 \\
MF-CEL & $0,6 \pm 0,2$ & $0,020 \pm 0,004$ & 30 \\
LF-CEL & $1,5 \pm 0,5$ & $0,041 \pm 0,008$ & 37 \\
ULF-CEL & $1,4 \pm 0,4$ & $0,04 \pm 0,02$ & 35 \\
BUT-CEL & - & $0,06 \pm 0,01$ & - \\
\hline
\end{tabular}

${ }^{\mathrm{a}}$ Comprimento (L) dividido pelo diâmetro (D). 


\subsubsection{Solventes}

Tolueno, com ponto de ebulição de $111^{\circ} \mathrm{C},{ }^{56}$ foi adquirido da Merck. Xileno, com ponto de ebulição de $137^{\circ} \mathrm{C}$ a $140^{\circ} \mathrm{C},{ }^{56}$ foi adquirido da Nuclear. Difenila, com ponto de fusão de $69^{\circ} \mathrm{C}$ a $71^{\circ} \mathrm{C}$ e ponto de ebulição de $254^{\circ} \mathrm{C}$ a $255^{\circ} \mathrm{C},{ }^{56}$ foi gentilmente cedida pelo Prof. Dr. Josef Wilhelm Baader. Clorobenzeno, com ponto de ebulição de $131^{\circ} \mathrm{C}$ a $132^{\circ} \mathrm{C},{ }^{56}$ foi gentilmente cedido pelo Prof. Dr. Yoshio Kawano. Acetona, com ponto de ebulição de $57^{\circ} \mathrm{C},{ }^{56}$ foi adquirida da Reatec. Os solventes (padrões analíticos) foram usados sem purificação prévia.

\subsection{Métodos}

\subsubsection{Funcionalização por processamento reativo}

A funcionalização por processamento reativo foi realizada em um reômetro de torque da marca Polylab Rheomix, modelo 600 HAAKE, instalado no Departamento de Engenharia Metalúrgica e Materiais, EPUSP.

O LMDPE (40,0 g ou 45,0 g) é colocado na câmara do reômetro de torque, já com a temperatura $\left(120^{\circ} \mathrm{C}\right)$, a velocidade de rotação dos dois rotores $(60 \mathrm{rpm})$ e o tempo total $(9 \mathrm{~min}$ ou $10 \mathrm{~min}$ ) de processamento previamente ajustados. Após um período de $3 \mathrm{~min}$ ou $4 \mathrm{~min}$, onde temos o LMDPE totalmente fundido e o valor de torque praticamente constante, é adicionada a solução de AGE e BPO (se necessário, é adicionado $1 \mathrm{~mL}$ a $2 \mathrm{~mL}$ de acetona). Deixa-se reagir por um período de $6 \mathrm{~min}$ ou $7 \mathrm{~min}$. No geral, a temperatura variou de $110^{\circ} \mathrm{C}$ a $145^{\circ} \mathrm{C}$, em virtude da alimentação do LMDPE na câmara e do cisalhamento produzido durante o processamento. $\mathrm{O}$ torque $(\mathrm{N} \mathrm{m})$ e a temperatura $\left({ }^{\circ} \mathrm{C}\right)$ são registrados continuamente, conforme ilustrado na Figura 21. Decorrido o tempo de processamento (9 min ou $10 \mathrm{~min}$ ), sob atmosfera de ar, a câmara é aberta e o material ainda 
fundido é retirado e permitido que se recristalize. Então, é cortado em pequenos pedaços ( $10 \mathrm{~mm}$ ). Na Figura 22(a) é mostrado o reômetro de torque, na Figura 22(b) a etapa de alimentação do LMDPE e na Figura 22(c) a etapa de retirada do material ainda fundido.

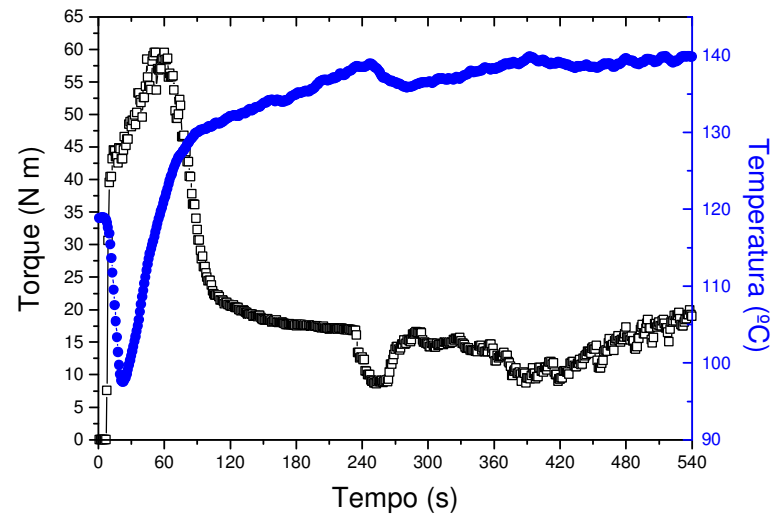

Figura 21 - Curvas típicas de torque (cor preta) e temperatura (cor azul) em função do tempo, registradas durante a funcionalização.
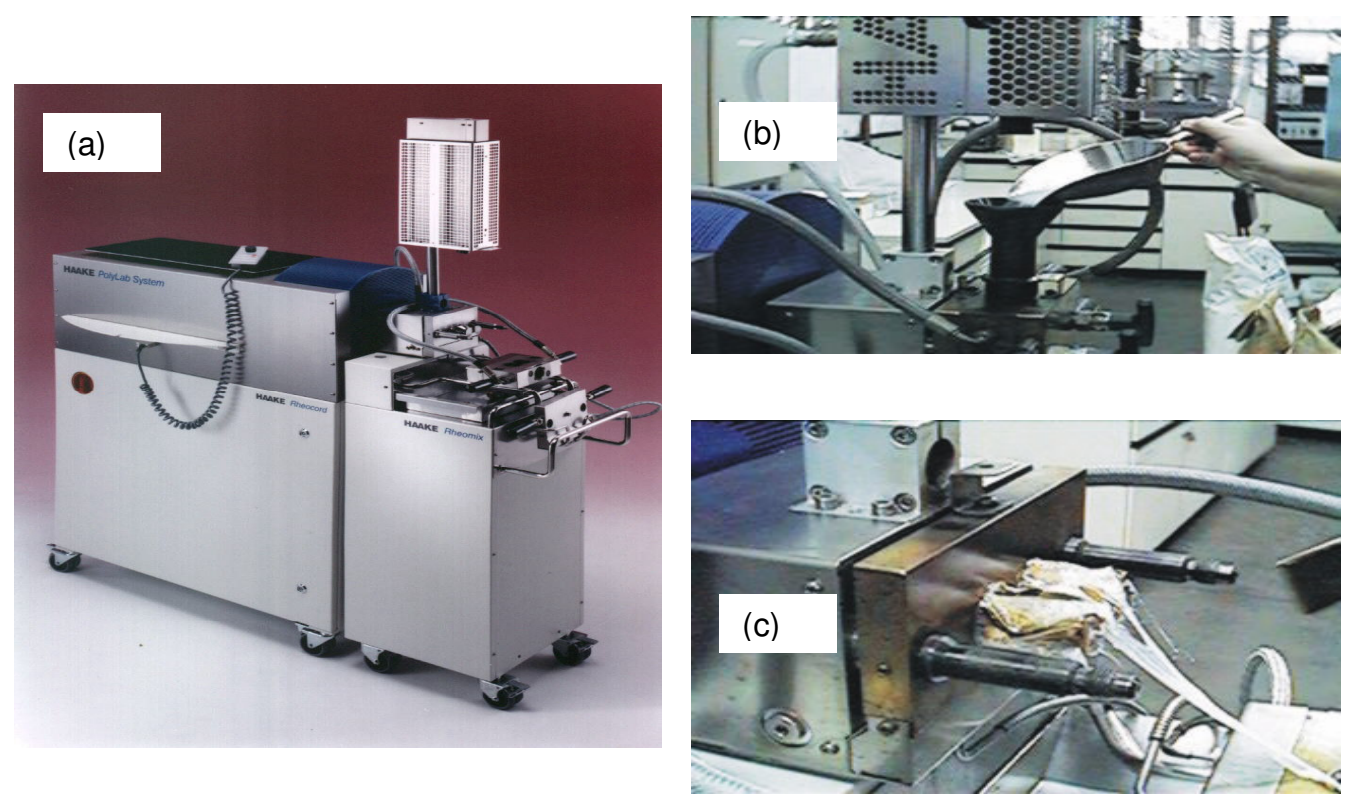

Figura 22 - (a) Reômetro de torque, (b) alimentação do LMDPE e (c) retirada do material ainda fundido. 


\subsubsection{Obtenção de compósitos (e blendas)}

Os compósitos foram preparados no reômetro de torque.

A sua obtenção se dá em duas etapas. Na primeira, é feita a funcionalização do LMDPE por processamento reativo, como descrito no item anterior. Na segunda, o LMDPE (previamente funcionalizado e cortado em pequenos pedaços) é carregado na câmara do reômetro de torque, já com a temperatura $\left(150^{\circ} \mathrm{C}\right)$, a velocidade de rotação dos dois rotores (80 rpm) e o tempo total (35 $\mathrm{min})$ de processamento previamente ajustados. Após um período de $5 \mathrm{~min}$, onde temos o LMDPE (funcionalizado) completamente fundido e o valor de torque praticamente constante, o polissacarídeo previamente seco (secagem sob vácuo, por $\sim 10$ dias a $70^{\circ} \mathrm{C}$, numa estufa Marconi, modelo MA 033) é adicionado. A formulação é preparada para uma quantidade total de material de $40,0 \mathrm{~g}$. No geral, a temperatura variou de $140^{\circ} \mathrm{C}$ a $180^{\circ} \mathrm{C}$, quando o polissacarídeo é celulose, ou de $140^{\circ} \mathrm{C}$ a $170^{\circ} \mathrm{C}$, quando é BUT-CEL, por causa da alimentação do LMDPE funcionalizado na câmara e do cisalhamento desenvolvido durante o processamento. $\mathrm{O}$ torque $(\mathrm{N} \mathrm{m})$ e a temperatura $\left({ }^{\circ} \mathrm{C}\right)$ são registrados continuamente, como ilustrado na Figura 23. Decorrido o tempo de processamento (35 $\mathrm{min}$ ), sob atmosfera de ar, a câmara é aberta e o material ainda fundido é retirado (Figura 22c) e permitido que se recristalize. Então, é cortado em pequenos pedaços ( $5 \mathrm{~mm})$. 


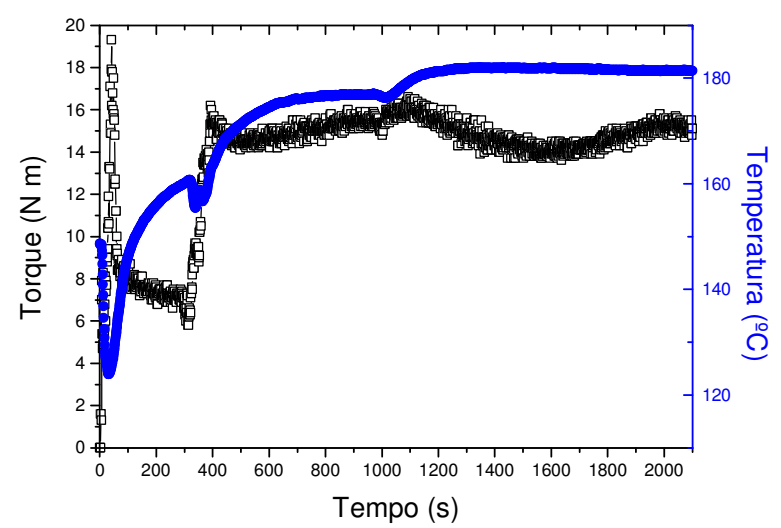

Figura 23 - Curvas típicas de torque (cor preta) e temperatura (cor azul) em função do tempo, registradas durante a obtenção de compósitos ou blendas.

\subsubsection{Funcionalização em solução}

A aparelhagem para a funcionalização em solução consiste de uma chapa térmica (Fisatom), óleo de silicone como fluido térmico, um balão de $250 \mathrm{~mL}$ de três bocas, um termômetro de $-10^{\circ} \mathrm{C}$ a $+210^{\circ} \mathrm{C}$ (sensibilidade $1^{\circ} \mathrm{C}$, Incoterm), uma corrente de nitrogênio gasoso e um condensador de bolas.

Adicionam-se $3,0 \mathrm{~g}$ do LMDPE e $100 \mathrm{~mL}$ do solvente (xileno ou clorobenzeno) ao balão. Colocam-se um termômetro em uma boca e uma pipeta de Pasteur em outra, para permitir a entrada de nitrogênio. Encaixase 0 balão no condensador e inicia-se 0 aquecimento sob agitação constante. Borbulha-se nitrogênio por $15 \mathrm{~min}\left(0,5 \mathrm{~L} \mathrm{~min}^{-1}\right.$ a $\left.1 \mathrm{~L} \mathrm{~min}{ }^{-1}\right)$. Após a dissolução total do LMDPE e já na temperatura desejada (93 $\pm 2^{\circ} \mathrm{C}$ ou 121 $\left.\pm 2^{\circ} \mathrm{C}\right)$, inicia-se a purga de nitrogênio $\left(0,5 \mathrm{~L} \mathrm{~min}^{-1}\right.$ a $\left.1 \mathrm{~L} \mathrm{~min}^{-1}\right)$. Depois de $15 \mathrm{~min}$, adiciona-se a solução de AGE e (1/3 da quantidade de) BPO, iniciando a contagem do tempo de reação. A segunda e a terceira terças partes da quantidade de BPO (previamente dissolvidos em $\sim 5 \mathrm{~mL}$ do solvente) são adicionadas depois de $10 \mathrm{~min}$ e $25 \mathrm{~min}$ (a partir do inicio da 
reação). Deixa-se reagir até o tempo desejado (40 min ou 4 h), sob atmosfera de nitrogênio.

\subsubsection{Funcionalização superficial por radiação ultravioleta (UV)}

A aparelhagem para a funcionalização superficial por UV (no laboratório do Prof. Dr. Luiz Henrique Catalani) consiste de um invólucro de vidro, dentro do qual tem uma fonte de radiação UV (lâmpada de $\mathrm{Hg}$, de $\lambda=$ $254 \mathrm{~nm}$ e intensidade de $22.800 \mu \mathrm{W} \mathrm{cm}{ }^{-2}$, sendo $1 \mathrm{~W}=1 \mathrm{~J} \mathrm{~s}^{-1}$ ) e um suporte para a amostra $(\sim 6 \mathrm{~cm} \times 11 \mathrm{~cm})$. É possível purgar nitrogênio gasoso e manter a temperatura controlada no interior desse invólucro. Aplica-se uma solução ( 0,3 mL a 0,6 mL) de monômero, iniciador e acetona sobre uma placa de $\operatorname{LMDPE}(\sim 2,5 \mathrm{~cm} \times 3 \mathrm{~cm} \times 0,16 \mathrm{~cm})$, previamente limpa com tolueno ou xileno e seca com nitrogênio. Com o auxílio de um pincel, essa solução é espalhada sobre a superfície da placa. Aguarda-se até que ocorra a evaporação da acetona e, então, aplica-se radiação UV por $4 \mathrm{~h}$, mantendo a temperatura em $25^{\circ} \mathrm{C}$ e sob atmosfera de nitrogênio. Quatro placas foram simultaneamente submetidas à radiação.

Depois de decorrido o tempo de exposição ( $4 \mathrm{~h}$ ), as quatro placas são retiradas e colocadas em um Soxhlet, para que se possa extrair (com acetona sob refluxo por $\sim 1 \mathrm{~h}$ ) os materiais que não tenham reagido. Então, as placas são secas com nitrogênio e mantidas acondicionadas em dessecador (com sílica gel) até a realização do ensaio de medidas de ângulo de contato.

\subsubsection{Purificação das amostras funcionalizadas}

A aparelhagem para a purificação consiste de uma chapa térmica, óleo de silicone, um balão de $500 \mathrm{~mL}$ de uma boca, um extrator Soxhlet, um condensador de bolas e uma estufa a vácuo. 
Ao final da funcionalização em solução, como descrito no item 3.2.3, verte-se a solução quente em $\sim 100 \mathrm{~mL}$ de acetona (temperatura ambiente). Filtra-se e deixa-se o precipitado secar ao ar.

Após a funcionalização por processamento reativo, como descrito no item 3.2.1, $\sim 3 \mathrm{~g}$ de amostra representativa é dissolvida em $\sim 100 \mathrm{~mL}$ de tolueno (105ํㅡ a 110ํㅡ). Então, a solução quente é vertida em $100 \mathrm{~mL}$ de acetona (temperatura ambiente). Filtra-se e deixa-se o precipitado secar ao ar.

Coloca-se o precipitado (previamente seco ao ar), envolvido por um papel-filtro qualitativo, no Soxhlet, no qual já se encontram encaixados um condensador e um balão. Deixa-se refluxar por 16 h. Então, deixa-se 0 material purificado secar ao ar. Depois, sob vácuo $\left(\sim 24 \mathrm{~h}\right.$ a $\left.\sim 100^{\circ} \mathrm{C}\right)$. A finalidade é remover os materiais que não tenham reagido e/ou os produtos secundários eventualmente formados.

\subsubsection{Obtenção de filme por evaporação do solvente ("casting”)}

Adicionam-se de $200 \mathrm{mg}$ a $220 \mathrm{mg}$ da amostra (purificada) e $\sim 20 \mathrm{~mL}$ de tolueno em um frasco de $\sim 30 \mathrm{~mL}$. Aquece-se sob agitação (constante) até dissolução total. Então, verte-se a solução quente em uma placa de Petri (diâmetro interno de $\sim 95 \mathrm{~mm}$ e altura de $\sim 10 \mathrm{~mm}$ ). Após a formação do filme, o conjunto "filme + placa" é colocado na estufa por 10 min (135ํㅡ a $\left.140^{\circ} \mathrm{C}\right)$. Então, é retirado e permitido que resfrie. Adiciona-se água destilada nas bordas do filme (para facilitar a sua remoção da placa) e, por meio de uma pinça apropriada, remove-se o filme. Em seguida, o filme é seco com nitrogênio gasoso e acondicionado em dessecador (com sílica gel) até a realização do ensaio no FTIR. Obtêm-se filmes com espessura de 0,03 mm (medida com um micrômetro, no laboratório do Prof. Dr. Luiz Henrique Catalani). 


\subsubsection{FTIR e curvas de calibração}

Os espectros no FTIR foram obtidos em filmes (obtidos a partir de amostras purificadas), utilizando-se o Espectrômetro FTIR ABB Bomem, modelo MB 100, no intervalo de $4000 \mathrm{~cm}^{-1}$ a $400 \mathrm{~cm}^{-1}$, com resolução de $4 \mathrm{~cm}^{-1}$, na Central Analítica do IQUSP.

Foi usado o método da linha base. Optou-se por medir a altura da banda (a partir da linha-base traçada), no programa de computador do próprio aparelho (Bomem), e não a área, em virtude da sobreposição de bandas. Para minimizar o efeito da (variação da) espessura do filme (que corresponde ao caminho óptico), foram calculadas as razões entre as alturas das bandas $1100 \mathrm{~cm}^{-1}$ e $1463 \mathrm{~cm}^{-1}$ e entre as das bandas $920 \mathrm{~cm}^{-1} \mathrm{e}$ $1463 \mathrm{~cm}^{-1}$. Os trabalhos com espectroscopia quantitativa no infravermelho, citados na literatura, em geral, usam a absorbância em função do número de onda. No entanto, foi usada a transmitância em função do número de onda. Como as bandas de interesse $\left(\sim 1100 \mathrm{~cm}^{-1} \mathrm{e} \sim 920 \mathrm{~cm}^{-1}\right)$ da matriz polimérica funcionalizada são de intensidades relativamente baixas, o sinal gerado é relativamente mais intenso quando se obtém o espectro em transmitância, permitindo eliminar, ou ao menos minimizar, eventuais erros nas medições das alturas das bandas.

Comparando-se a Figura 11 (espectro no FTIR do LMDPE, item 3.1.1) com a Figura 13 (espectro no FTIR do AGE, item 3.1.2) nota-se claramente que podemos usar a banda de $\sim 1100 \mathrm{~cm}^{-1}$ (AGE), de média intensidade, como indicativo da incorporação química do AGE na matriz polimérica. Pois, a absorção do LMDPE nessa região é relativamente desprezível. O mesmo se aplica para a banda de $\sim 920 \mathrm{~cm}^{-1}$ (AGE). Porém, sendo de baixa intensidade, não é adequada para essa finalidade. Mesmo assim, a banda de $\sim 920 \mathrm{~cm}^{-1}$ (que nos filmes aparece em $\sim 910 \mathrm{~cm}^{-1}$, e por esse motivo, daqui por diante, essa banda será referida como $\sim 910 \mathrm{~cm}^{-1}$ ) também foi 
usada, por ser característica de anéis epóxidos. Já a banda de $\sim 1463 \mathrm{~cm}^{-1}$ (LMDPE) foi usada como padrão interno.

A partir de soluções preparadas pela mistura de um óleo mineral (com espectro no FTIR muito parecido com o do LMDPE, exceto, obviamente, por não conter os dois pares de dubletos clássicos do polietileno, como mostrado na Figura 24(a) e do AGE, em várias concentrações (1\%, 2\%, 3\%, $4 \%, 5 \%$ e $10 \%$ de AGE sobre a quantidade de óleo, massa/massa), foram obtidos espectros no FTIR, como mostrados na Figura 24(b). Foi usado um espaçador de 0,015 mm (tentou-se com um de 0,025 mm, com espessura mais próxima da do filme, $\sim 0,03 \mathrm{~mm}$, porém "estouraram" algumas bandas). 

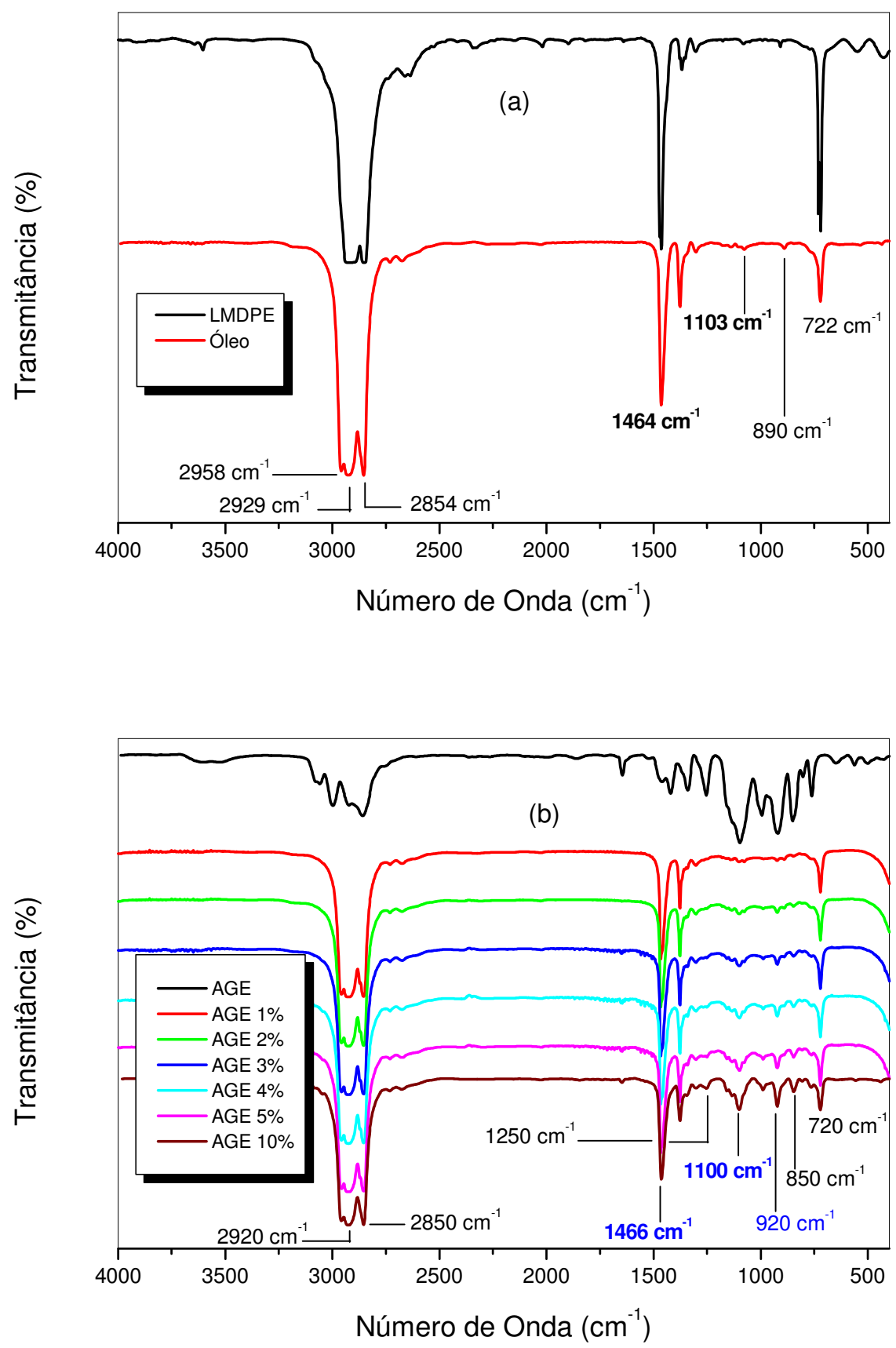

Figura 24 - Espectros no FTIR do (a) LMDPE e óleo mineral e (b) AGE e soluções de AGE e óleo mineral (1\%, 2\%, 3\%, 4\%, 5\% e 10\% de AGE sobre o óleo mineral, massa/massa). 
Então, duas curvas de calibração foram construídas. Curva de calibração 1, \%AGE/óleo (0\%, 1\%, 2\% e 3\%) em função da razão entre as alturas das bandas $1100 \mathrm{~cm}^{-1}$ e $1463 \mathrm{~cm}^{-1}$ (Figura 25a). Curva de calibração 2, \%AGE/óleo (0\%, 1\%, 2\% e 3\%) em função da razão entre as alturas das bandas $910 \mathrm{~cm}^{-1}$ e $1463 \mathrm{~cm}^{-1}$ (Figura 25b). Observa-se que, optou-se por usar somente as concentrações (\%AGE/óleo) de 0\%, 1\%, 2\% e $3 \%$, pois os ajustes obtidos das curvas são relativamente melhores. Foram obtidas as seguintes equações para as duas curvas, $y=79,9423 x^{2}+$ $5,8976 x-0,2672, R^{2}=0,9921$ (curva de calibração 1) e $y=106,5785 x^{2}+$ $7,3135 x-0,4730, R^{2}=0,9987$ (curva de calibração 2 ).
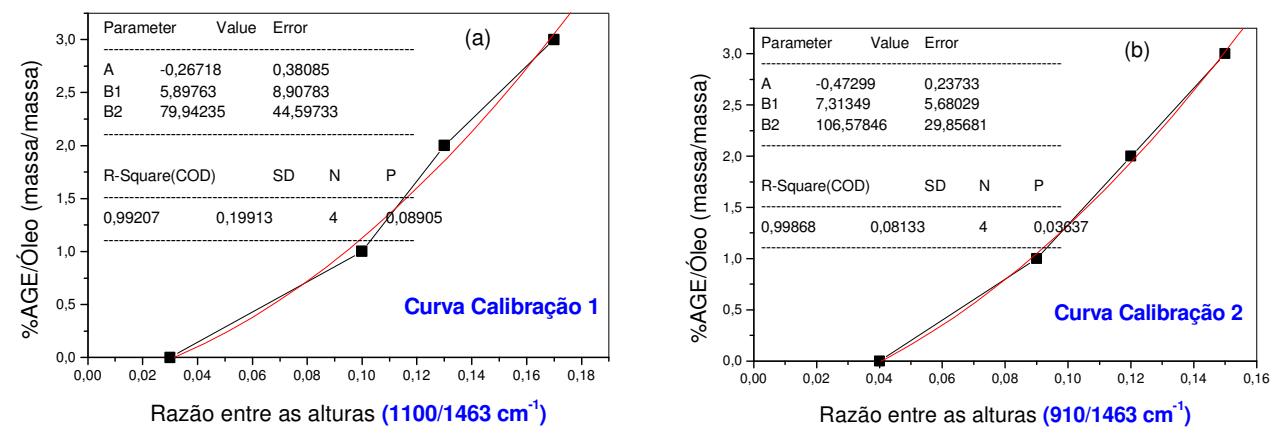

Figura 25 - (a) Curva de calibração 1 e (b) curva de calibração 2.

Interpolando-se o valor experimental da razão entre as alturas das bandas $1100 \mathrm{~cm}^{-1}$ e $1463 \mathrm{~cm}^{-1}\left(h_{1100} / h_{1463}\right)$ na curva de calibração 1 , obtémse o grau de funcionalização (GF) expresso na forma de \%AGE/LMDPE (massa/massa). Interpolando-se o valor experimental da razão entre as alturas das bandas $910 \mathrm{~cm}^{-1}$ e $1463 \mathrm{~cm}^{-1}\left(h_{910} / h_{1463}\right)$ na curva de calibração 2, obtém-se o GF também expresso na forma de \%AGE/LMDPE (massa/massa). 
A eficiência da funcionalização (EF) foi calculada de acordo com a eq. (11).

$$
E F=\frac{[\% A G E / L M D P E]_{g}}{[\% A G E / L M D P E]_{i}} \times 100
$$

onde [\%AGE/LMDPE] $]_{g}$ é a quantidade de AGE inserida quimicamente no LMDPE, expressa em \% de AGE sobre o LMDPE, e [\%AGE/LMDPE] é a quantidade de AGE inicial na formulação, expressa em \% de AGE sobre o LMDPE.

\subsubsection{GC-MS}

O cromatograma e espectro de massas foram obtidos no GC-MS da marca Shimadzu, modelo QP 5050 A (O GC da marca Shimadzu, modelo 17 A), na Central Analítica do IQUSP.

Após o término da reação do AGE $(3,0 \mathrm{~g})$ com BPO (na ausência de LMDPE), em $100 \mathrm{~mL}$ de tolueno, numa razão molar entre AGE e BPO de 16,6 por $4 \mathrm{~h}$ a $93 \pm 2^{\circ} \mathrm{C}$ (com purga de nitrogênio gasoso somente nos primeiros $30 \mathrm{~min}$ de reação), a chapa térmica foi desligada. Ainda sob refrigeração com água corrente e sob agitação, aguardou-se até que a solução atingisse a temperatura ambiente. Posteriormente, desconectou-se o balão da aparelhagem e concentrou-se a solução por evaporação do solvente a temperatura ambiente. Aparentemente, não houve formação de depósitos no fundo do recipiente. Então, a amostra foi injetada na coluna do GC-MS.

Tanto a solução concentrada obtida conforme descrito acima, como o AGE tal qual recebido, foram analisados numa coluna DB-5 (30 m). A quantidade de amostra injetada foi de $1 \mu \mathrm{L}$. A temperatura no injetor foi de 
$250^{\circ} \mathrm{C}$. A temperatura na coluna (rate) foi de $60^{\circ} \mathrm{C}(3 \mathrm{~min})^{-1}, 20^{\circ} \mathrm{C}(3 \mathrm{~min})^{-1} \mathrm{e}$ $250^{\circ} \mathrm{C}(10 \mathrm{~min})^{-1}$. A temperatura no detector foi de $250^{\circ} \mathrm{C}$. O MS foi obtido por El.

\subsubsection{Análise elementar}

A amostra é colocada no tubo de oxidação $\left(925^{\circ} \mathrm{C}\right)$, o qual é mantido sob fluxo de $\mathrm{O}_{2}$ e $\mathrm{He}$. Os produtos de reação $\left(\mathrm{CO}_{2}, \mathrm{H}_{2} \mathrm{O}\right.$ e $\left.\mathrm{NO}_{x}\right)$, que saem do tubo de oxidação, passam pelo tubo de redução $(\mathrm{Cu})$, mantido a $640^{\circ} \mathrm{C}$, que causa a redução dos $\mathrm{NO}_{x}$ a $\mathrm{N}_{2}$. Então, $\mathrm{CO}_{2}, \mathrm{H}_{2} \mathrm{O}$ e $\mathrm{N}_{2}$, além de $\mathrm{He}$ e (do excesso de) $\mathrm{O}_{2}$, seguem para a coluna de separação. Depois de resolvidos, passam pelo detector de condutividade térmica.

Os teores de $\mathrm{C}, \mathrm{H}$ e $\mathrm{N}$, das amostras purificadas, foram obtidos no equipamento Elemental Analyser CHN, marca Perkin Elmer, modelo 2400, na Central Analítica do IQUSP.

\subsubsection{DSC}

As curvas DSC, das amostras purificadas, foram obtidas na célula DSC-50, da marca Shimadzu, no Laboratório do Prof. Dr. Jivaldo do Rosário Matos.

As amostras foram submetidas a duas corridas. Na primeira, a amostra, em um cadinho de $\mathrm{Al}$, foi aquecida $\left(\beta=5^{\circ} \mathrm{C} \mathrm{min}^{-1}\right)$ de $25^{\circ} \mathrm{C}$ a $150^{\circ} \mathrm{C}$ e, imediatamente, resfriada $\left(5^{\circ} \mathrm{C} \mathrm{min}^{-1}\right)$ de $150^{\circ} \mathrm{C}$ a $25^{\circ} \mathrm{C}$, para eliminar $\mathrm{O}$ histórico térmico (tensões internas) da amostra. $\mathrm{Na}$ segunda, ela foi novamente aquecida $\left(\beta=5^{\circ} \mathrm{C} \mathrm{min}^{-1}\right)$ de $25^{\circ} \mathrm{C}$ a $150^{\circ} \mathrm{C}$. O ensaio foi realizado sob atmosfera dinâmica de nitrogênio gasoso $\left(100 \mathrm{~mL} \mathrm{~min}^{-1}\right)$. Os valores de temperatura de fusão e calor de fusão, assim como os calculados de grau de cristalinidade, foram obtidos a partir das curvas DSC do segundo aquecimento. Observou-se que, $\operatorname{com} \beta$ igual a $5^{\circ} \mathrm{C} \mathrm{min}^{-1}$, a sensibilidade das medições da temperatura de fusão (no máximo do pico) e da variação da 
entalpia de fusão aumentou, principalmente no caso da temperatura de fusão.

O grau de cristalinidade $\left(\chi_{c}\right)$ de uma amostra de polímero pode ser determinado (indiretamente) a partir do pico endotérmico relativo à fusão cristalina. Assim, o $\chi_{c}$ pode ser calculado através da eq. (12).

$$
\chi_{c}=\frac{\Delta H_{f(\text { amostra })}}{\Delta H_{f(\text { PE } 100 \% \text { cristalino })}} x 100
$$

onde $\Delta \mathrm{H}_{\mathrm{f}}$ (amostra) é a variação da entalpia de fusão da amostra sob investigação (em J g ${ }^{-1}$ ) e $\Delta \mathrm{H}_{\mathrm{f}}$ (PE 100\% cristalino) é a variação da entalpia de fusão de uma amostra de polietileno calculada como sendo $100 \%$ cristalina $\left(293 \mathrm{~J} \mathrm{~g}^{-1}\right){ }^{60}$

\subsubsection{TG e DTG}

As curvas TG e DTG, das amostras purificadas, foram obtidas na termobalança TGA-50, da marca Shimadzu, no Laboratório do Prof. Dr. Jivaldo do Rosário Matos.

As amostras, em um cadinho de $\mathrm{Pt}$, foram aquecidas $\left(\beta=10^{\circ} \mathrm{C} \mathrm{min}^{-1}\right)$ de $25^{\circ} \mathrm{C}$ a $750^{\circ} \mathrm{C}$, sob atmosfera dinâmica de nitrogênio gasoso $\left(50 \mathrm{~mL} \mathrm{~min}^{-1}\right)$. Os valores de T onset (temperatura inicial extrapolada), T pico (temperatura no pico da curva DTG ou no ponto de inflexão da curva TG), T endset (temperatura final extrapolada) e perda de massa foram obtidos a partir das curvas TG e DTG.

\subsubsection{MFI}

Os ensaios de MFI, das amostras não purificadas, foram realizados no equipamento Plastômetro, marca Kayeness Galaxy I Melt Indexer, 
modelo D 7050, no Departamento de Engenharia Química, EPUSP, seguindo a norma ASTM D-1238.

\subsubsection{Obtenção de placas por prensagem}

As placas $(\sim 10 \mathrm{~cm} \times 10 \mathrm{~cm} \times 0,16 \mathrm{~cm}$ ) foram obtidas (de amostras não purificadas) na prensa hidráulica com aquecimento, marca Sirma, no Departamento de Engenharia Metalúrgica e Materiais, EPUSP.

A amostra, previamente cortada ( $31 \mathrm{~g} \mathrm{e} \sim 5 \mathrm{~mm}$ de tamanho) e seca a vácuo (por 2 dias a $80^{\circ} \mathrm{C}$ ), é espalhada dentro da moldura (de latão), a qual está apoiada a uma chapa de aço inoxidável $(\sim 20 \mathrm{~cm})$ revestida por um filme (de poliéster, comercial). Então, uma outra chapa de aço inoxidável (também revestida com filme) é colocada por cima. Coloca-se esse conjunto entre os pratos da prensa e deixa-se lá de $15 \mathrm{~min}$ a $30 \mathrm{~min}\left(\sim 170^{\circ} \mathrm{C}\right)$ com os

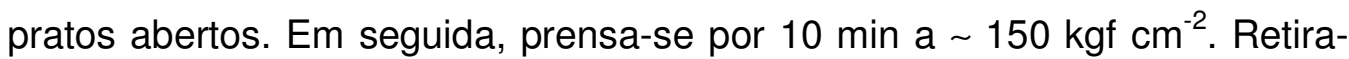
se o conjunto e aguarda-se até que ocorra a recristalização do material. Então, remove-se a placa da moldura.

A partir das placas foram cortados corpos de provas usando o cunho do Laboratório de Plásticos e Borrachas, IPT. Na Figura 26 é mostrado o desenho esquemático de um corpo de prova típico que é usado na realização dos ensaios mecânicos de tração, bem como as suas dimensões.

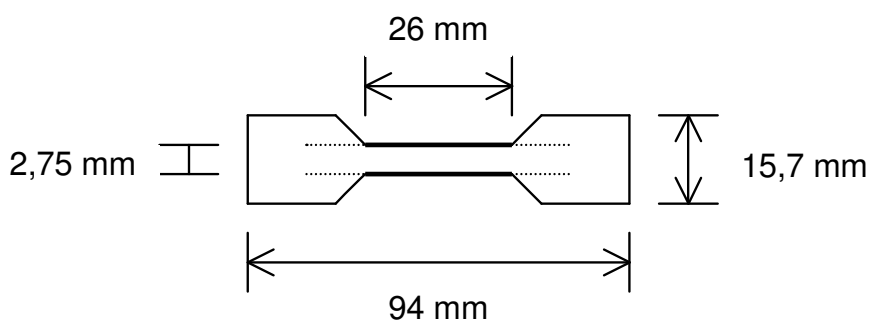

Figura 26 - Dimensões de um corpo de prova típico para a realização de ensaios mecânicos. 


\subsubsection{Medidas de ângulo de contato}

A aparelhagem para a medição do ângulo de contato $\theta$ consiste de uma fonte de luz fria, um suporte para a amostra, uma lente de aumento, uma câmara digital Cássio QV 10 e um anteparo (de papel branco) sobre o qual será projetada a imagem da gota.

Aplica-se, com 0 auxílio de uma microsseringa, $10 \mu \mathrm{L}$ de água destilada sobre a placa $(2,5 \mathrm{~cm} \times 3 \mathrm{~cm} \times 0,16 \mathrm{~cm}$, obtida na prensagem). Tira-se uma foto da projeção da imagem da gota, a qual corresponde ao $\theta_{\text {avanço. }}$ Em seguida, com o auxílio da microsseringa, retira-se $5 \mu \mathrm{L}$ de água destilada, do volume inicial de $10 \mu \mathrm{L}$. Tira-se outra foto da projeção da (nova) imagem da gota, a qual corresponde ao $\theta_{\text {recesso. Isso é feito em até }}$ três pontos distintos da placa. Para cada foto, foram feitas duas medidas de ângulo de contato. Os valores médios de $\theta_{\text {avanço }} \mathrm{e} \theta_{\text {recesso }}$ foram determinados por meio do aplicativo CorelDraw 8.0. $O$ valor da $\Delta \theta$ de contato foi calculado através da eq. (13).

$$
\Delta \theta=\theta_{\text {avanço }}-\theta_{\text {recesso }}
$$

\subsubsection{XRD}

Os difratogramas foram obtidos no equipamento X-Ray Difractometer, marca Rigaku, com geometria Bragg-Brentano, no Laboratório de Cristalografia, IFUSP.

O ensaio foi realizado em placas $(\sim 2 \mathrm{~cm} \times 3 \mathrm{~cm} \times 0,16 \mathrm{~cm}$, obtidas na prensagem), nas seguintes condições: feixe monocromático de raios $X$ de $0,154 \mathrm{~nm}\left(\mathrm{CuK}_{\alpha}\right)$, voltagem de aceleração de $40 \mathrm{kV}$, corrente de $20 \mathrm{~mA}$, intervalo de ângulo $2 \theta \times$ de $10^{\circ}$ a $50^{\circ}$, leitura de $0,05^{\circ}$ em $0,05^{\circ}$, com tempo de aquisição de $10 \mathrm{~s}$. 


\subsubsection{SEM}

Pequenas tiras $(\sim 1 \mathrm{~mm}$ a $2 \mathrm{~mm}$ de largura, $\sim 2 \mathrm{~mm}$ a $3 \mathrm{~mm}$ de comprimento $e \sim 1,6 \mathrm{~mm}$ de espessura, das placas obtidas na prensagem) foram fraturadas em nitrogênio líquido e, depois, metalizadas com ouro. Então, as superfícies de fratura foram analisadas em um microscópio eletrônico de varredura, marca Phillips XL30, no Laboratório de Microscopia Eletrônica e Microanálise, EPMT-USP. Os elétrons secundários gerados da interação entre o feixe de elétrons e a amostra são coletados por um detector e convertidos em sinais eletrônicos, os quais são projetados numa tela de vídeo.

\subsubsection{Ensaios mecânicos de tração}

Os valores de resistência à tração e elongação, bem como o módulo de Young, foram obtidos no Instron 4400R, no Laboratório de Ensaios Mecânicos, CCTM-IPEN.

A velocidade de deslocamento ascendente da garra superior foi de $30 \mathrm{~mm} \mathrm{~min}^{-1}$. Para cada ensaio, foram ensaiados até cinco corpos de provas (como mostrado na Figura 26, item 3.2.13). A média e o desvio padrão foram calculados para a resistência à tração no ponto de escoamento $\left(\sigma_{y}\right)$, para a elongação no ponto de escoamento $\left(\varepsilon_{y}\right)$, para a resistência à tração máxima $\left(\sigma_{\mathrm{m}}\right)$, para a resistência à tração na ruptura $\left(\sigma_{\mathrm{b}}\right)$, para a elongação na ruptura $\left(\varepsilon_{\mathrm{b}}\right)$ e para o módulo de Young $(\mathrm{E})$. Os valores de $\sigma_{\mathrm{m}}, \sigma_{\mathrm{b}}$ e $\varepsilon_{\mathrm{b}}$ foram obtidos diretamente do equipamento (apenas foi feita conversão para a unidade apropriada). Os valores de $\sigma_{y}$ e $\varepsilon_{y}$, para os compósitos, foram obtidos no ponto onde se dá a intersecção do prolongamento de duas tangentes, como mostrado na Figura 27(a). ${ }^{61}$ Os valores de E correspondem aos coeficientes angulares das retas compreendidas no intervalo de $\sim 2 \%$ a $2,5 \%$ de $\varepsilon$, fixado arbitrariamente, como ilustrado na Figura 27(b). 

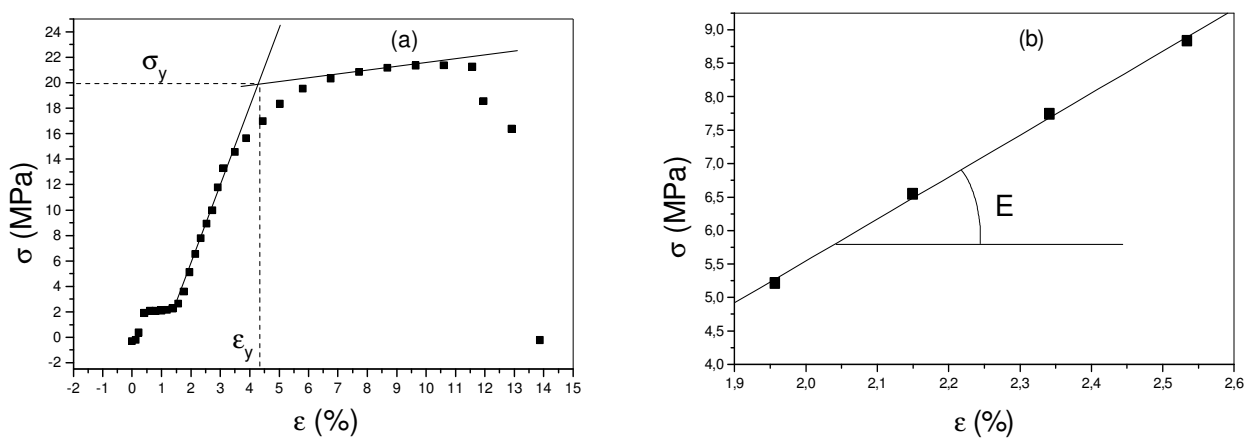

Figura 27 - (a) Curva da $\sigma$ em função da $\varepsilon$ ilustrando a determinação de $\sigma_{y}$ e $\varepsilon_{y}$ e (b) curva da $\sigma$ em função da $\varepsilon$ (no intervalo de $~ 2 \%$ a 2,5\%) mostrando a determinação de $\mathrm{E}$. 


\section{RESULTADOS e DISCUSSÃO}

\subsection{Funcionalização em solução}

Na primeira tentativa (não mostrada), o solvente usado foi tolueno, a temperatura de reação $93^{\circ} \mathrm{C}$ e o tempo de reação $4 \mathrm{~h}$ ou $8 \mathrm{~h}$. As quantidades de AGE variaram de $50 \%$ a $100 \%$ (\% sobre o LMDPE, $\mathrm{m} / \mathrm{m}$ ) e a razão molar entre AGE e BPO de 16,6 a 250. Inclusive, comparou-se a performance do BPO com a do AIBN. Nitrogênio gasoso foi borbulhado apenas nos primeiros 30 min de reação e a solução de AGE e BPO foi adicionada totalmente em uma única etapa. Comparando-se os valores de GF obtidos com aquele obtido para um controle (reação processada na ausência de AGE), verificouse que eram comparáveis, evidenciando (por FTIR) ausência de incorporação química do AGE na matriz polimérica. As reações paralelas que competem com a funcionalização, como a homopolimerização do monômero e a reticulação do LMDPE (podendo ser evidenciada pela formação de gel) poderiam estar sobrepujando a reação principal. Porém, somente foi observada a presença de gel em dois casos, e com conteúdos (secos) relativamente baixos, $\sim 6 \%$ (em relação à quantidade inicial de LMDPE). Quanto à possível homopolimerização do AGE, foi feito um estudo a respeito e está descrito no próximo item. Na segunda tentativa (tampouco mostrada), foi feita investigação em xileno (a 135ํㅡ por $40 \mathrm{~min}$ ), difenila (a $135^{\circ} \mathrm{C}$ por $40 \mathrm{~min}$ ) e clorobenzeno (a $93^{\circ} \mathrm{C}$ por $4 \mathrm{~h}$ ). A quantidade de $\mathrm{AGE}$ usada foi de $50 \%$ e a razão molar entre AGE e BPO de 20. Nitrogênio gasoso foi borbulhado apenas nos primeiros $15 \mathrm{~min}\left(135^{\circ} \mathrm{C}\right)$ ou $30 \mathrm{~min}$ $\left(93^{\circ} \mathrm{C}\right)$ de reação e a solução de AGE e BPO foi adicionada totalmente em uma única vez. Contudo, essa investigação foi prejudicada pela ocorrência de franjas de interferências (produzidas por reflexão da radiação do infravermelho nas superfícies planas e paralelas do filme da amostra). ${ }^{62}$ Para eliminar esse problema, foram realizados novos ensaios, seguindo a metodologia descrita no item 3.2.3. Este estudo está descrito no item 4.1.2. 


\subsubsection{Reatividade do alil glicidil éter (AGE) na ausência de polietileno (PE) em tolueno (93ㅇ)}

Resolveu-se avaliar a reatividade do AGE quanto à homopolimerização, na ausência do LMDPE. Pois, isso facilita a caracterização dos produtos de reação por GC-MS.

A Figura 28(a) mostra o cromatograma dos produtos de reação (ver item 3.2.8). A Figura 28(b) mostra o espectro de massas do pico número 2 (da Figura 28a).
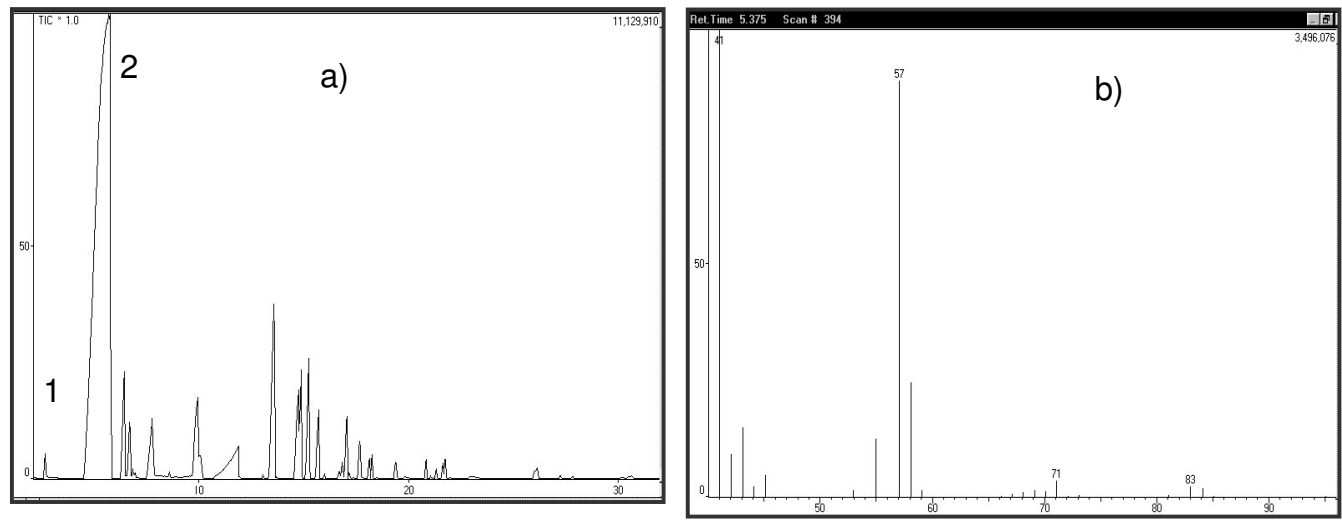

Figura 28 - (a) Cromatograma e (b) Espectrograma de Massas (do pico número 2) obtidos por GC-MS.

A área do pico número 2, na Figura 28(a), corresponde à $78 \%$ da soma das áreas de todos os picos. Aquele pico refere-se ao AGE que não reagiu, conforme pode ser visto comparando-se a Figura 28 (b) com a Figura 14(b) (item 3.1.2). Assim, do volume injetado e evaporado na coluna, apenas cerca de $20 \%$ de AGE teria reagido. Não foi possível identificar os produtos de reação envolvendo o AGE.

Sabe-se da literatura que a homopolimerização de compostos de éter alílicos é muito difícil de se realizar, porém seus copolímeros (por exemplo, com acrilonitrila ou com cloreto de vinila) são fáceis de se obter. ${ }^{63-65}$ Contudo, tanto a homopolimerização quanto a copolimerização dão origem a 
oligômeros, devido à ocorrência de transferência degradante de cadeia ("degradative chain transfer"), típica de monômeros alílicos. É ocasionada quando há abstração de átomos de hidrogênio alílicos, pela cadeia em crescimento, dando origem à interrupção do crescimento da cadeia em questão e formação do radical alílico. Devido a sua baixa reatividade (estabilizado por efeito mesomérico) não consegue iniciar uma nova cadeia, levando-o a combinar-se com outro radical ou a abstrair um átomo de hidrogênio de outra molécula do meio reacional (por exemplo, do AGE ou do solvente).

O pico número 1 (Figura 28a) refere-se ao resíduo de tolueno, cuja área sob o pico é de $0,2 \%$. Constatou-se que, com o auxílio da biblioteca eletrônica de espectros de massas da Central Analítica (IQUSP), de 3 fontes distintas, todos os picos, com áreas maiores que 1\%, eram produtos de reação envolvendo reações de acoplamento radicalar de anéis aromáticos. ${ }^{66}$ Estas reações envolviam o radical benzila (proveniente da abstração de um átomo de hidrogênio benzílico da molécula de tolueno por um radical gerado direta ou indiretamente na homólise térmica do BPO) e moléculas de tolueno. Bem como, entre o radical fenila (originado da homólise térmica do BPO) e moléculas de tolueno. A presença de álcool benzílico e benzaldeído também pôde ser observada.

Isso evidencia que o tolueno é um solvente ativo, no que tange à facilidade de ceder átomos de hidrogênio em reações radicalares. Portanto, a presença de um solvente ativo poderia estar afetando de sobremaneira a funcionalização do LMDPE com AGE, na presença de BPO ou AIBN. O macrorradical (formado pela abstração de um átomo de hidrogênio da cadeia polimérica por um radical) poderia estar sendo desativado antes de se adicionar à ligação dupla da molécula de AGE, se, por exemplo, abstrair um átomo de hidrogênio do meio reacional. 


\subsubsection{Funcionalização em clorobenzeno $\left(93^{\circ} \mathrm{C}\right.$ e $\left.121^{\circ} \mathrm{C}\right)$ e xileno $\left(121^{\circ} \mathrm{C}\right)$}

Este estudo tem por objetivo avaliar a influência de um solvente relativamente bom doador de átomos de hidrogênio (xileno) contra um relativamente mau doador (clorobenzeno) na funcionalização do LMDPE com AGE, na presença de BPO. Assim como, a influência da temperatura (e tempo) de reação $\left(93^{\circ} \mathrm{C}\right.$, por $4 \mathrm{~h}$, contra $121^{\circ} \mathrm{C}$, por $\left.0,67 \mathrm{~h}\right)$. O uso de clorobenzeno justifica-se por este conter átomos de hidrogênio, bem como um átomo de cloro, ligados diretamente aos átomos de carbono $\mathrm{sp}^{2}$ do anel benzênico, tornando-o um doador de átomos de hidrogênio bem menos eficiente que xileno (ou tolueno). Pois, daria origem ao radical clorofenila (se perder um átomo de $\mathrm{H}$ ), que por não ser estabilizado por ressonância, é relativamente energético e, portanto, menos estável. O átomo de cloro também pode ser transferido (o que daria origem ao radical fenila, se perder um átomo de $\mathrm{Cl}$ ), pois as reações radicalares envolvem, principalmente, a transferência de átomos monovalentes. ${ }^{36 a}$ As energias de dissociação das ligações $\mathrm{Ph}-\mathrm{H}$ e $\mathrm{Ph}-\mathrm{Cl}$ são, respectivamente, 111 e $96 \mathrm{kcal} \mathrm{mol}^{-1}$. ${ }^{36 \mathrm{~b}}$ Já o do xileno, por sua maior tendência relativa de sofrer abstração de átomos de hidrogênio numa reação radicalar, pois o radical (benzila) que se origina é estabilizado por ressonância. A energia de dissociação da ligação $\mathrm{PhCH}_{2}-\mathrm{H}$ é $88 \mathrm{kcal} \mathrm{mol}^{-1} .^{36 \mathrm{~b}}$ Ademais, seu ponto de ebulição $\left(137^{\circ} \mathrm{C}\right.$ a $\left.140^{\circ} \mathrm{C}\right)$ é compatível com a temperatura da reação $\left(121^{\circ} \mathrm{C}\right)$.

$\mathrm{Na}$ Tabela 2 encontram-se as condições e formulações usadas neste estudo. Os ensaios B, D e $\mathbf{F}$ correspondem aos controles (reação na ausência de AGE) dos ensaios $\mathbf{A}, \mathbf{C}$ e $\mathbf{E}$, respectivamente. 
Tabela 2 - Condições e formulações usadas nos ensaios A-F.

\begin{tabular}{|c|c|c|c|c|c|c|}
\hline \multirow{4}{*}{ Ensaio } & \multicolumn{3}{|c|}{ Condição } & & & \\
\hline & \multirow{3}{*}{ Solvente } & \multirow{3}{*}{$\begin{array}{l}\text { Temperatura } \\
\text { de reação } \\
\left({ }^{\circ} \mathrm{C}\right)\end{array}$} & \multirow{3}{*}{$\begin{array}{l}\text { Tempo de } \\
\text { reação } \\
\text { (h) }\end{array}$} & \multicolumn{3}{|c|}{ Formulação } \\
\hline & & & & \multicolumn{2}{|c|}{ \% sobre LMDPE (m/m) } & \multirow{2}{*}{$\begin{array}{c}\text { Razão } \\
\text { molar } \\
\text { (AGE/BPO }\end{array}$} \\
\hline & & & & AGE & BPO & \\
\hline A & Clorobenzeno & 93 & 4 & 50,0 & 10,61 & 10,0 \\
\hline B & Clorobenzeno & 93 & 4 & - & 10,61 & - \\
\hline C & Clorobenzeno & 121 & 0,67 & 50,0 & 10,61 & 10,0 \\
\hline D & Clorobenzeno & 121 & 0,67 & - & 10,61 & - \\
\hline $\mathbf{E}$ & Xileno & 121 & 0,67 & 50,0 & 10,61 & 10,0 \\
\hline $\mathbf{F}$ & Xileno & 121 & 0,67 & - & 10,61 & - \\
\hline
\end{tabular}

Foi observada a presença de pequena quantidade de gel aderida às paredes do balão nos ensaios de A a F (aparentemente, maior quando o solvente é clorobenzeno). Porém, não foi possível a sua quantificação, exceto para o ensaio $\mathbf{B}$, cujo conteúdo (seco) foi de $1,7 \%$, em relação à quantidade inicial de LMDPE.

\subsubsection{Determinação do grau de funcionalização (GF) por FTIR}

$\mathrm{Na}$ Tabela 3 são apresentados os valores de GF obtidos (a partir de amostras purificadas) para os ensaios de A a F (Tabela 2). Na construção da curva de calibração 1 (Figura 25a, item 3.2.7), para $0 \%$ de AGE, a razão entre as alturas usada foi de 0,03. Na construção da curva de calibração 2 (Figura 25b, item 3.2.7), para $0 \%$ de AGE, a razão entre as alturas foi de 0,04 . 
Tabela 3 - Valores de GF obtidos para os ensaios A-F.

\begin{tabular}{ccccc}
\hline \multirow{2}{*}{ Ensaio } & & GF & & GF \\
\cline { 3 - 3 } \cline { 5 - 5 } & $\left(\mathrm{h}_{\mathbf{1 1 0 0}} / \mathrm{h}_{1463}\right)$ & $(\%$ AGE/LMDPE $)$ & $\left(\mathrm{h}_{\mathbf{9 1 0}} / \mathrm{h}_{1463}\right)$ & (\%AGE/LMDPE $)$ \\
\hline B & $\mathbf{0 , 0 6 5}$ & $\mathbf{0 , 4 5}$ & $\mathbf{0 , 0 4 1}$ & - \\
C & 0,031 & - & 0,026 & - \\
D & $\mathbf{0 , 0 6 6}$ & $\mathbf{0 , 4 7}$ & $\mathbf{0 , 0 5 4}$ & $\mathbf{0 , 2 3}$ \\
E & 0,024 & - & 0,030 & - \\
F & $\mathbf{0 , 0 4 9}$ & $\mathbf{0 , 2 1}$ & $\mathbf{0 , 0 3 9}$ & - \\
\hline
\end{tabular}

Analisando-se os valores de GF obtidos (Tabela 3), pode-se observar que no caso dos ensaios $\mathbf{A}(0,45 \%)$ e $\mathbf{C}(0,47 \%)$, onde o solvente usado foi clorobenzeno, nas temperaturas de $93^{\circ} \mathrm{C}$ e $121^{\circ} \mathrm{C}$, respectivamente, há fortes evidências (por FTIR) de que tenha ocorrido funcionalização. Já para o ensaio $\mathbf{E}(0,21 \%)$, com xileno a $121^{\circ} \mathrm{C}$, as evidências são menos fortes (por FTIR).

Mesmo quando a temperatura de reação é incrementada de $93^{\circ} \mathrm{C}$ para $121^{\circ} \mathrm{C}$ (o tempo de reação é reduzido de $4 \mathrm{~h}$ para $0,67 \mathrm{~h}$ ), com clorobenzeno, os valores de GF obtidos para os ensaios A $(0,45 \%)$ e $\mathbf{C}$ $(0,47 \%)$ são comparáveis. Quando a temperatura e o tempo de reação são mantidos constantes, $121^{\circ} \mathrm{C}$ e $0,67 \mathrm{~h}$, respectivamente, o GF obtido para o ensaio C $(0,47 \%)$, em clorobenzeno, é superior ao obtido para o ensaio E $(0,21 \%)$, em xileno. Portanto, a variável solvente, nas condições estudadas, é mais importante para o GF que as variáveis temperatura e tempo de reação. Na Figura 29 são mostrados os espectros no FTIR dos ensaios de $\mathbf{A}$ a F. 


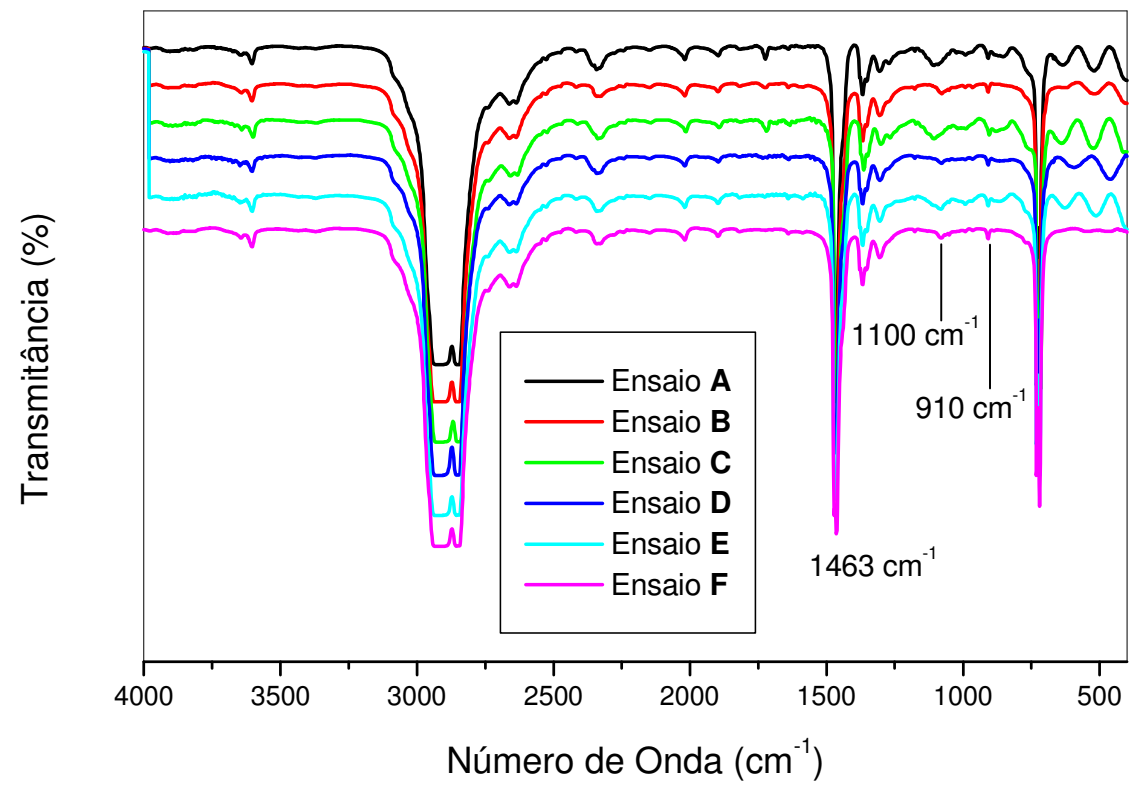

Figura 29 - Espectros no FTIR dos ensaios A-F.

A performance superior, em termos de GF, do ensaio C $(0,47 \%)$, em clorobenzeno a $121^{\circ} \mathrm{C}$, em relação à do ensaio $\mathbf{E}(0,21 \%)$, em xileno a $121^{\circ} \mathrm{C}$, e a do ensaio $\mathbf{A}(0,45 \%)$, em clorobenzeno a $93^{\circ} \mathrm{C}$, em relação aos insucessos obtidos na (primeira) tentativa de funcionalização em tolueno a 93ํㅡ (conforme descrito no item 4.1), está em consonância quando se leva em conta o fato do monômero usado (AGE) ser relativamente pouco reativo. $\mathrm{O}$ macrorradical formado pode ser desativado antes de se adicionar à ligação dupla do AGE, se, por exemplo, abstrair um átomo de hidrogênio do meio reacional. Esta reação é favorecida na presença de solventes bons doadores de átomos de hidrogênio. De Vito et al. ${ }^{67}$ também observaram o efeito de solvente, no entanto, utilizando outro monômero (anidrido maléico). $O$ radical derivado do solvente poderia se adicionar à ligação dupla do AGE e, iniciar, por exemplo, sua homopolimerização. No entanto, não foi possível detectar eventuais produtos dessa reação, no estudo realizado no item 4.1.1 (quando da realização do ensaio na ausência do LMDPE). Tal reação secundária poderia afetar negativamente a performance da funcionalização. 
Shechter et al. ${ }^{68}$ e Bickford et al. ${ }^{69}$ estudaram a reação radicalar de adição a compostos insaturados, envolvendo alquil-benzenos (arenos) e anidrido maléico.

Os valores de GF obtidos variaram de 0,21\% (ensaio E) a 0,47\% (ensaio C) e os valores calculados de EF variaram de 0,42\% (ensaio E) a 0,94\% (ensaio C).

\subsubsection{Mecanismo na funcionalização em solução}

O Esquema 1 ilustra algumas das possibilidades, por mecanismo de radicais livres, que possam estar envolvidas na funcionalização em solução do LMDPE com AGE, na presença de BPO.

Inicialmente, ocorre a decomposição térmica unimolecular do BPO, que gera dois radicais benzoílas. Mas também pode ser bimolecular, ou seja, induzida (não mostrada). Em seguida, cada radical benzoíla se decompõe em um radical fenila $\left(\mathrm{I}^{\circ}\right)$ e em uma molécula de $\mathrm{CO}_{2}$. Devido ao efeito gaiola do solvente, ${ }^{57 b}$ o radical benzoíla também pode vir a participar da etapa posterior da reação (não mostrado). O radical fenila $\left(I^{\bullet}\right)$, primariamente formado, no sentido que foi formado a partir da homólise térmica do BPO, ou um radical qualquer $\left(R^{\bullet}\right.$ ou $\left.S^{\bullet}\right)$, formado secundariamente no decorrer da reação, então abstrai um átomo de hidrogênio ligado a um átomo de carbono terciário da cadeia polimérica, gerando um macrorradical (LMDPE`). Porém, por fatores estatísticos, também é possível que átomos de hidrogênio ligados a átomos de carbono secundários sejam abstraídos. O macrorradical LMDPE$^{\bullet}$ se adiciona à ligação dupla do AGE, produzindo um novo radical (LMDPE-AGE'). Contudo, também é possível que o macrorradical LMDPE $^{\bullet}$ sofra reações secundárias (indesejadas), que competem com a funcionalização, tais como: ele pode abstrair um átomo de hidrogênio (não mostrado); se combinar, por exemplo, com o radical solvente $\left(\mathrm{S}^{\bullet}\right)$ ou com outro macrorradical (LMDPE ${ }^{\bullet}$ ), 
que, neste caso, geraria um LMDPE reticulado; sofrer fragmentação da cadeia polimérica por $\beta$-cisão (não mostrado) ou participar de reações de desproporção (não mostrado). Então, o radical LMDPE-AGE• formado pode abstrair um átomo de hidrogênio do meio reacional, tarefa facilitada se 0 solvente $(\mathrm{SH})$ for ativo (que daria origem ao radical solvente, $\mathrm{S}^{\bullet}$, estabilizado por ressonância), gerando o produto a, ou pode se adicionar à ligação dupla de uma ou mais moléculas de AGE, ocasionando uma homopolimerização lateral do $A G E$ na cadeia polimérica (LMDPE-AGE ${ }_{n+1}$ ). Esta reação é indesejada, por diminuir a efetividade da funcionalização (pois poderia diminuir o número de cadeias funcionalizadas, por exemplo), e pouco provável, em virtude da baixa reatividade do $A G E$, conforme já discutido (item 4.1.1). O radical LMDPE-AGE ${ }_{\mathrm{n}+1}$ poderia então abstrair um átomo de hidrogênio e gerar o produto b. No transcorrer da reação, um radical qualquer, presente no meio reacional, poderia abstrair um átomo de hidrogênio alílico da molécula de AGE, produzindo o radical monômero ( $\mathrm{AGE}^{\circ}$ ) estabilizado por ressonância. O radical $\mathrm{AGE}^{\bullet}$ poderia, por sua vez, se combinar, por exemplo, com um macrorradical (LMDPE`), o que geraria o produto c ou d.

É digno de nota a possibilidade de se ter também abstrações intramoleculares de hidrogênio da cadeia polimérica, pelo mecanismo "backbiting" ("morder a própria cauda"), onde se dá migrações 1,4 e 1,5 de átomos de hidrogênio, passando por estados de transições envolvendo cinco ou seis membros, respectivamente. ${ }^{37}$ 


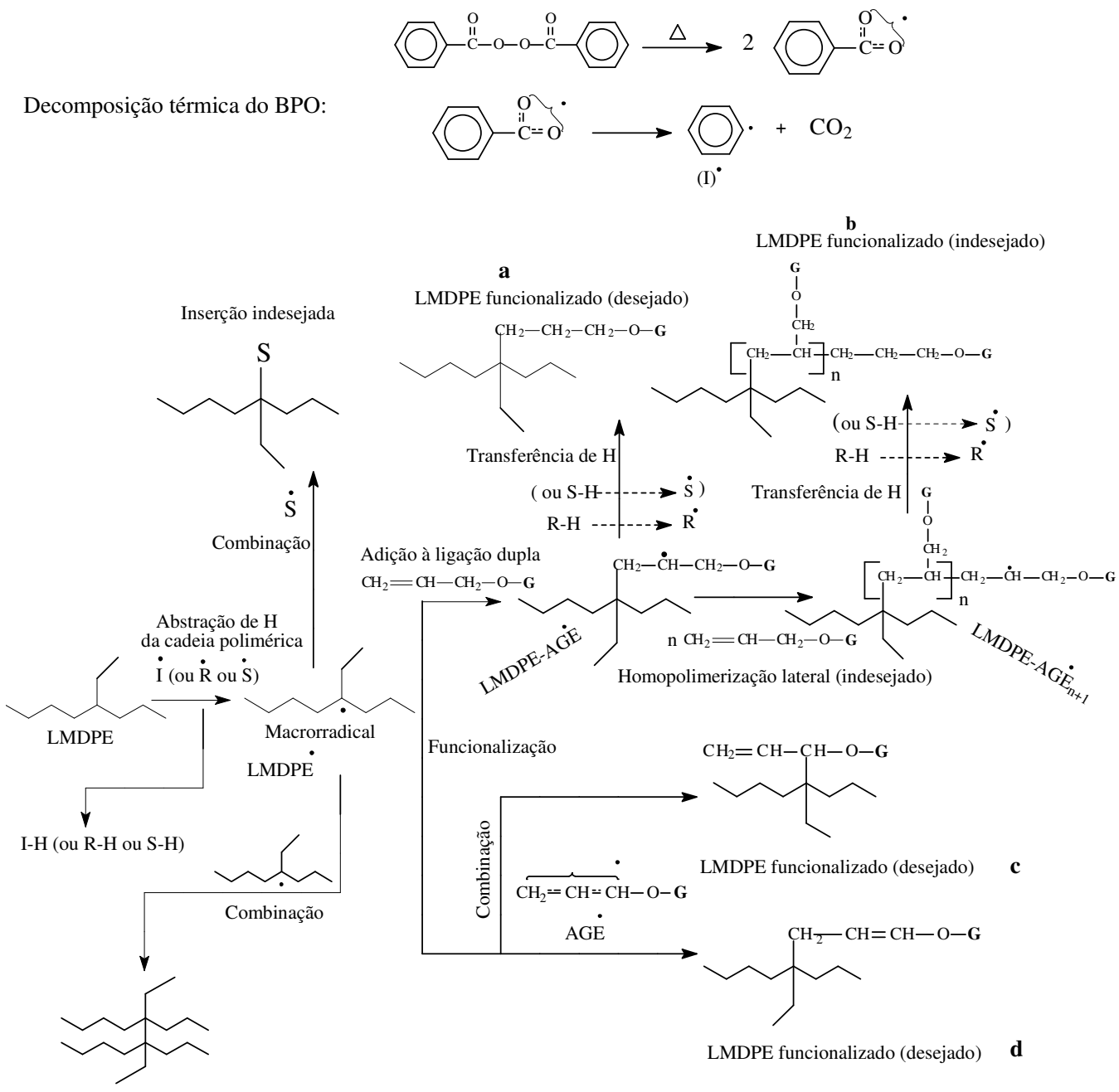

LMDPE reticulado (indesejado)

Legenda:

$$
\begin{aligned}
& \mathrm{AGE}=\mathrm{CH}_{2}=\mathrm{CH}-\mathrm{CH}_{2}-\mathrm{O}-\overbrace{\mathrm{CH}_{2}-\overbrace{{ }_{\mathrm{O}}^{\prime}}^{\mathrm{CH}}-\mathrm{CH}_{2}}^{\mathrm{G}} \\
& \text { Solvente }(\mathbf{S}-\mathbf{H})=\overbrace{\mathrm{CH}}^{\mathrm{CH}_{3}}
\end{aligned}
$$

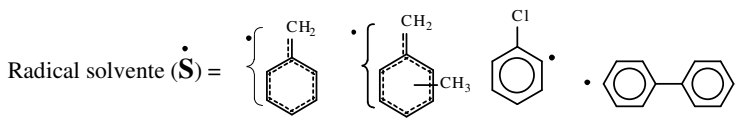

\section{Esquema 1 - Mecanismo na funcionalização em solução.}




\subsection{Funcionalização superficial por radiação UV}

A superfície das placas do LMDPE, previamente recoberta com monômero e iniciador, foi irradiada com UV. A caracterização da superfície foi feita por medidas de ângulo de contato. Algumas das possibilidades envolvidas no mecanismo radicalar da funcionalização superficial também são abordadas.

A Tabela 4 mostra as formulações usadas nesta pesquisa. Há três tipos de controle. Em um deles, não foi aplicada a solução de monômero e iniciador $\left(\mathbf{A}_{\mathbf{u v}}, \mathbf{E}_{\mathbf{u v}}\right.$ e $\left.\mathbf{I}_{\mathbf{u v}}\right)$. No outro, foi aplicada somente a solução de iniciador ( $\mathbf{B}_{\mathbf{u v}}, \mathbf{F}_{\mathbf{u v}}$ e $\mathbf{J}_{\mathbf{u v}}$ ). No terceiro, foi aplicado apenas $\operatorname{AGE}\left(\mathbf{C}_{\mathbf{u v}}\right)$. O ensaio $\mathbf{C}_{\mathrm{uv}}$ justifica-se, pois foi feito o espectro no UV (não mostrado) de uma solução de $\operatorname{AGE}(0,2 \mathrm{~mL})$ em $\mathrm{CHCl}_{3}(1,8 \mathrm{~mL})$, obtido no Espectrofotômetro DU-640, Beckman Coulter, a 25ํㅡ, e foi observado que o AGE absorve radiação na região de $310 \mathrm{~nm}$ a $245 \mathrm{~nm}$. 
Tabela 4 - Formulações usadas nos ensaios $\mathbf{A}_{\mathrm{uv}}-\mathbf{L}_{\mathrm{uv}}$.

\begin{tabular}{|c|c|c|c|c|c|c|c|}
\hline \multirow[b]{3}{*}{ Ensaio } & \multicolumn{7}{|c|}{ Formulação } \\
\hline & \multicolumn{3}{|c|}{ Monômero } & \multicolumn{2}{|c|}{ Iniciador } & \multirow{2}{*}{$\begin{array}{c}\text { Razão } \\
\text { molar } \\
\text { Monômero / } \\
\text { iniciador }\end{array}$} & \multirow{2}{*}{$\begin{array}{c}\text { Solvente } \\
\text { Acetona } \\
(\mathrm{mL})\end{array}$} \\
\hline & $\begin{array}{l}\text { AGE } \\
(m L)\end{array}$ & $\begin{array}{c}\mathrm{MAH} \\
(\mathrm{g})\end{array}$ & $\begin{array}{c}\text { THFAH } \\
\text { (g) }\end{array}$ & $\begin{array}{c}\text { BPO } \\
\text { (g) }\end{array}$ & $\begin{array}{l}\text { BP } \\
(g)\end{array}$ & & \\
\hline$A_{u v}$ & - & - & - & - & - & - & - \\
\hline$B_{u v}$ & - & - & - & 0,0594 & - & - & 0,3 \\
\hline $\mathrm{C}_{\mathrm{uv}}$ & 0,3 & - & - & - & - & - & - \\
\hline$D_{u v}$ & 0,3 & - & - & 0,0594 & - & 10 & 0,3 \\
\hline$E_{u v}$ & - & - & - & - & - & - & - \\
\hline$F_{u v}$ & - & - & - & 0,0124 & - & - & 0,3 \\
\hline $\mathbf{G}_{\mathrm{uv}}$ & - & 0,10 & - & 0,0124 & - & 20 & 0,3 \\
\hline $\mathrm{H}_{\mathrm{uv}}$ & - & - & 0,10 & 0,0080 & - & 20 & 0,3 \\
\hline$I_{u v}$ & - & - & - & - & - & - & - \\
\hline$J_{u v}$ & - & - & - & - & 0,0186 & - & 0,3 \\
\hline $\mathrm{K}_{\mathrm{uv}}$ & - & 0,10 & - & - & 0,0186 & 10 & 0,3 \\
\hline$L_{u v}$ & - & - & 0,10 & - & 0,0120 & 10 & 0,3 \\
\hline
\end{tabular}

Os ensaios $A_{u v}-D_{u v}$ foram expostos à radiação UV simultaneamente, para assegurar que estivessem sob as mesmas condições experimentais. $O$ mesmo foi feito para os ensaios $\mathbf{E}_{\mathrm{uv}}-\mathrm{H}_{\mathrm{uv}}$ e $\mathbf{I}_{\mathrm{uv}}-\mathbf{L}_{\mathrm{uv}}$.

\subsubsection{Caracterização das superfícies por medidas de ângulo de contato}

O $\theta_{\text {avanço }}$ é um indicativo de molhabilidade da superfície em relação à água. Ângulo próximo a $0^{\circ}$ é um indicativo de forte caráter hidrofílico da superfície. Ângulo próximo a 90 é um indicativo do caráter hidrofóbico dela. A eficácia da funcionalização da superfície das placas do LMDPE é evidenciada por uma diminuição relativa do $\theta_{\text {avanço, uma vez que a superfície }}$ 
hidrofóbica do LMDPE original deve se tornar mais hidrofílica após a inserção do grupo polar.

Em uma placa de LMDPE original, que não foi aplicada solução de monômero e iniciador, tampouco exposta à radiação UV, obteve-se $\theta_{\text {avanço }}$ de $\sim 90^{\circ}$ e $\Delta \theta \sim 1^{0}$. Na Tabela 5 são apresentados os dados obtidos de $\theta_{\text {avanço, }}$ $\theta_{\text {recesso }}$ e os calculados para $\Delta \theta$ de contato, a partir da eq. (13) (item 3.2.14).

Tabela 5 - Valores médios, e respectivos desvios padrões, de $\theta_{\text {avanço, }} \theta_{\text {recesso }}$ e $\Delta \theta$ de contato obtidos para os ensaios $A_{u v}-L_{u v}$.

\begin{tabular}{cccc}
\hline Ensaio & $\begin{array}{c}\boldsymbol{\theta}_{\text {avanço }} \\
(\mathrm{grau})\end{array}$ & $\begin{array}{c}\boldsymbol{\theta}_{\text {recesso }} \\
(\mathrm{grau})\end{array}$ & $\begin{array}{c}\Delta \boldsymbol{\theta} \\
(\mathrm{grau})\end{array}$ \\
\hline $\mathbf{A}_{\mathrm{uv}}$ & $81 \pm 8$ & $54 \pm 4$ & $27 \pm 7$ \\
$\mathbf{B}_{\mathrm{uv}}$ & $79 \pm 3$ & $69 \pm 13$ & $10 \pm 8$ \\
$\mathbf{C}_{\mathrm{uv}}$ & $80 \pm 5$ & $65 \pm 4$ & $15 \pm 4$ \\
$\mathbf{D}_{\mathrm{uv}}$ & $79 \pm 10$ & $70 \pm 12$ & $9 \pm 7$ \\
$\mathbf{E}_{\mathrm{uv}}$ & 84 & 59 & 25 \\
$\mathbf{F}_{\mathrm{uv}}$ & 81 & 69 & 12 \\
$\mathbf{G}_{\mathrm{uv}}$ & 78 & 54 & 24 \\
$\mathbf{H}_{\mathrm{uv}}$ & 75 & 58 & $20 \pm 5$ \\
$\mathbf{I}_{\mathrm{uv}}$ & $78 \pm 5$ & $58 \pm 2$ & $31 \pm 3$ \\
$\mathbf{J}_{\mathrm{uv}}$ & $75 \pm 4$ & $44 \pm 4$ & $13 \pm 11$ \\
$\mathbf{K}_{\mathrm{uv}}$ & $74 \pm 0$ & $61 \pm 8$ & $10 \pm 8$ \\
$\mathbf{L}_{\mathrm{uv}}$ & $72 \pm 4$ & $62 \pm 8$ &
\end{tabular}

Para ilustração, na Figura 30 são mostradas as medidas de $\theta_{\text {avanço }} \mathrm{e}$ $\theta_{\text {recesso }}$ do ensaio $\mathbf{H}_{\mathbf{u v}}$. 

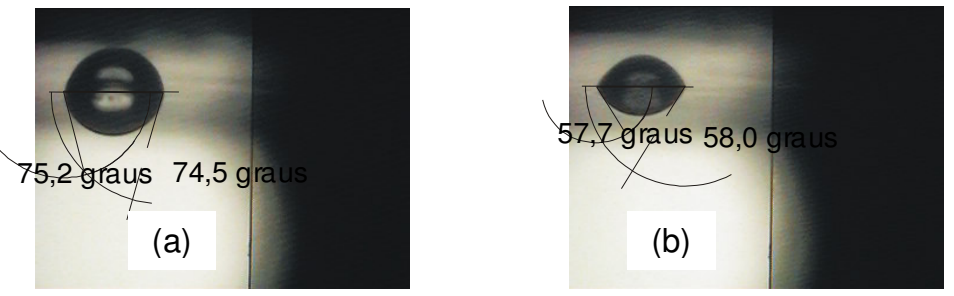

Figura 30 - Medidas de ângulo de contato do ensaio $\boldsymbol{H}_{\mathrm{uv}}$ de (a) $\theta_{\text {avanço }}$ e (b) $\theta_{\text {recesso. }}$

Analisando-se os dados da Tabela 5, observa-se que o valor de $\theta_{\text {avanço }}$ para o ensaio $D_{u v}(A G E+B P O)$ é comparável aos obtidos para os ensaios $\mathbf{A}_{\mathrm{uv}}-\mathbf{C}_{\mathrm{uv}}$ (controles), indicando que não há evidência (por medidas de ângulo de contato) de que tenha ocorrido funcionalização do LMDPE. Por outro lado, quando se comparam os valores de $\theta_{\text {avanço }}$ dos ensaios $\mathbf{G}_{\mathrm{uv}}$ (MAH + BPO) e $\mathbf{H}_{\mathrm{uv}}\left(\mathrm{THFAH}+\mathrm{BPO}\right.$ ) com os dos ensaios $\mathbf{E}_{\mathrm{uv}}$ e $\mathbf{F}_{\mathrm{uv}}$ (controles), há evidência (por medidas de ângulo de contato) de que tenha ocorrido funcionalização do LMDPE no caso do ensaio $\boldsymbol{H}_{\mathrm{uv}}$ (THFAH + BPO), embora fracas. Pois, uma queda relativa de $6^{0}$ pode estar dentro do erro experimental, o qual não foi determinado. $O$ erro experimental global médio (calculado a partir dos desvios padrões obtidos para os outros ensaios) é de $5^{0}$. Já quando os valores de $\theta_{\text {avanço }}$ dos ensaios $K_{u v}(M A H+B P)$ e $L_{u v}$ (THFAH + BP) são comparados com os dos ensaios $I_{u v}$ e $J_{u v}$ (controles), não há evidência (por medidas de ângulo de contato) de que tenha ocorrido funcionalização do LMDPE nesses ensaios. Observa-se uma $\Delta \theta$ de contato relativamente alta, variando de $9^{0}$ a $31^{\circ}$, tendo em vista o valor encontrado para a placa de LMDPE original $\left(\sim 1^{0}\right)$. Essa $\Delta \theta$ de contato alta pode ser atribuída praticamente ao aumento da rugosidade da superfície durante o ensaio. Isso poderia estar, por si só, comprometendo a qualidade dos dados obtidos.

Quando o monômero usado é líquido, como o AGE, devido à tensão interfacial, ele não é espalhado por toda a superfície da placa de LMDPE, 
ficando localizado no centro dela. Antes de decorrido o tempo (4 h) de exposição à radiação UV, o AGE já havia sido totalmente evaporado. Já quando o monômero é sólido, como o MAH e THFAH, embora a solução (monômero + iniciador + acetona) se espalhe por toda a superfície, após a evaporação do solvente observam-se cristais de monômero (e iniciador) distribuídos pela superfície. Esses cristais na superfície poderiam espalhar e/ou refletir parte da radiação. Portanto, parte da radiação pode estar sendo perdida.

\subsubsection{Mecanismo na funcionalização superficial por radiação UV}

O Esquema 2 mostra algumas das possibilidades, por mecanismo de radicais livres, que poderiam estar envolvidas na funcionalização superficial por UV do LMDPE com THFAH, na presença de BPO ou BP, caso ela ocorresse.

Geralmente, a absorção de radiação resulta na produção de radicais por meio de qualquer um desses dois caminhos: 1 Alguns compostos sofrem excitação pela absorção de energia e, subseqüentemente, decompõem-se em radicais, ou seja, a absorção de radiação conduz à cisão homolítica da ligação (fotólise homolítica); 2 alguns compostos sofrem excitação e a espécie excitada interage com um segundo composto (ou por meio de transferência de energia ou por meio de reação redox) para formar radicais derivados do último e/ou do primeiro composto(s). ${ }^{57 \mathrm{c}}$ No caso do BPO, a produção de radicais se dá pelo caminho 1 .

Quando o iniciador é BPO, a fotólise homolítica (de uma molécula de BPO) produz, como no caso da termólise homolítica, dois radicais benzoílas. Em seguida, cada radical benzoíla se decompõe em um radical fenila $\left(1^{\bullet}\right)$ e em uma molécula de $\mathrm{CO}_{2}$. Os radicais fenilas $\left(\mathrm{I}^{\circ}\right)$ então abstraem átomos de hidrogênio das cadeias do polímero (LMDPE), ocasionando a formação de macrorradicais (LMDPE'). Os macrorradicais (LMDPE') adicionam-se às 
ligações duplas das moléculas do monômero (THFAH), gerando novos radicais ( $\mathrm{LMDPE}^{\mathrm{T}} \mathrm{THFAH}{ }^{\circ}$ ). Então, os radicais (LMDPE-THFAH') podem abstrair átomos de hidrogênio e darem origem ao produto a, ou podem se ligar a uma ou mais moléculas de THFAH, resultando na homopolimerização lateral do THFAH nas cadeias poliméricas, que origina os radicais (LMDPETHFAH $_{n+1}{ }_{n+1}$ ). Os radicais (LMDPE-THFAH ${ }_{n+1}$ ) podem, então, abstrair átomos de hidrogênio e darem origem ao produto $\mathbf{b}$.

No caso do iniciador ser BP, quando ocorre absorção de radiação UV (pelo BP), ele é excitado ao estado singleto, de tempo de vida relativamente curto, o qual, por cruzamento entre sistemas (ISC), ${ }^{36 c}$ sofre relaxação ao estado tripleto $(\mathrm{BP})^{\top}$, de tempo de vida mais longo. Então, os espécimes $(\mathrm{BP})^{\top}$ formados podem abstrair átomos de hidrogênio das cadeias do LMDPE e dar origem aos macrorradicais (LMDPE $\left.{ }^{\bullet}\right) .{ }^{70,71} \mathrm{~A}$ partir desta etapa, os macrorradicais (LMDPE`) seguem o mesmo mecanismo descrito acima.

O BP excitado forma um estado tripleto e não é um verdadeiro birradical (espécie que possui dois elétrons ímpares independentes, ou seja, não interagem magneticamente e eletronicamente entre si), ${ }^{72}$ mas apenas tem caráter de birradical.

A acetona, usada como solvente, também absorve radiação UV. Como conseqüência, decompõe-se, dando origem a radicais metilas, ${ }^{73}$ que também poderiam participar do mecanismo radicalar. 


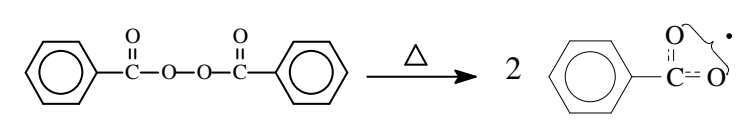

Fotólise homolítica do BPO:

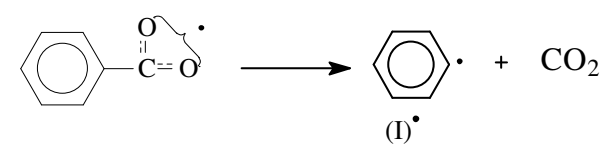

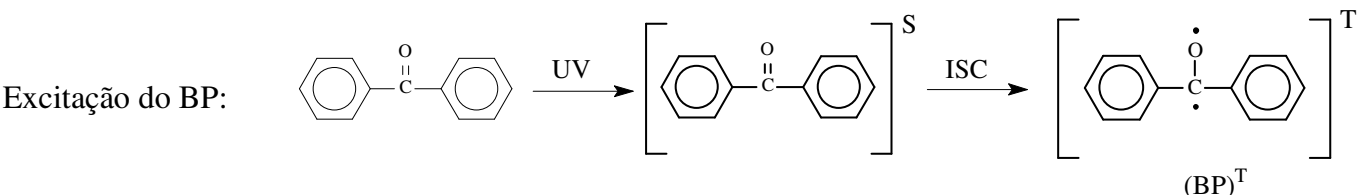

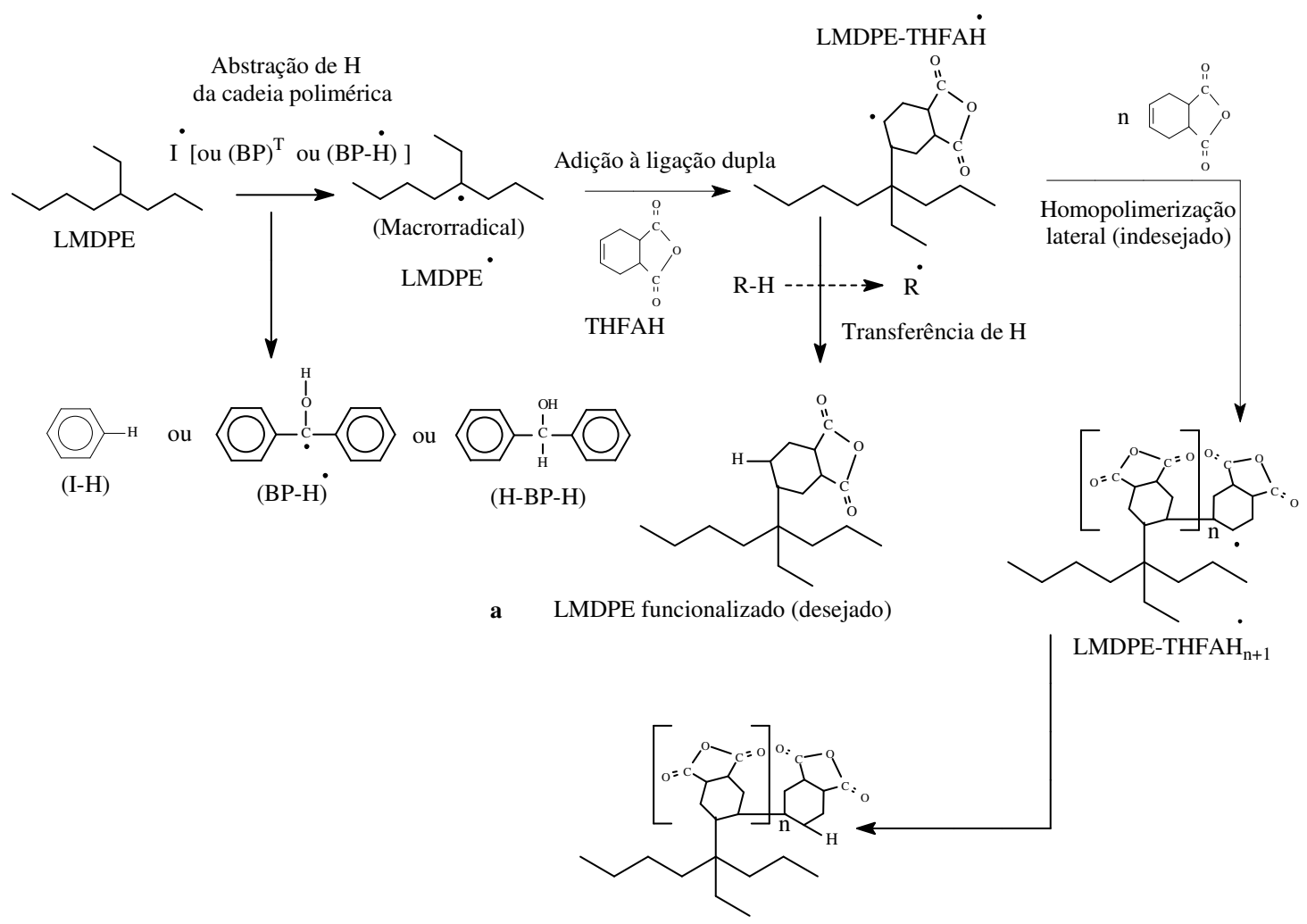

b LMDPE funcionalizado (desejado)

\section{Esquema 2 - (Eventual) mecanismo na funcionalização superficial por UV.}




\subsection{Funcionalização por processamento reativo}

Avaliaram-se as influências no GF da quantidade de AGE (\% sobre o LMDPE, m/m), com valores de $10 \%$ e $20 \%$; da razão molar entre AGE e BPO, com valores de 10, 20 e 30; da quantidade de LMDPE, com valores de 40,0 g e 45,0 g; da ordem de adição de AGE e BPO, comparando-se a adição simultânea (de uma solução de) AGE e BPO (adotada como padrão), contra uma em que se adiciona primeiro BPO e, em seguida, AGE.

A Tabela 6 mostra as formulações e os parâmetros de processamento. No ensaio 15, apenas o LMDPE foi processado, servindo como controle para o torque. No ensaio 59, não foi adicionado AGE, e por isso foi usado como controle na caracterização das amostras. 
Tabela 6 - Formulações e parâmetros de processamento usados nos ensaios 12, 13, 13A, 13B, 15, 25, 59 e 77.

\begin{tabular}{|c|c|c|c|c|c|c|c|c|}
\hline \multirow[b]{3}{*}{ Ensaio } & \multicolumn{3}{|c|}{ Formulação } & \multirow{2}{*}{\multicolumn{5}{|c|}{ Parâmetros de processamento }} \\
\hline & \multicolumn{2}{|c|}{$\begin{array}{c}\% \text { sobre } \\
\text { LMDPE }(\mathrm{m} / \mathrm{m})\end{array}$} & \multirow[b]{2}{*}{$\begin{array}{c}\text { Razão } \\
\text { molar } \\
\text { (AGE/BPO) }\end{array}$} & & & & & \\
\hline & AGE & BPO & & $\begin{array}{l}\text { Tempo } \\
\text { fusão } \\
\text { (min) }\end{array}$ & $\begin{array}{c}\text { Tempo } \\
\text { reação } \\
\text { (min) }\end{array}$ & $\begin{array}{c}\text { Temperatura } \\
\left({ }^{\circ} \mathrm{C}\right) \text { antes } \\
\text { da adição } \\
\text { de AGE e } \\
\text { BPO }\end{array}$ & $\begin{array}{l}\text { Temperatura } \\
\left({ }^{\circ} \mathrm{C}\right) \text { após os } \\
9 \text { min ou } \\
10 \text { min de } \\
\text { processamento }\end{array}$ & $\begin{array}{c}\text { Torque } \\
\text { final } \\
(\mathrm{N} \mathrm{m})\end{array}$ \\
\hline \multirow[t]{2}{*}{12} & 10,0 & 0,72 & 30,0 & $3^{a}$ & $6^{a}$ & 132,9 & 141,1 & 17,3 \\
\hline & & & & $3^{b}$ & $7^{\mathrm{b}}$ & $135,0 \pm 0,1$ & $145 \pm 1$ & $16,9 \pm 0,7$ \\
\hline 13 & 20,0 & 4,24 & 10,0 & $3^{a}$ & $6^{a}$ & 132,3 & 120,6 & 0,9 \\
\hline \multirow[t]{2}{*}{ 13A } & 20,0 & 4,24 & 10,0 & $4^{b}$ & $6^{b}$ & 138,1 & 123,1 & 1,0 \\
\hline & & & & $3^{b}$ & $7^{b}$ & $134,8 \pm 0,3$ & $122,9 \pm 0,6$ & $2,7 \pm 0,9$ \\
\hline $13 B^{c}$ & 20,0 & 4,24 & 10,0 & $4^{b}$ & $6^{b}$ & 138,4 & 141,4 & 13,0 \\
\hline 15 & - & - & - & $9^{a}$ & - & - & $142 \pm 2$ & $15,4 \pm 0,6$ \\
\hline 25 & 20,0 & 2,12 & 20,0 & $3^{b}$ & $7^{\mathrm{b}}$ & $133,6 \pm 0,6$ & $138 \pm 2$ & $13 \pm 4$ \\
\hline 59 & - & 4,24 & - & $4^{a}$ & $6^{a}$ & 134,8 & 144,7 & 16,5 \\
\hline 77 & 20,0 & 1,41 & 30,0 & $3^{b}$ & $7^{\mathrm{b}}$ & $134,4 \pm 0,6$ & $139 \pm 1$ & $13,6 \pm 0,7$ \\
\hline
\end{tabular}

${ }^{\mathrm{a}}$ Massa inicial de LMDPE de 40,0 g, ${ }^{\mathrm{b}}$ massa inicial de LMDPE de 45,0 g, ${ }^{\mathrm{c}}$ ordem de adição alterada, primeiramente foi adicionado BPO e, imediatamente depois, AGE.

Os dados da Tabela 6 mostram que, quando a quantidade de massa inicial de LMDPE é de 45,0 g e o tempo de fusão é de $4 \mathrm{~min}$, a temperatura na câmara do equipamento é de $\sim 138^{\circ} \mathrm{C}$ (13A e 13B), na hora da adição de AGE e BPO. Porém, se o tempo de fusão é de $3 \mathrm{~min}$, a temperatura passa a ser de $\sim 135^{\circ} \mathrm{C}(12,13 \mathrm{~A}, 25$ e 77). Quando a massa de LMDPE é de 40,0 g e o tempo de fusão é de $3 \mathrm{~min}$, a temperatura é ainda mais baixa, $\sim 133^{\circ} \mathrm{C}$ (12 e 13). Esse fato é relevante se for levado em conta o ponto de ebulição do $A G E\left(154^{\circ} \mathrm{C}\right)$ e o tempo de meia-vida do BPO (ver item 3.1.3).

Sempre que houve necessidade de se repetir o experimento de uma determinada formulação, como para os ensaios 12, 13A, 25 e 77 (nestes 
dois últimos, inclusive as primeiras), foram usados 45,0 $\mathrm{g}$ de LMDPE e os tempos de fusão e reação foram de 3 min e $7 \mathrm{~min}$, respectivamente. Para os casos onde foram feitas pelo menos duas replicatas, os dados (das três últimas colunas da Tabela 6) foram apresentados em termos da média e do seu desvio padrão. Essa "necessidade" refere-se à obtenção de compósitos ou blendas.

Observando-se os valores de torque final e tendo como valor de referência o do ensaio $15(15,4 \mathrm{~N} \mathrm{~m})$, em que foi processado somente o LMDPE, vê-se claramente que houve aumento relativo do torque nos ensaios $12(16,9 \mathrm{~N}$ m) e 59 (16,5 N m). Enquanto que, nos ensaios 13 $(0,9 \mathrm{~N} \mathrm{~m}), 13 \mathrm{~A}(2,7 \mathrm{~N} \mathrm{~m}), 13 \mathrm{~B}(13,0 \mathrm{~N} \mathrm{~m})$ e $77(13,6 \mathrm{~N} \mathrm{~m})$, houve queda do torque. No caso do ensaio 25, obteve-se valores bem diferentes $(10,6 \mathrm{~N} \mathrm{~m}$ e $16,2 \mathrm{~N} \mathrm{~m}$ ). O valor de 10,6 N m parece ser o mais coerente. Pois, é intermediário em relação àqueles obtidos para os ensaios 13 (e 13A) e 77, para os quais o torque é tanto menor quanto maior é a proporção de BPO.

Esse aumento ou diminuição relativo do torque, na literatura, costuma-se associar à reticulação ou à fragmentação e/ou funcionalização da cadeia polimérica, respectivamente. ${ }^{74}$ Contudo, não foi observada a presença de gel após a dissolução das amostras (dos ensaios mostrados na Tabela 6) em tolueno quente, a qual seria esperada, se houvesse reticulação. A fragmentação é discutida em termos de $\mathrm{MFI}$, no item 4.3.4. A funcionalização, em termos do GF, no item 4.3.1. Além disso, valores relativos bem inferiores de resistência à tração, discutido no item 4.4.1, também podem ser usados como indicativo de eventual fragmentação da cadeia polimérica.

É digno de nota o valor de torque final obtido para o ensaio 13B (13,0 N m), onde BPO é adicionado primeiro, seguido da adição de AGE, ser relativamente muito superior aos obtidos para os ensaios $13(0,9 \mathrm{~N} \mathrm{~m})$ e 13A (2,7 N m), onde AGE e BPO são adicionados simultaneamente na forma de 
solução. Isso poderia estar vinculado ao fato de que quando o BPO é adicionado primeiro, segue-se um estampido forte junto com o aparecimento de uma nevoa branca, podendo, assim, uma parte do BPO estar sendo projetada para fora da câmara de mistura. Por conseguinte, diminuindo a proporção de BPO na mistura inicial. Isso também ocorre para o ensaio 59 (controle, ausência de AGE).

\subsubsection{Determinação do GF por FTIR}

A caracterização das amostras (purificadas) foi feita pela técnica de FTIR, a partir da qual calculou-se o GF, mostrado na Tabela 7. $\mathrm{Na}$ construção da curva de calibração 1 (Figura 25a, item 3.2.7), para 0\% de AGE, a razão entre as alturas usada foi de 0,03. Na construção da curva de calibração 2 (Figura 25b, item 3.2.7), para 0\% de AGE, a razão entre as alturas foi de 0,04 . No ensaio 59 não foi adicionado $A G E$, e por isso foi usado como controle na avaliação da eficácia da funcionalização.

Tabela 7 - Valores de GF obtidos para os ensaios 12, 13, 13A, 13B, 25, 59 e 77 .

\begin{tabular}{|c|c|c|c|c|}
\hline \multirow{2}{*}{ Ensaio } & & GF & \multirow[b]{2}{*}{$\left(h_{910} / h_{1463}\right)$} & \multirow{2}{*}{$\begin{array}{c}\text { GF } \\
\text { (\%AGE/LMDPE) }\end{array}$} \\
\hline & $\left(h_{1100} / h_{1463}\right)$ & (\%AGE/LMDPE) & & \\
\hline 12 & 0,050 & 0,23 & 0,053 & 0,21 \\
\hline 13 & 0,070 & 0,54 & 0,045 & 0,07 \\
\hline $13 A$ & 0,081 & 0,74 & 0,054 & 0,23 \\
\hline $13 B$ & 0,064 & 0,44 & 0,025 & - \\
\hline 25 & 0,056 & 0,31 & 0,037 & - \\
\hline 59 & 0,025 & - & 0,025 & - \\
\hline 77 & 0,054 & 0,28 & 0,033 & - \\
\hline
\end{tabular}

Analisando-se os valores de GF, pode-se constatar que há fortes evidências (por FTIR) de que tenha ocorrido funcionalização nos ensaios 12 , 
13, 13A, 13B, 25 e 77. Quando o valor de GF do ensaio $13(0,54 \%)$ é comparado com o do ensaio 13A (0,74\%), vê-se nitidamente que o incremento da massa inicial de LMDPE de 40,0 g para 45,0 g, respectivamente (Tabela 6), é acompanhado de aumento no GF. Por outro lado, ao compararmos o valor de GF do ensaio 13B (0,44\%), com o do ensaio 13A (0,74\%), nota-se que a adição de BPO seguida pela adição de AGE, contra a adição simultânea de AGE e BPO, respectivamente, é acompanhada de diminuição no GF. Pode-se notar a tendência de aumento no GF à medida que a quantidade inicial de AGE aumenta de 10,0\% para 20,0\% e a razão molar (entre AGE e BPO) é reduzida de 30,0 para 10,0 (implicando aumento na proporção de BPO). Porém, a quantidade de AGE limite é de 20,0\% (para uma massa inicial de LMDPE de 45,0 g), para se evitar perdas (por vazamento lateral) durante a alimentação. Para a razão molar, o valor limite é 10,0; o qual já ocasiona uma queda drástica no torque final (ver ensaios 13 e 13A, Tabela 6).

Na Figura 31 são mostrados os espectros no FTIR dos ensaios 59 (controle), 12, 13, 13A, 13B, 25 e 77. Pode-se notar que ocorre um alargamento relativo da banda de $\sim 1100 \mathrm{~cm}^{-1}$ com o aumento do valor do GF. 


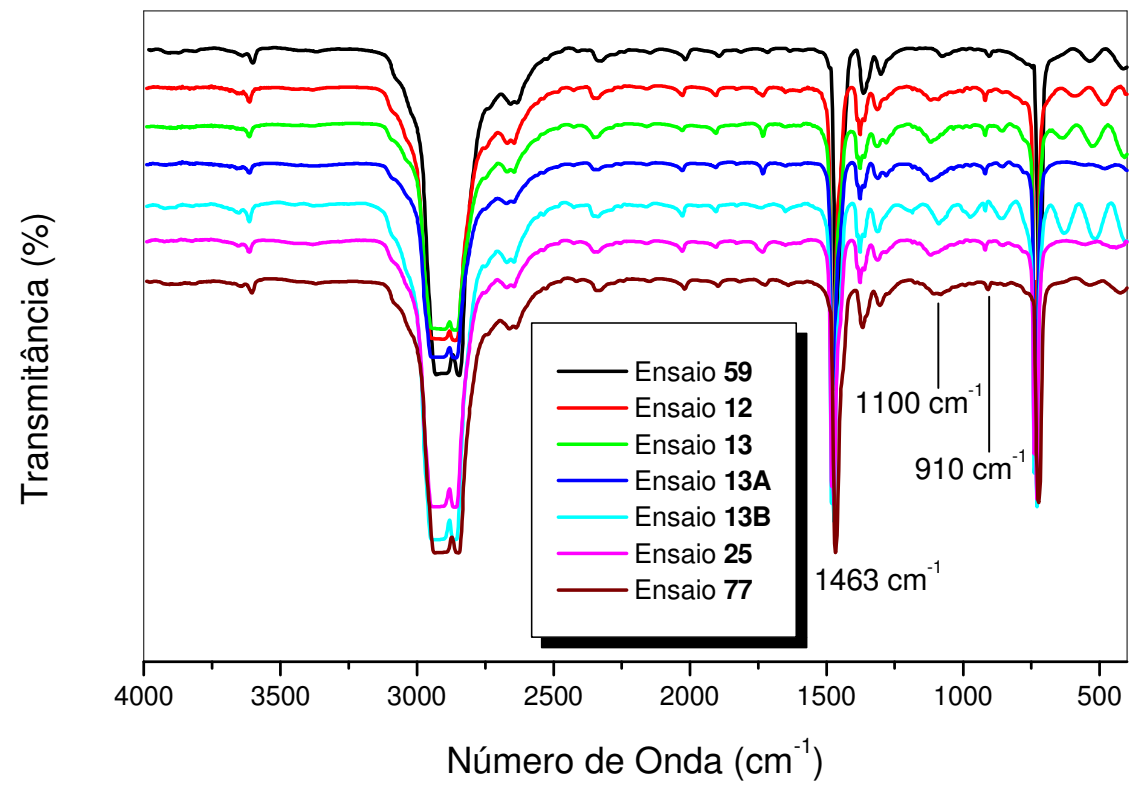

Figura 31 - Espectros no FTIR dos ensaios 59, 12, 13, 13A, 13B, 25 e 77.

É digno de nota o GF ter variado de $0,23 \%$ (ensaio 12) a $0,74 \%$ (ensaio 13A) e a EF de 1,4\% (ensaio 77) a 3,7\% (ensaio 13A). Para comparação, na funcionalização de polietileno com o monômero metacrilato de glicidil, que também contém um grupo epóxido, obtêm-se valores de GF < $1,5 \%$ e EF variando de $7 \%$ a $30 \%$. No entanto, quando um segundo monômero é adicionado, por exemplo, estireno, o GF pode chegar até $5 \%$ e EF alcança valores de até $70 \% .{ }^{17-19}$ 


\subsubsection{Mecanismo na funcionalização por processamento reativo}

O Esquema 3 ilustra algumas das possibilidades, por mecanismo de radicais livres, que possam estar envolvidas na funcionalização por processamento reativo do LMDPE com AGE, na presença de BPO.

Inicialmente, ocorre a decomposição térmica unimolecular do BPO, que gera dois radicais benzoílas. Embora, também pode ser bimolecular, ou seja, induzida (não mostrada). Em seguida, cada radical benzoíla se decompõe em um radical fenila $\left(I^{\circ}\right)$ e em uma molécula de $\mathrm{CO}_{2}$. O radical fenila $\left(\mathrm{I}^{\bullet}\right)$, primariamente formado, no sentido que foi formado a partir da homólise térmica do $\mathrm{BPO}$, ou um radical qualquer $\left(\mathrm{R}^{\circ}\right)$, formado secundariamente no decorrer da reação, então abstrai um átomo de hidrogênio ligado a um átomo de carbono terciário da cadeia polimérica, gerando o macrorradical (LMDPE`). Porém, por fatores estatísticos, também é possível que átomos de hidrogênio ligados a átomos de carbono secundários sejam abstraídos. O macrorradical LMDPE $^{\bullet}$ se adiciona à ligação dupla do AGE, produzindo um novo radical (LMDPE-AGE'). Contudo, também é possível que o macrorradical LMDPE $^{\bullet}$ sofra reações secundárias (indesejadas), que competem com a funcionalização, tais como: ele pode abstrair um átomo de hidrogênio (não mostrado); se combinar, por exemplo, com outro macrorradical (LMDPE'), que geraria um LMDPE reticulado; sofrer fragmentação da cadeia polimérica por $\beta$-cisão ou participar de reações de desproporção. Então, o radical LMDPE-AGE formado pode abstrair um átomo de hidrogênio do meio reacional, gerando o produto a, ou pode se adicionar à ligação dupla de uma ou mais moléculas de AGE, ocasionando uma homopolimerização lateral do AGE na cadeia polimérica (LMDPE-AGE ${ }_{n+1}$ ). Esta reação é indesejada, por diminuir a efetividade da funcionalização (pois poderia diminuir o número de cadeias funcionalizadas, por exemplo), e pouco provável, em virtude da baixa reatividade do AGE, conforme já discutido (item 4.1.1). O radical LMDPE$\mathrm{AGE}_{\mathrm{n}+1}$ poderia então abstrair um átomo de hidrogênio e gerar o produto $\mathbf{b}$. 
No decorrer da reação, um radical qualquer, presente no meio reacional, poderia abstrair um átomo de hidrogênio alílico da molécula de AGE, produzindo o radical monômero ( $\mathrm{AGE}^{\bullet}$ ) estabilizado por ressonância. $\mathrm{O}$ radical $\mathrm{AGE}^{\bullet}$ poderia, por sua vez, se combinar, por exemplo, com um macrorradical (LMDPE'), o que geraria o produto $\mathbf{c}$ ou $\mathbf{d}$.

É digno de nota a possibilidade de se ter também abstrações intramoleculares de hidrogênio da cadeia polimérica, pelo mecanismo "backbiting" ("morder a própria cauda"), onde se dá migrações 1,4 e 1,5 de átomos de hidrogênio, passando por estados de transições envolvendo cinco ou seis membros, respectivamente. ${ }^{37}$ 


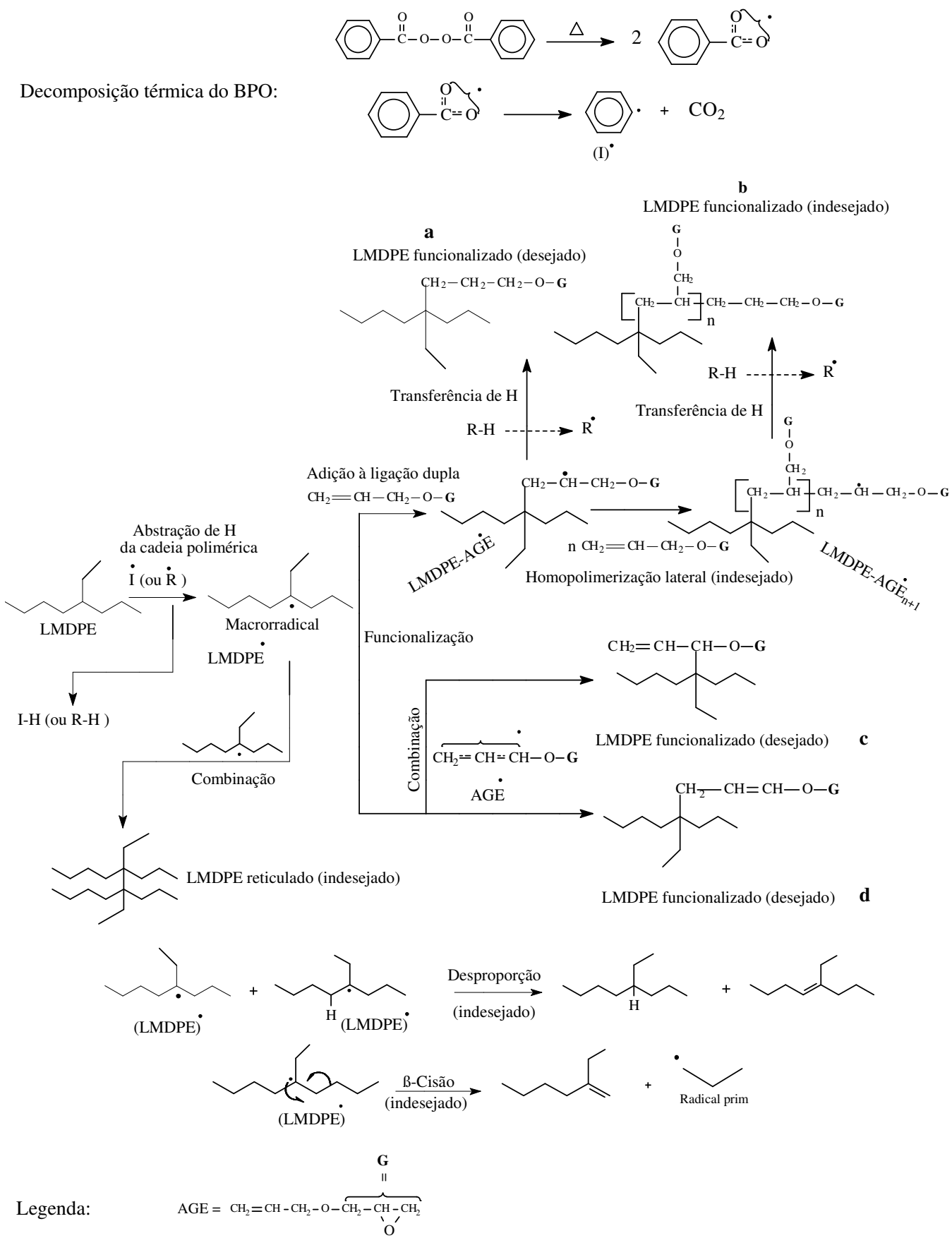

\section{Esquema 3 - Mecanismo na funcionalização por processamento reativo.}




\subsubsection{Confirmação da funcionalização por meio de outras técnicas}

A confirmação da funcionalização dos ensaios 12, 13, 13A, 25 e 77, sobretudo no caso dos ensaios 13 e 13A, por apresentarem valores relativamente maiores de GF (Tabela 7) foi tentada por análise elementar, análise térmica por TG e DTG, análise térmica por DSC e análise por XRD.

\subsubsection{Análise elementar}

Em virtude da molécula de AGE apresentar dois átomos de oxigênio, a presença de oxigênio nas amostras dos ensaios 13 e 13A pode ser atribuída à funcionalização, desde que o valor encontrado seja maior em relação ao obtido para o ensaio 59 (controle, ausência de AGE).

A análise elementar das amostras (purificadas) dos ensaios 13 (GF = 0,54\%), 13A (GF = 0,74\%) e 59 (controle, ausência de AGE) foi feita para carbono, hidrogênio e nitrogênio. $O$ teor de oxigênio foi calculado (o detector de oxigênio estava em conserto). O resultado é mostrado na Tabela 8.

Tabela 8 - Resultado da análise elementar das amostras dos ensaios 13, $13 \mathrm{~A}$ e 59.

\begin{tabular}{cccccc}
\hline Ensaio & $\% \mathbf{C}^{a}$ & $\% \mathbf{H}^{a}$ & $\% \mathbf{N}^{a}$ & Total $^{0}$ & $\% \mathbf{O}^{\mathrm{c}}$ \\
\hline $\mathbf{1 3}$ & 85,5 & 14,2 & 0 & 99,7 & 0,3 \\
$\mathbf{1 3 A}$ & 85,9 & 13,9 & 0,2 & 100,0 & zero \\
$\mathbf{5 9}$ & 86,1 & 13,8 & 0,1 & 100,0 & zero \\
\hline
\end{tabular}

a Determinação direta desses elementos químicos, ${ }^{b}$ somatório de \% C + $\% \mathrm{H}+\% \mathrm{~N},{ }^{\mathrm{C}}$ obtido por diferença $(100,0 \%$ - total).

Apesar do teor de oxigênio (obtido por cálculo) para o ensaio 13 ter sido de $0,3 \%$, esse valor está dentro do erro experimental $( \pm 0,3$ ponto percentual). $O$ ideal teria sido determinar somente o teor de oxigênio, num instrumento com um detector mais sensível. 
Calculou-se o teor teórico de oxigênio para uma amostra com o maior valor de GF (do ensaio 13A, GF = 0,74\%). A massa molar do AGE $\left(\mathrm{C}_{6} \mathrm{H}_{10} \mathrm{O}_{2}\right)$ é igual a $114 \mathrm{~g} \mathrm{~mol}^{-1} \mathrm{e}$ a massa molar média numérica do LMDPE varia de $20.000 \mathrm{~g} \mathrm{~mol}^{-1}$ a $30.000 \mathrm{~g} \mathrm{~mol}^{-1}$, de acordo com o fabricante. Admitindo-se que a unidade de repetição do LMDPE seja constituída de $\left(-\mathrm{CH}_{2}-\mathrm{CH}_{2}-\right)_{n}$, obtém-se um teor (teórico) de oxigênio de 0,21\%. Portanto, estaria dentro do erro experimental. Caso tivéssemos, em média, 2 moléculas de AGE inseridas por cadeia polimérica, teríamos um teor estimado de oxigênio de $0,32 \%$.

O número de moléculas de AGE inseridas pode ser estimado a partir da razão entre os números de moles de AGE e LMDPE. Para um GF de 0,74\%, o número de moléculas de AGE inseridas, em média, por cadeia polimérica, é estimado em 1,3 a 1,9, para massa molar média numérica de LMDPE de $20.000 \mathrm{~g} \mathrm{~mol}^{-1}$ e $30.000 \mathrm{~g} \mathrm{~mol}^{-1}$, respectivamente.

\subsubsection{Análise térmica por TG e DTG}

A análise térmica por TG e DTG das amostras justifica-se, pois no processo de funcionalização ocorre aumento relativo na proporção de átomos de carbono quartenários (e terciários), como conseqüência da inserção do monômero na cadeia polimérica. Assim, se esse aumento relativo for suficientemente grande a ponto de ocasionar redução na estabilidade térmica do LMDPE funcionalizado, em relação à do LMDPE virgem, então ficaria evidenciada, indiretamente, a ocorrência da funcionalização.

A análise térmica por TG e DTG das amostras (purificadas) dos ensaios 13 (GF = 0,54\%), 13A (GF = 0,74\%), 59 (controle, ausência de AGE) e do LMDPE virgem (também purificado), foi feita e os resultados obtidos são mostrados na Tabela 9. 
Tabela 9 - Resultado da análise térmica por TG e DTG das amostras dos ensaios 13, 13A, 59 e do LMDPE virgem.

\begin{tabular}{|c|c|c|c|c|c|}
\hline Ensaio & $\begin{array}{c}\text { Massa inicial } \\
(\mathrm{mg})\end{array}$ & $\begin{array}{c}{\text { T } \text { onset }^{\mathrm{a}}} \\
\left({ }^{\circ} \mathrm{C}\right)\end{array}$ & $\begin{array}{c}\text { T pico } \\
\left({ }^{\circ} \mathrm{C}\right)\end{array}$ & $\begin{array}{c}\text { T endset }^{\mathrm{C}} \\
\left({ }^{\circ} \mathrm{C}\right)\end{array}$ & $\begin{array}{c}\text { Perda de } \\
\text { massa }(\%)\end{array}$ \\
\hline LMDPE virgem & 4,059 & 455,5 & 481,4 & 494,2 & $\sim 100$ \\
\hline 13 & 4,303 & 457,6 & 484,7 & 496,4 & $\sim 100$ \\
\hline $13 \mathrm{~A}$ & 4,044 & 451,8 & 478,5 & 491,8 & $\sim 100$ \\
\hline 59 & 4,090 & 457,7 & 484,3 & 496,2 & $\sim 100$ \\
\hline
\end{tabular}

a Temperatura inicial extrapolada, ${ }^{b}$ temperatura no máximo do pico da curva DTG (ou no ponto de inflexão da curva TG), ${ }^{c}$ temperatura final extrapolada.

Analisando-se os dados da Tabela 9, nota-se que a perda de massa, para todos os ensaios, foi de $\sim 100 \%$. Pode-se inferir que o LMDPE é isento de cargas minerais. Quanto à temperatura de decomposição experimental, somente no caso do ensaio 13A observa-se ligeira diminuição relativa da temperatura durante o evento. Portanto, houve redução na estabilidade térmica desta amostra. Essa redução poderia ser uma indicação de funcionalização no ensaio 13A. Porém, no caso do ensaio 13, a temperatura de decomposição experimental, durante o evento, foi inclusive maior do que a do LMDPE virgem. Conseqüentemente, a variação da temperatura deve estar dentro do erro experimental.

A análise térmica por TG mostrou-se ser uma técnica inadequada para confirmar a funcionalização das amostras. Uma explicação para isso poderia ser que a quantidade de AGE inserida na cadeia polimérica (GF < $1 \%$ ) não seja suficiente para provocar alterações (significativas) na estabilidade térmica das amostras.

As curvas TG e DTG do LMDPE virgem e do ensaio 13A são mostradas na Figura 32. 

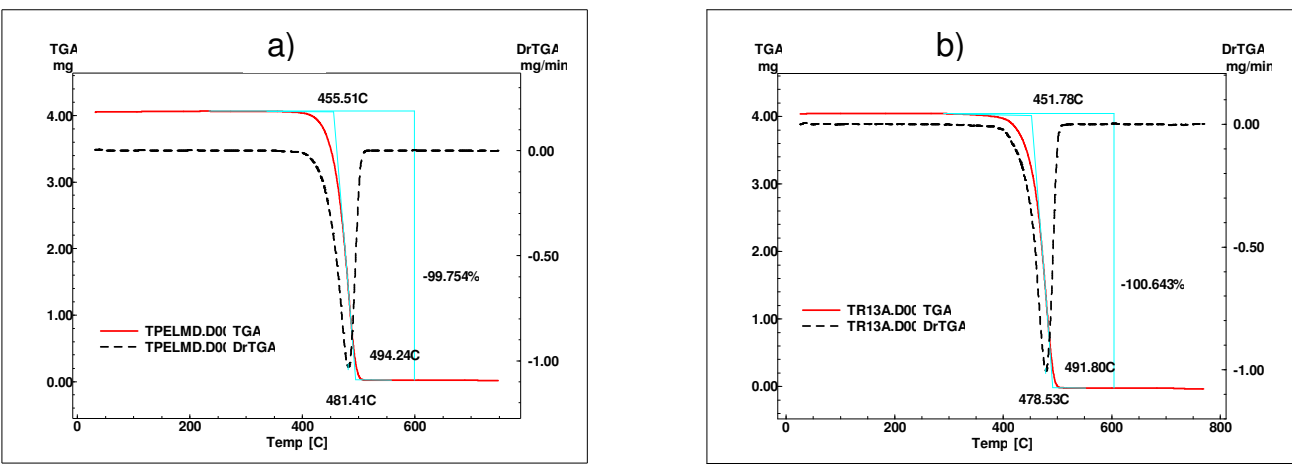

Figura 32 - Curvas TG (linha cheia, cor vermelha) e DTG (linha pontilhada, cor preta) do (a) LMDPE virgem e (b) ensaio 13A.

\subsubsection{Análise térmica por DSC}

Foi feita a análise térmica por DSC das amostras (purificadas) dos ensaios 12 (GF = 0,23\%), 13 (GF =0,54\%), 13A (GF =0,74\%), 25 (GF = 0,31\%), 59 (controle, ausência de AGE), 77 (GF = 0,28\%) e do LMDPE virgem (também purificado). O resultado é mostrado na Tabela 10. 
Tabela 10 - Resultado da análise térmica por DSC das amostras dos ensaios 12, 13, 13A, 25, 59, 77 e do LMDPE virgem, obtidos no segundo aquecimento.

\begin{tabular}{ccccc}
\hline Ensaio & $\begin{array}{c}\text { Massa inicial } \\
(\mathrm{mg})\end{array}$ & $\begin{array}{c}\text { Temperatura de } \\
\text { fusão }\left(\mathrm{T}_{\mathrm{f}}\right) \text { no pico } \\
\left({ }^{\circ} \mathrm{C}\right)\end{array}$ & $\begin{array}{c}\text { Variação da } \\
\text { entalpia de fusão } \\
\left(\Delta \mathrm{H}_{\mathrm{f}}\right)\left(\mathrm{J} \mathrm{g}^{-1}\right)\end{array}$ & $\begin{array}{c}\boldsymbol{\chi}_{\mathbf{c}^{\mathrm{b}}} \\
(\%)\end{array}$ \\
\hline LMDPE virgem & 2,230 & 123,0 & 154,9 & 52,9 \\
$\mathbf{1 2}$ & 2,360 & 121,5 & 133,8 & 45,7 \\
$\mathbf{1 3}$ & 2,260 & 121,8 & 133,9 & 45,7 \\
$\mathbf{1 3 A}$ & 2,230 & 121,8 & 128,2 & 43,7 \\
$\mathbf{2 5}$ & 2,350 & 121,3 & 138,0 & 47,1 \\
$\mathbf{5 9}$ & 2,310 & 123,4 & 143,0 & 48,8 \\
$\mathbf{7 7}$ & 2,290 & 123,6 & 133,0 & 45,4 \\
\hline
\end{tabular}

${ }^{\mathrm{a}}$ Determinada no intervalo de $80^{\circ} \mathrm{C}$ a $140^{\circ} \mathrm{C}$, ${ }^{\mathrm{b}}$ calculado pela eq. (12), ver item 3.2.10.

Pode-se notar que a $\Delta \mathrm{H}_{\mathrm{f}}$ decresce, acompanhada de decréscimo na $\mathrm{T}_{\mathrm{f}}$, nas amostras dos ensaios 12, 13, 13A, 25 e 77 (neste, não há diminuição relativa da $\mathrm{T}_{\mathrm{f}}$ ) em relação à do LMDPE virgem e à do ensaio 59 (controle, ausência de AGE). Como a área do pico endotérmico relativo à fusão cristalina está diretamente relacionada à quantidade de calor absorvida na fusão, e esta diretamente relacionada ao $\chi_{c}$, também se observa decréscimo relativo do $\chi_{c}$. À medida que o $\chi_{c}$ da amostra diminui, a $\Delta \mathrm{H}_{\mathrm{f}}$ também diminui, por causa da diminuição da área do pico endotérmico ocasionada pela diminuição do grau de organização das cadeias do LMDPE modificado quimicamente. Salienta-se que, o $\chi_{c}$ da amostra do ensaio 59 também foi reduzido, em relação ao do LMDPE virgem, porém em menor proporção. Esta redução no $\chi_{c}$ é coerente com o fato de que no ensaio 59 é adicionado BPO (na ausência de AGE), que por iniciar reações radicalares, pode estar provocando aumento na desorganização das cadeias do polímero. Por exemplo, pela eventual inserção aleatória de grupos laterais, como pela combinação do radical fenila com o macrorradical. 
As curvas DSC do LMDPE virgem e ensaio 13A são mostradas na Figura 33. Para efeito ilustrativo, as curvas DSC do $1^{\circ}$ e $2^{\circ}$ aquecimentos são mostradas para realçar a importância de se eliminar o histórico térmico da amostra.
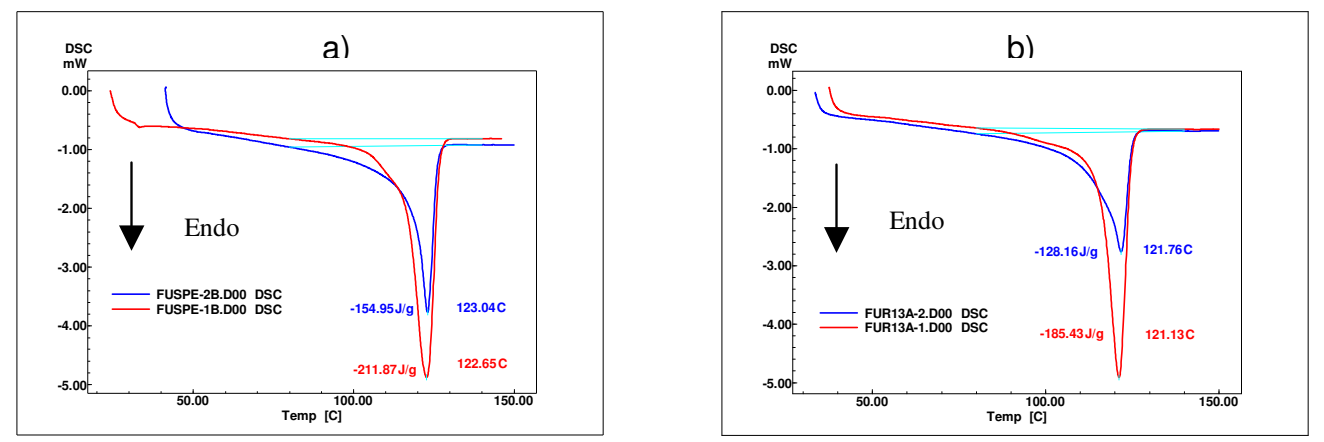

Figura 33 - Curvas DSC do $1^{\circ}$ aquecimento (cor vermelha) e $2^{\circ}$ aquecimento (cor azul) do (a) LMDPE virgem e (b) ensaio 13A.

Ao construir-se um gráfico de $\chi_{c}$ em função de GF, das amostras dos ensaios $12\left(\chi_{c}=45,7 \%\right.$ e GF = 0,23\%), $13\left(\chi_{c}=45,7 \%\right.$ e GF = 0,54\%), $13 \mathrm{~A}$ $\left(\chi_{C}=43,7 \%\right.$ e GF $\left.=0,74 \%\right), 25\left(\chi_{C}=47,1 \%\right.$ e GF = 0,31\%), 59 (controle, ausência de AGE, $\left.\chi_{C}=48,8 \%\right), 77\left(\chi_{C}=45,4 \%\right.$ e GF =0,28\%) e do LMDPE virgem $\left(\chi_{c}=52,9 \%\right)$, mostrado na Figura 34 , vê-se claramente que o $\chi_{c}$ da amostra decresce à medida que aumenta o GF. Esse resultado é consistente com a premissa de que a funcionalização pode provocar aumento no grau de desorganização estrutural do LMDPE, pelo aumento do número de ramificações na cadeia hidrocarbônica, por meio da inserção (aleatória) de monômero (s), ou outros grupos químicos (como no caso do ensaio 59). Então, há evidência (por DSC) de que tenha ocorrido funcionalização dos ensaios 12, 13, 13A, 25 e 77. 


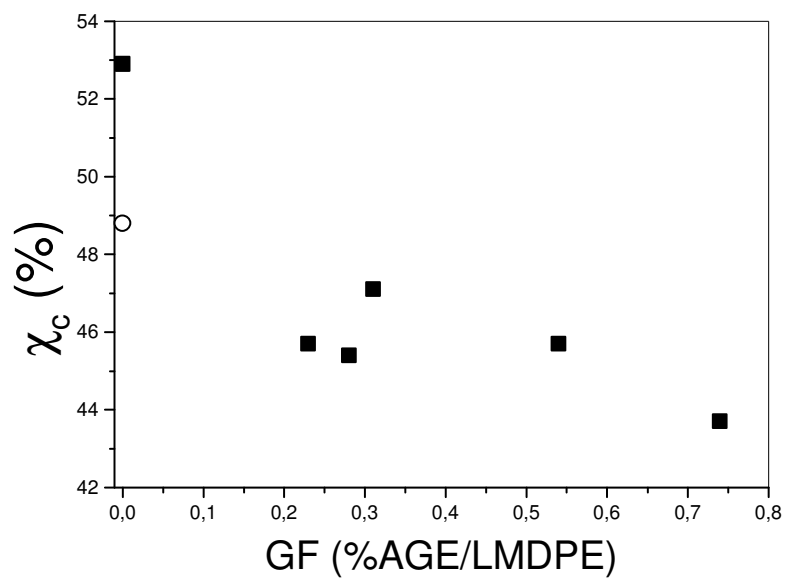

Figura 34 - $\chi_{C}$ em função do GF das amostras dos (•) ensaios 12, 13, 13A, 25, 77 e LMDPE virgem. O GF do (o) ensaio 59 é mostrado para comparação.

\subsubsection{Análise por XRD}

O padrão de difração de raios $X$ obtido a partir de polímeros semicristalinos, como o LMDPE, consiste de uma superposição de padrões cristalinos e amorfos.

Na Figura 35(a) é mostrado o difratograma de uma amostra (não purificada) do LMDPE virgem e, a partir do qual, foi feito um ajuste por Lorentziana de picos múltiplos. Para efeito de comparação, na Figura 35(b) são ilustrados os difratogramas obtidos a partir das amostras do LMDPE virgem e as dos ensaios 13, 59 e 77 (também não purificadas). O ajuste de lorentziana foi repetido (não mostrado) para as amostras dos ensaios 13 (GF = 0,54\%), 59 (controle, ausência de AGE) e 77 (GF = 0,28\%). Os dados obtidos quanto à área e à posição (do máximo do "pico") do halo amorfo e dos picos cristalinos (110) e (200), bem como os valores calculados das porcentagens das respectivas áreas, são mostrados na Tabela 11. 

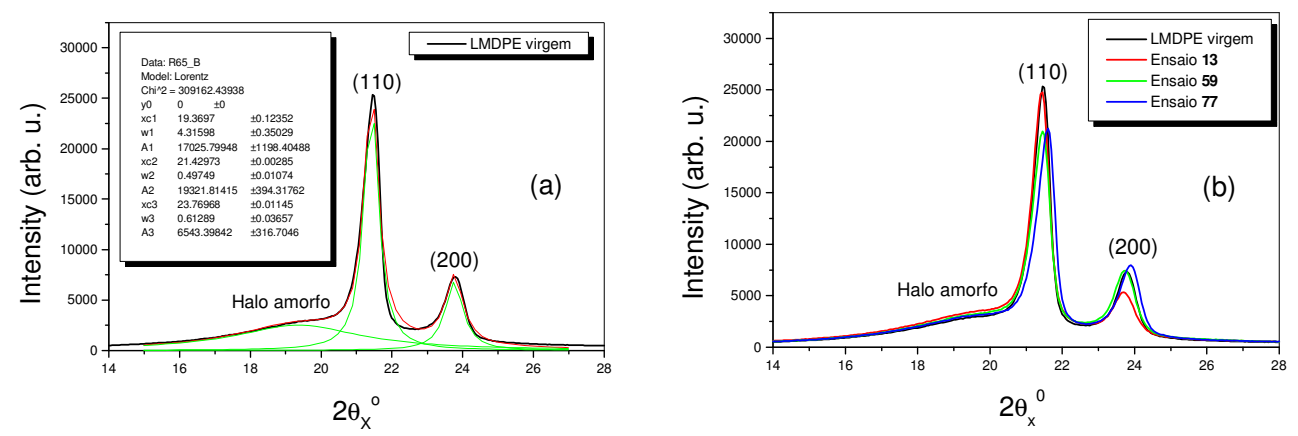

Figura 35 - (a) Difratograma com ajuste de Lorentziana do LMDPE virgem e (b) difratogramas do LMDPE virgem e dos ensaios 13, 59 e 77.

Tabela 11 - Dados obtidos após ajuste por Lorentziana dos difratogramas do LMDPE virgem e dos ensaios 13, 59 e 77.

\begin{tabular}{ccccc}
\hline Ensaio & "Pico" & Área (u. arb.) & Posição $\left(2 \theta_{x}{ }^{0}\right)$ & Área (\%) $^{\text {a }}$ \\
\hline \multirow{2}{*}{ LMDPE virgem } & Halo amorfo & 17026 & 19,4 & 39,7 \\
& $(110)$ & 19322 & 21,4 & 45,0 \\
& $(200)$ & 6543 & 23,8 & 15,3 \\
\hline \multirow{2}{*}{13} & Halo amorfo & 20823 & 19,4 & $\mathbf{4 6 , 0}$ \\
& $(110)$ & 19375 & 21,4 & $\mathbf{4 2 , 8}$ \\
& $(200)$ & 5031 & 23,7 & $\mathbf{1 1 , 2}$ \\
\multirow{2}{*}{59} & Halo amorfo & 19836 & 19,5 & 45,2 \\
& $(110)$ & 16927 & 21,4 & 38,5 \\
& $(200)$ & 7178 & 23,7 & 16,3 \\
\hline \multirow{2}{*}{77} & Halo amorfo & 19346 & 19,4 & $\mathbf{4 3 , 9}$ \\
& $(110)$ & 16952 & 21,4 & $\mathbf{3 9 , 0}$ \\
& $(200)$ & 7435 & 23,8 & $\mathbf{1 7 , 1}$ \\
\hline
\end{tabular}

a O cálculo é feito dividindo a área de cada "pico" pelo somatório das áreas do halo amorfo, pico cristalino (110) e pico cristalino (200). O resultado de cada uma dessas divisões é multiplicado por 100.

Analisando-se os dados da Tabela 11, vê-se decréscimo das porcentagens das áreas dos picos cristalinos (110) e (200) do ensaio 13, em relação aos respectivos valores obtidos para o LMDPE virgem. Resultado 
esperado, à luz do que foi discutido sobre a diminuição do $\chi_{c}$ com a funcionalização (discutido no item anterior). A porcentagem da área do halo amorfo do ensaio 13 aumentou, em relação à do LMDPE virgem, possivelmente em virtude do aumento do grau de desorganização das cadeias poliméricas, como conseqüência da funcionalização. No caso do ensaio 59 (controle, ausência de AGE), nota-se decréscimo da porcentagem da área no pico cristalino (110), em relação à obtida para o LMDPE virgem e, inclusive, em relação à obtida para o ensaio 13. Porém, no pico cristalino (200) houve acréscimo da porcentagem da área, em relação à do LMDPE virgem. Também é observado aumento da porcentagem da área no halo amorfo do ensaio 59, em relação à do LMDPE virgem. Salienta-se o fato das placas (a partir das quais são realizados os ensaios de XRD), obtidas por prensagem, se cristalizarem de forma não controlada. $O \chi_{c}$ de um polímero semicristalino pode variar de acordo com as condições ambientais durante a cristalização. Isso poderia explicar o fato da diminuição das porcentagens das áreas dos picos cristalinos (110) e (200) do ensaio 13, em relação aos respectivos valores obtidos para o LMDPE virgem, não ter sido significativa, quando se leva em conta a diminuição relativa das porcentagens das áreas obtidas para o ensaio 59 (controle, ausência de AGE). Assim como, explicaria o fato dos valores obtidos para o ensaio 77 terem sido similares àqueles observados para o ensaio 59. Quando as porcentagens das áreas dos picos cristalinos (110) e (200) são somadas, obtém-se a seguinte ordem: $\underline{60 \%}($ LMDPE virgem) $>\underline{56 \%}$ (ensaio 77, GF = 0,28\%), > 55\% (ensaio 59 controle, ausência de AGE) > $\underline{54 \%}$ (ensaio 13, GF = 0,54\%). Mostrando que a tendência da diminuição do valor referente a soma das áreas dos picos cristalinos (110) e (200) nas amostras funcionalizadas (13 e 77), em relação àquele do LMDPE virgem, é similar à observada para o ensaio 59 (controle, ausência de AGE). Observa-se que, no caso do LMDPE virgem e dos ensaios 13 e 59, foram obtidos filmes (de espessura de $\sim 0,5 \mathrm{~mm}$, preparados por evaporação do solvente da respectiva solução polimérica, depositada sobre um disco de vidro de diâmetro de $\sim 31 \mathrm{~mm}$ ) a partir das respectivas amostras purificadas. Os filmes foram previamente recozidos 
("annealed"), inicialmente, a 135-140ㄷ ( 40 min); depois, sob vácuo a $\sim 105^{\circ} \mathrm{C}(\sim 24 \mathrm{~h})$. Os valores obtidos (não mostrados) foram similares aos respectivos valores descritos na Tabela 11.

A funcionalização não provocou deslocamento (significativo) na posição dos picos relativos aos planos (110) e (200), evidenciando que tanto a amostra do LMDPE virgem, quanto as do LMDPE funcionalizado, seguem o mesmo padrão de cristalização, a partir da cela unitária ortorrômbica. Com os dados obtidos para a posição do máximo do "pico" (Tabela 11), é possível calcular as dimensões a e b da cela unitária ortorrômbica do LMDPE (Figura 2, item 1.2), a partir das eqs. (9) e (10) (item 1.5.7). Os valores obtidos foram $\mathrm{a}=0,74 \mathrm{~nm}$ e $\mathrm{b}=0,49 \mathrm{~nm}$, para as amostras do LMDPE virgem e as dos ensaios 13 e 77. Em perfeita concordância com os dados da literatura para o polietileno $(\mathrm{a}=0,742 \mathrm{~nm}$ e $\mathrm{b}=0,495 \mathrm{~nm}) .^{31}$

Porém, não foi possível determinar a dimensão c, que é atribuída à direção da cadeia. Pois, a sua posição está localizada no ângulo $2 \theta_{x}$ em $\sim 75^{\circ}$, enquanto que, o ensaio foi feito no intervalo de ângulo $20 \times$ de $10^{\circ} \mathrm{a}$ $50^{\circ}$. O valor de c é igual a $0,254 \mathrm{~nm}$, portanto correspondendo à distância (de contorno) entre as unidades de repetição do polietileno $\left[-\mathrm{CH}_{2} \mathrm{CH}_{2}\right]_{\mathrm{n}}$ na conformação linear ou cadeia totalmente estendida ou cadeia em ziguezague ou conformação toda trans, nas terminologias usadas em química macromolecular, ou conformação toda antiperiplanar, na terminologia usada em química orgânica. ${ }^{75} \mathrm{O}$ polietileno (cuja força estérica é mais importante que a eletrostática na determinação da conformação) idealmente se cristaliza naquela conformação, porque a distância entre os átomos de hidrogênio não ligados $(0,254 \mathrm{~nm})$ é maior que a soma dos raios de van der Waals $(0,24 \mathrm{~nm}) \cdot{ }^{75}$ Por conseguinte, não há repulsão de van der Waals. 


\subsubsection{Determinação do MFI}

Como o MFI está inversamente relacionado com a massa molar média ponderal, ${ }^{3 a}$ ou seja, o MFI aumenta à medida que a massa molar média ponderal decresce, pensou-se em usar essa propriedade (característica de poliolefinas) para avaliar a eventual ocorrência de fragmentação da amostra do ensaio 13.

Foi determinado o MFI das amostras (não purificadas) dos ensaios 13 ( $\mathrm{AGE}=20,0 \%$ e razão molar $=10,0$-torque final = 0,9 $\mathrm{N} \mathrm{m}$ ), 15 (controle, somente LMDPE processado por $9 \mathrm{~min}$-torque final $=15,4 \mathrm{~N} \mathrm{~m}), 59$ (controle, ausência de AGE -torque final = 16,5 $\mathrm{N} \mathrm{m}$ ) e do LMDPE virgem. $O$ resultado é mostrado na Tabela 12.

Tabela 12 - Resultado do ensaio de MFI das amostras dos ensaios 13, 15, 59 e do LMDPE virgem.

\begin{tabular}{cc}
\hline Ensaio & MFI \\
& $g(10 \mathrm{~min})^{-1}$ \\
\hline LMDPE virgem & $1,70 \pm 0,04$ \\
13 & $0,2 \pm 0$ \\
15 & 1,7 \\
59 & $0,3 \pm 0$ \\
\hline
\end{tabular}

Surpreendentemente, o valor do MFI do ensaio 13 diminuiu, ao invés de ter aumentado, como era esperado (associando queda drástica no torque à fragmentação da cadeia polimérica e, conseqüentemente, diminuição da massa molar média). O valor do MFI do ensaio 59 é comparável ao observado para o ensaio 13, não obstante apresentarem valores de torque final de $16,5 \mathrm{~N} \mathrm{~m}$ e 0,9 $\mathrm{N} \mathrm{m}$, respectivamente. As amostras coletadas após o ensaio de MFI são solúveis em tolueno quente (indicando ausência de gel). Portanto, a diminuição relativa dos valores de MFI não poderia ser atribuída a uma eventual reticulação da amostra durante o ensaio (de MFI na 
temperatura de $190^{\circ} \mathrm{C}$ ), a qual produziria aumento da massa molar média. $\mathrm{O}$ fato das amostras não terem sido previamente purificadas poderia ter uma parcela de contribuição para com esses resultados inesperados. Porém, o resultado do ensaio de MFI na amostra purificada do ensaio 13A (não havia mais amostra do ensaio 13 para purificar) foi ainda mais surpreendente. Pois, além de não ser possível coletar a amostra na saída do orifício padrão, a sua remoção da câmera somente foi possível forçando-a para fora no sentido do bocal de alimentação da câmera. Assim, o valor de MFI do ensaio 13A purificado foi de $0 \mathrm{~g}(10 \mathrm{~min})^{-1}$. Também aqui, a amostra coletada depois do ensaio de MFI é solúvel em tolueno quente (indicando ausência de gel).

Foram obtidos espectros no FTIR de três amostras distintas do ensaio 13. Ensaio 13 não purificado, ensaio 13 coletado após o ensaio de MFI (não purificado) e ensaio 13 purificado. Os espectros no FTIR são mostrados na Figura 36.

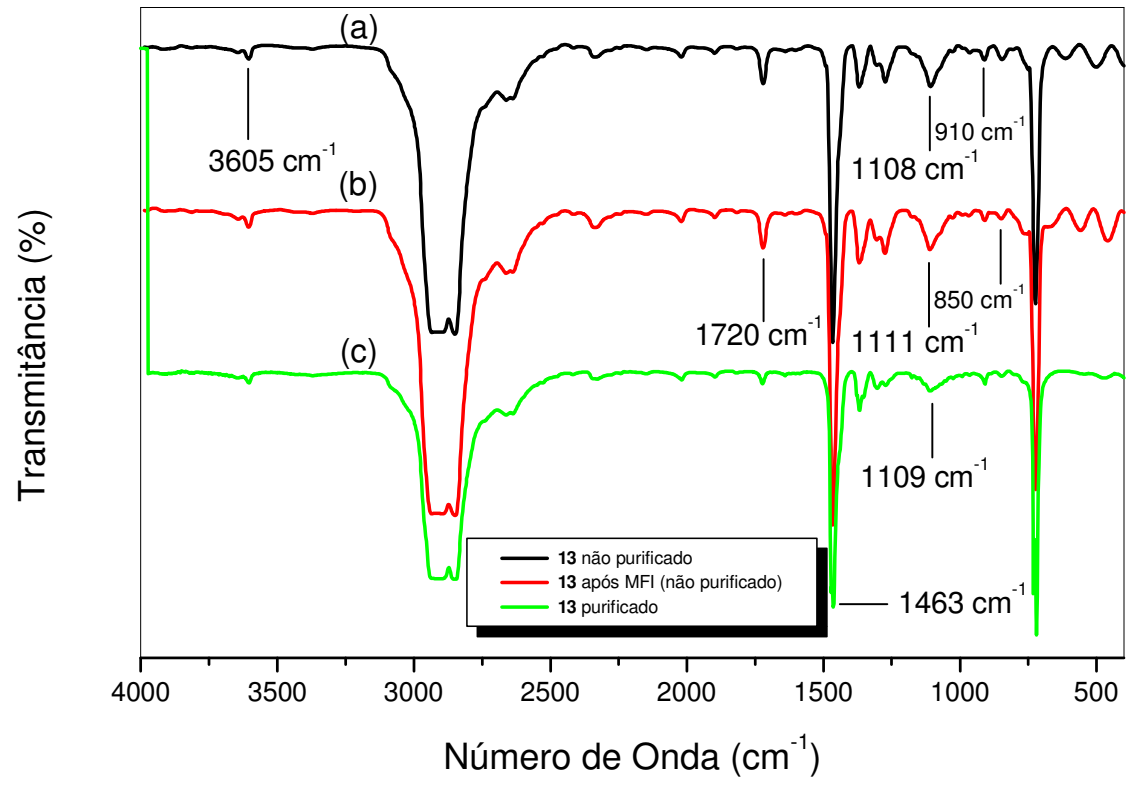

Figura 36 - Espectros no FTIR do (a) ensaio 13 não purificado, (b) ensaio 13 coletado após o ensaio de MFI (não purificado) e (c) ensaio 13 purificado. 
Comparando-se os espectros no FTIR do ensaio 13 não purificado com o do ensaio 13 coletado após o ensaio de MFI (não purificado), não se nota praticamente diferença entre eles. Porém, quando esses dois espectros são confrontados com o do ensaio 13 purificado, observa-se diminuição relativa na intensidade das bandas do ensaio 13 purificado, inclusive na banda de maior interesse $\left(\sim 1100 \mathrm{~cm}^{-1}\right)$, apontando o quão importante é o processo prévio de purificação na caracterização das amostras por FTIR. A banda em $1720 \mathrm{~cm}^{-1}$ é característica de estiramento da ligação $\mathrm{C}=\mathrm{O} \mathrm{em}$ aldeídos, cetonas ou ácidos carboxílicos. ${ }^{40} \mathrm{~A}$ banda em $3605 \mathrm{~cm}^{-1}$ poderia ser de estiramento da ligação $\mathrm{O}-\mathrm{H}$ em ácidos carboxílicos com hidroxilas livres $\left(\sim 3520 \mathrm{~cm}^{-1}\right)$ ou em álcoois $\left(3605 \mathrm{~cm}^{-1}\right.$ a $\left.3584 \mathrm{~cm}^{-1}\right) \cdot{ }^{40}$ Poderia ser o resultado da combinação das bandas $720 / 730 \mathrm{~cm}^{-1}$ com a banda em $2913 \mathrm{~cm}^{-1}$ ou $2850 \mathrm{~cm}^{-1}$. Quando se comparam os espectros no FTIR (não mostrados) das amostras do ensaio 77 não purificado com a do ensaio 77 purificado observa-se a mesma diminuição relativa da intensidade das bandas (em especial, as das bandas em $\sim 1100 \mathrm{~cm}^{-1}$ e $1720 \mathrm{~cm}^{-1}$ ) que foi verificada para o ensaio 13 (descrito acima). No caso do ensaio 59 (controle, ausência de AGE), os espectros no FTIR (não mostrados), da amostra não purificada contra o da purificada, também é observada diminuição relativa da intensidade das bandas (especialmente, a da banda em $1720 \mathrm{~cm}^{-1}$ ). Contudo, a intensidade da banda em $1720 \mathrm{~cm}^{-1}$, da amostra não purifica, é cerca de 1/4 daquela observada nos espectros das amostras dos ensaios 13 e 77 não purificados. Gaylord et al. ${ }^{76}$ observaram que, no estudo envolvendo a funcionalização de HDPE (MFI de $17 \mathrm{dg} \min ^{-1}$ ) com MAH, na presença de peróxido de alquila, apesar do torque final não ter praticamente variado e não ter sido observado a presença de gel, o valor de MFI das amostras funcionalizadas foi de $\sim 1 \mathrm{dg} \min ^{-1}$. Atribuíram isso à combinação de radicais (HDPE` com HDPE-MAH). 


\subsection{Obtenção de compósitos (e blendas)}

O objetivo aqui é avaliar se o GF obtido na funcionalização por processamento reativo, que variou de $0,23 \%$ a $0,74 \%$, é suficiente para permitir uma melhor dispersão da fase dispersa (polissacarídeo) na matriz polimérica. Uma melhor compatibilidade entre essas fases propicia um aumento na adesão entre elas, o que possibilitaria uma melhor transferência de tensão da matriz polimérica para o polissacarídeo. Como resultado, compósitos (e blendas) com melhores resistências mecânicas poderiam ser obtidos. A avaliação da performance dos compósitos (e das blendas) foi feita por meio de ensaios mecânicos de tração. A avaliação da interface matriz polimérica e polissacarídeo foi feita por SEM. A extração em xileno sob refluxo foi realizada para avaliar se a interação entre os grupos epóxidos inseridos nas cadeias de LMDPE e os grupos hidroxilas presentes no polissacarídeo é de origem química ou física.

Assim, nesta investigação, como matrizes poliméricas foram usadas as amostras do LMDPE funcionalizado dos ensaios 12 (GF =0,23\%), 13A $(\mathrm{GF}=0,74 \%), 25(\mathrm{GF}=0,31 \%$ ) e $77(\mathrm{GF}=0,28 \%$ ), Tabelas 6 (item 4.3) e 7 (item 4.3.1). LMDPE virgem foi usado para obtenção de controles. Como polissacarídeos foram usados SF-CEL (comp. = 0,13 mm), MF-CEL (comp. = 0,6 mm), LF-CEL (comp. = 1,5 mm), ULF-CEL (comp. = 1,4 mm) e BUTCEL (diâm. = 0,06 mm).

\subsubsection{Efeito da funcionalização e do processamento nas propriedades mecânicas do PE}

Antes do estudo dos compósitos (e das blendas), seria interessante avaliar as propriedades mecânicas, em termos de resistência à tração, elongação e módulo de Young, das placas obtidas a partir dos ensaios 13 (GF = 0,54\%), 77 (GF = 0,28\%), 59 (controle, na ausência de AGE) e do LMDPE virgem. Também, a partir dos ensaios 15 (LMDPE processado no reômetro de torque na ausência de AGE e BPO, por 9 min a $120^{\circ} \mathrm{C}$ e $60 \mathrm{rpm}$ 
-condição usada na funcionalização) e 39 (LMDPE processado no reômetro de torque na ausência de AGE e BPO, por 35 min a $150^{\circ} \mathrm{C}$ e $80 \mathrm{rpm}$ condição usada na obtenção dos compósitos e blendas). A finalidade é avaliar se há perda relativa de resistência ocasionada pela funcionalização $e$ pelo processamento. Caso isso ocorra, poderia afetar a performance final do compósito (ou da blenda). Tal investigação se justifica à luz do que foi discutido a respeito do valor de torque final (item 4.3), o qual poderia indicar eventual reticulação, quando se observa aumento relativo do torque, ou funcionalização e/ou fragmentação da cadeia, quando se observa diminuição relativa do torque. No caso do ensaio $\mathbf{3 9}$, os valores de torque e temperatura finais são, respectivamente, $11,6 \mathrm{~N} \mathrm{~m}$ e $173,5^{\circ} \mathrm{C}$. Este valor de torque é inferior ao do ensaio $15\left(15,4 \mathrm{~N} \mathrm{~m}\right.$ a $\left.142^{\circ} \mathrm{C}\right)$, possivelmente porque a temperatura final é bem maior. De modo geral, quanto maior a temperatura, menor é a viscosidade de uma substância, e com isso, menor o torque necessário para manter os dois rotores girando na velocidade ajustada.

A Tabela 13 contém os resultados médios obtidos de resistência à tração, elongação e módulo de Young, bem como os respectivos desvios padrões das médias, para as amostras dos ensaios 13, 15, 39, 59, 77 e do LMDPE virgem. 
Tabela 13 - Propriedades mecânicas obtidas para os ensaios 13, 15, 39, 59, 77 e para LMDPE virgem.

\begin{tabular}{ccccccc}
\hline Ensaio & $\begin{array}{c}\sigma_{\mathbf{y}} \\
(\mathrm{MPa})\end{array}$ & $\begin{array}{c}\boldsymbol{\varepsilon}_{\mathbf{y}} \\
(\%)\end{array}$ & $\begin{array}{c}\sigma_{\mathbf{m}} \\
(\mathrm{MPa})\end{array}$ & $\begin{array}{c}\sigma_{\mathbf{b}} \\
(\mathrm{MPa})\end{array}$ & $\begin{array}{c}\boldsymbol{\varepsilon}_{\mathbf{b}} \\
(\%)\end{array}$ & $\begin{array}{c}\mathbf{E} \\
(\mathrm{GPa})\end{array}$ \\
\hline LMDPE virgem & $15,1 \pm 0,3$ & $18,6 \pm 0,8$ & $26,6 \pm 0,7$ & $26,2 \pm 0,6$ & $1361 \pm 33$ & $0,26 \pm 0,02$ \\
$\mathbf{1 3}$ & $11,3 \pm 0,4$ & $27 \pm 16$ & $14 \pm 2$ & $14 \pm 1$ & $519 \pm 161$ & $0,10 \pm 0,03$ \\
$\mathbf{1 5}$ & $12,5 \pm 0,1$ & $18,4 \pm 0,5$ & $27,4 \pm 0,7$ & $27,0 \pm 0,9$ & $1239 \pm 38$ & $0,15 \pm 0,02$ \\
$\mathbf{3 9}$ & $12,5 \pm 0,2$ & $18,9 \pm 0,4$ & $27 \pm 1$ & $27 \pm 1$ & $1229 \pm 55$ & $0,15 \pm 0,01$ \\
$\mathbf{5 9}$ & $13,0 \pm 0,2$ & $16,6 \pm 0,2$ & $26,6 \pm 0,8$ & $26,1 \pm 0,8$ & $1190 \pm 35$ & $0,16 \pm 0,05$ \\
$\mathbf{7 7}$ & $15,2 \pm 0,1$ & $15,1 \pm 0,3$ & $26,4 \pm 0,4$ & $26,1 \pm 0,2$ & $1174 \pm 23$ & $0,33 \pm 0,03$ \\
\hline
\end{tabular}

onde $\sigma$ é a resistência à tração no ponto de escoamento $(\mathrm{y})$, máxima $(\mathrm{m})$ e na ruptura (b); $\varepsilon$ é a elongação no ponto de escoamento (y) e na ruptura (b); E é o módulo de Young.

Na Figura 37 são mostradas as curvas de $\sigma$ em função de $\varepsilon$ para os ensaios 13 e 77 e para LMDPE virgem. Essas três curvas apresentam comportamento típico de amostras de polietileno (fratura dúctil, com formação de pescoço, seguido de estiramento a frio, onde o ponto de escoamento é de fácil localização), quando os ensaios de $\sigma$ em função de $\varepsilon$ são realizados em temperaturas acima de sua $T_{g}$. Dependendo do autor, o valor da $\mathrm{T}_{\mathrm{g}}$ pode ser $-30^{\circ} \mathrm{C},-80^{\circ} \mathrm{C}$ ou $-128^{\circ} \mathrm{C} .^{77}$ 


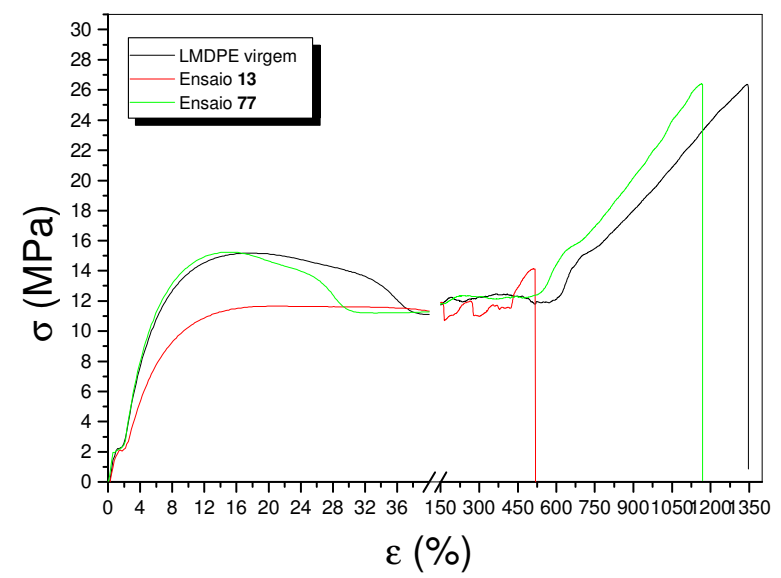

Figura 37 - Curvas de $\sigma$ em função de $\varepsilon$ para os ensaios 13 e 77 e para LMDPE virgem.

Analisando-se os dados da Tabela 13, quanto ao processamento, quando se comparam os dados dos ensaios 15 e 39, com os do LMDPE virgem, nota-se um ligeiro decréscimo de $\sigma_{y}(\sim 17 \%)$ e $\varepsilon_{b}(\sim 9 \%)$ e um acentuado decréscimo de E ( 40\%), independentemente das condições (mais brandas ou mais severas) de processamento do LMDPE na ausência de AGE e BPO. Comportamento similar foi obtido para o ensaio 59 (controle, ausência de AGE). Quanto à funcionalização, quando se comparam os dados dos ensaios 13 e 77, com os do LMDPE virgem, observa-se que, o ensaio 77, no geral, apresenta valores comparáveis aos obtidos para LMDPE virgem. No caso do ensaio 13, há um moderado decréscimo de $\sigma_{\mathrm{y}}$ ( 25\%), porém, um drástico decréscimo de $\sigma_{\mathrm{m}}(\sim 47 \%), \sigma_{\mathrm{b}}(\sim 47 \%)$, $\varepsilon_{\mathrm{b}}$ $(\sim 62 \%)$ e $E(\sim 62 \%)$. Podendo indicar que a acentuada queda relativa no torque final verificada para o ensaio $13(0,9 \mathrm{~N} \mathrm{~m})$, em relação àquela observada para o ensaio $15(15,4 \mathrm{~N}$ m), não poderia ser atribuída somente à funcionalização, mas também à fragmentação da cadeia polimérica. Geralmente, E é sensível à variação de $\chi_{c}$, tendendo a diminuir com a diminuição de $\chi_{\mathrm{c}}$. Isso pôde ser constatado nos ensaios $13(\mathrm{E}=0,10 \mathrm{GPa}$ e $\left.\chi_{\mathrm{c}}=45,7 \%\right)$ e $59\left(\mathrm{E}=0,16 \mathrm{GPa}\right.$ e $\left.\chi_{\mathrm{c}}=48,8 \%\right)$, levando-se em conta os respectivos valores obtidos para o LMDPE virgem $\left(\mathrm{E}=0,26 \mathrm{GPa}\right.$ e $\chi_{\mathrm{c}}=$ 
52,9\%). Porém, essa tendência não foi observada no caso do ensaio 77 ( $E$ = $0,33 \mathrm{GPa}$ e $\left.\chi_{\mathrm{c}}=45,4 \%\right)$.

Para efeitos práticos, quando da discussão da obtenção de compósitos (e de blendas), as propriedades mecânicas para a amostra do ensaio 13A foram consideradas iguais àquelas obtidas para o ensaio 13.

\subsubsection{Compósitos obtidos com celulose fibra curta}

Neste estudo, variou-se a proporção de SF-CEL de $20 \%$ a $50 \%$. A composição $70 \%$ de matriz polimérica e $30 \%$ de SF-CEL foi escolhida para comparar-se a performance das quatro amostras de LMDPE funcionalizado que foram usadas na obtenção de compósitos. As quatro amostras são as dos ensaios 12 (GF = 0,23\%), 13A (GF = 0,74\%), 25 (GF = 0,31\%) e 77 (GF $=0,28 \%$ ). As amostras do ensaio 77 são as que geram os compósitos com as melhores performances. As amostras dos ensaios 13A e 77 foram usadas mais extensivamente.

Nas Tabelas 14 e 15 são mostrados os valores médios obtidos de resistência à tração, elongação e módulo de Young, assim como os respectivos desvios padrões das médias. Os compósitos foram obtidos usando de $20 \%$ a $50 \%$ de SF-CEL (comp. = 0,13 $\mathrm{mm}$ ) e LMDPE virgem (LMDPE $)_{v}$ ), para servirem como controles, Tabela 14, ou LMDPE funcionalizado $\left(\right.$ LMDPE $_{\mathbf{x}}$, onde $\mathrm{x}$ refere-se ao número do ensaio da amostra funcionalizada, podendo ser 12, 13A, 25 ou 77), Tabela 15. 
Tabela 14 - Propriedades mecânicas dos compósitos obtidos com LMDPE e SF-CEL (controles).

\begin{tabular}{ccccccc}
\hline Ensaio & $\begin{array}{c}\boldsymbol{\sigma}_{\mathbf{y}} \\
(\mathrm{MPa})\end{array}$ & $\begin{array}{c}\boldsymbol{\varepsilon}_{\mathbf{y}} \\
(\%)\end{array}$ & $\begin{array}{c}\boldsymbol{\sigma}_{\mathbf{m}} \\
(\mathrm{MPa})\end{array}$ & $\begin{array}{c}\boldsymbol{\sigma}_{\mathbf{b}} \\
(\mathrm{MPa})\end{array}$ & $\begin{array}{c}\boldsymbol{\varepsilon}_{\mathbf{b}} \\
(\%)\end{array}$ & $\begin{array}{c}\mathbf{E} \\
(\mathrm{GPa})\end{array}$ \\
\hline $\mathbf{6 3} \mathbf{( 8 0 \% L M D P E V} / 20 \%$ SF-CEL) & $18,7 \pm 0,8$ & $4,3 \pm 0,1$ & $20,6 \pm 0,5$ & $18 \pm 1$ & $13,6 \pm 0,9$ & $0,64 \pm 0,02$ \\
$\mathbf{6 4} \mathbf{( 7 0 \% L M D P E V} / 30 \%$ SF-CEL) & $19,2 \pm 0,5$ & $5,3 \pm 0,6$ & $20,3 \pm 0,7$ & $14 \pm 1$ & $30 \pm 1$ & $0,55 \pm 0,02$ \\
$\mathbf{7 4}{ }_{(60 \% L M D P E V / 40 \% S F-C E L)}$ & $14,6 \pm 0,8$ & $3,2 \pm 0,3$ & $16,9 \pm 0,7$ & $12,0 \pm 0,9$ & $6,0 \pm 0,6$ & $0,84 \pm 0,03$ \\
$\mathbf{9 3}(50 \%$ LMDPEV/50\%SF-CEL) & $7,6 \pm 0,3$ & $2,62 \pm 0,04$ & $7,7 \pm 0,4$ & $4 \pm 1$ & $5,0 \pm 0,4$ & $0,50 \pm 0,04$ \\
\hline
\end{tabular}

onde $\sigma$ é a resistência à tração no ponto de escoamento $(\mathrm{y})$, máxima $(\mathrm{m})$ e na ruptura (b); $\varepsilon$ é a elongação no ponto de escoamento (y) e na ruptura (b); E é o módulo de Young.

Tabela 15 - Propriedades mecânicas dos compósitos obtidos com LMDPE $\mathbf{x}$ e SF-CEL.

\begin{tabular}{|c|c|c|c|c|c|c|}
\hline Ensaio & $\begin{array}{c}\sigma_{y} \\
(\mathrm{MPa})\end{array}$ & $\begin{array}{l}\varepsilon_{y} \\
(\%)\end{array}$ & $\begin{array}{c}\boldsymbol{\sigma}_{\mathrm{m}} \\
(\mathrm{MPa})\end{array}$ & $\begin{array}{c}\boldsymbol{\sigma}_{\mathrm{b}} \\
(\mathrm{MPa})\end{array}$ & $\begin{array}{c}\varepsilon_{b} \\
(\%)\end{array}$ & $\begin{array}{c}\mathbf{E} \\
(\mathrm{GPa})\end{array}$ \\
\hline $69{ }_{(80 \% L M D P E}{ }_{13 \alpha} 20 \%$ SF-CEL) & $13,9 \pm 0,7$ & $5,4 \pm 0,3$ & $14,9 \pm 0,4$ & $10,5 \pm 0,7$ & $24 \pm 3$ & $0,40 \pm 0,03$ \\
\hline $79{ }_{\left(80 \% L_{M D P E} E_{12} / 20 \% \text { SF-CEL) }\right.}$ & $18,3 \pm 0,2$ & $5,9 \pm 0,2$ & $19,0 \pm 0,2$ & $12 \pm 1$ & $35 \pm 4$ & $0,53 \pm 0,03$ \\
\hline 80 (80\%LMDPE ${ }_{77} / 20 \%$ SF-CEL) & $16,0 \pm 0,5$ & $5,2 \pm 0,2$ & $19,1 \pm 0,5$ & $14 \pm 2$ & $27 \pm 3$ & $0,52 \pm 0,02$ \\
\hline 70 (70\%LMDPE $E_{12} / 30 \%$ SF-CEL) & $20,5 \pm 0,6$ & $5,1 \pm 0,3$ & $22 \pm 1$ & $21 \pm 2$ & $21 \pm 3$ & $0,69 \pm 0,05$ \\
\hline 71 (70\%LMDPE ${ }_{13 \AA} / 30 \%$ SF-CEL) & $16,7 \pm 0,7$ & $4,6 \pm 0,2$ & $21 \pm 1$ & $19 \pm 1$ & $20 \pm 3$ & $0,58 \pm 0,06$ \\
\hline 72 (70\% LMDPE $_{25} / 30 \%$ SF-CEL) & $17,0 \pm 0,9$ & $4,4 \pm 0,2$ & $19,5 \pm 0,8$ & $18,0 \pm 0,5$ & $12 \pm 2$ & $0,59 \pm 0,03$ \\
\hline 83 (70\%LMDPE $E_{77} / 30 \%$ SF-CEL) & $20,9 \pm 0,4$ & $5,5 \pm 0,3$ & $23,2 \pm 0,3$ & $21,7 \pm 0,3$ & $27 \pm 3$ & $0,71 \pm 0,02$ \\
\hline 78 (60\%LMDPE ${ }_{13 \alpha} / 40 \%$ SF-CEL) & $18 \pm 1$ & $4,1 \pm 0,2$ & $20,3 \pm 0,6$ & $20,0 \pm 0,5$ & $10 \pm 2$ & $0,69 \pm 0,02$ \\
\hline $\left.90{ }_{(60 \% L M D P E}{ }_{77} / 40 \% \mathrm{SF}-\mathrm{CEL}\right)$ & $25,3 \pm 0,7$ & $4,5 \pm 0,1$ & $29,4 \pm 0,4$ & $28 \pm 1$ & $17 \pm 1$ & $1,01 \pm 0,05$ \\
\hline $\left.99{ }_{\left(60 \% L_{M D P E} / 40 \%\right.} 40 \mathrm{SF}-\mathrm{CEL}\right)$ & $24 \pm 2$ & $3,6 \pm 0,2$ & $29 \pm 1$ & $29 \pm 1$ & $16 \pm 3$ & $0,92 \pm 0,03$ \\
\hline 91 (50\%LMDPE ${ }_{13 /} / 50 \%$ SF-CEL) & $22 \pm 1$ & $3,82 \pm 0,02$ & $24,7 \pm 0,9$ & $24,6 \pm 0,9$ & $8,1 \pm 0,7$ & $0,96 \pm 0,03$ \\
\hline 95 (50\%LMDPE ${ }_{77} / 50 \%$ SF-CEL) & $24,5 \pm 0,5$ & $4,0 \pm 0,3$ & $27,4 \pm 0,6$ & $27,2 \pm 0,6$ & $12,0 \pm 0,9$ & $1,02 \pm 0,04$ \\
\hline $100{ }_{\left(50 \% L_{M P P E} 25\right.} 50 \%$ SF-CEL) & $24 \pm 2$ & $3,8 \pm 0,1$ & $28 \pm 1$ & $27,6 \pm 0,7$ & $10 \pm 2$ & $1,10 \pm 0,05$ \\
\hline
\end{tabular}

onde $\sigma$ é a resistência à tração no ponto de escoamento $(\mathrm{y})$, máxima $(\mathrm{m})$ e na ruptura (b); $\varepsilon$ é a elongação no ponto de escoamento $(\mathrm{y})$ e na ruptura (b); E é o módulo de Young. 
Para ilustração, na Figura 38 são mostradas as curvas da $\sigma$ em função da $\varepsilon$ para os ensaios 64, 83, 93 e 95. Por causa da presença da SFCEL, observam-se mudanças no comportamento dos compósitos em relação ao da matriz polimérica (Figura 37). No caso dos compósitos, notam-se, no geral, desde fraturas dúcteis (porém, em alguns, com formação de pescoço, mas sem estiramento a frio; em outros, sem formação de pescoço), até fraturas frágeis, dependendo da proporção de SF-CEL.

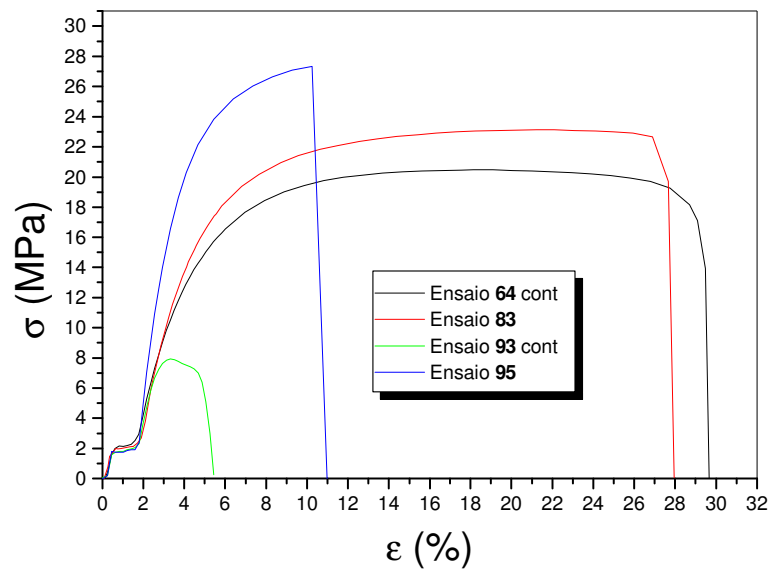

Figura 38 - Curvas da $\sigma$ em função da $\varepsilon$ para os ensaios 64, 83, 93 e 95.

Quando se comparam as propriedades mecânicas dos compósitos obtidos a partir das amostras dos ensaios 12 (com 20\% e 30\% de SF-CEL) e 25 (com 30\% de SF-CEL), ver Tabela 15, com aquelas obtidas para os controles, ver Tabela 14, em geral, são comparáveis. Porém, com proporções de $40 \%$ e $50 \%$ de SF-CEL, os compósitos obtidos a partir das amostras do ensaio 25 apresentam um extraordinário aumento na $\sigma_{\mathrm{y}}, \sigma_{\mathrm{m}}, \sigma_{\mathrm{b}}$ e E.

Na Figura 39 é mostrada a $\sigma_{y}$ em função da proporção da SF-CEL, para os compósitos obtidos a partir das amostras do $L_{M D P E}{ }_{13 A}, L_{M D P E} 77$ LMDPE $_{\mathrm{v}}$. Observa-se um aumento relativo de $\sigma_{\mathrm{y}}$ à medida que aumenta a proporção da SF-CEL, para os compósitos obtidos com $\operatorname{LMDPE}_{13 A}$ e 
LMDPE $_{77}$, exceto quando a proporção da SF-CEL é $50 \%$, onde se observa ligeira queda para o compósito contendo LMDPE 77 . Contudo, nota-se um efeito oposto para os compósitos contendo LMDPE $_{\mathrm{v}}$ (em proporções da SFCEL maiores que 30\%). Salienta-se que, quando a proporção da SF-CEL é

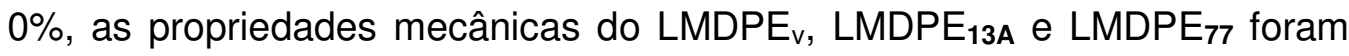
extraídas da Tabela 13 (item 4.4.1).

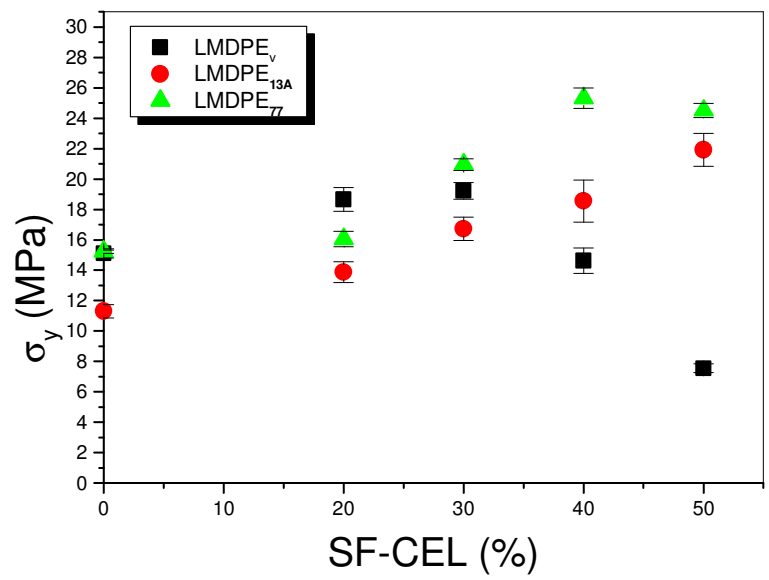

Figura $39-\sigma_{y}$ em função da proporção da SF-CEL, usando LMDPE

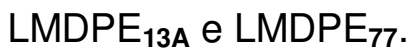

Na Figura 40(a) é mostrada a $\sigma_{m}$ em função da proporção da SF-CEL e na Figura 40(b) a $\sigma_{b}$ em função da proporção da SF-CEL, para os compósitos obtidos a partir das amostras do LMDPE $_{13 \mathrm{~A}}, \mathrm{LMDPE}_{77}$ e LMDPE $_{v}$. Para os compósitos obtidos a partir do LMDPE $_{v}$, nota-se que à medida que a proporção da SF-CEL cresce, os valores de $\sigma_{m}$ e $\sigma_{b}$ decrescem. Efeito oposto é obtido para os compostos contendo LMDPE $_{13 A}$ (porém, notem os valores relativamente baixos de $\sigma_{\mathrm{m}}$ e $\sigma_{\mathrm{b}}$ na ausência da SF-CEL). Já no caso dos compósitos obtidos a partir do LMDPE $_{77}$, quando a proporção da SF-CEL é de $20 \%$, há uma queda acentuada tanto em $\sigma_{\mathrm{m}}$ quanto em $\sigma_{\mathrm{b}}$. Contudo, incrementos da SF-CEL fazem com que os valores de $\sigma_{\mathrm{m}}$ e $\sigma_{\mathrm{b}}$ aumentem a tal ponto de superarem (quando a proporção da SFCEL é de $40 \%$ e $50 \%$ ) os de $\sigma_{m}$ e $\sigma_{b}$ quando a proporção da SF-CEL é $0 \%$. 
Zhang et al. ${ }^{78}$ também observaram o aumento da resistência à tração (e do módulo de Young) com o aumento da quantidade de celulose, porém usando o monômero anidrido maléico.
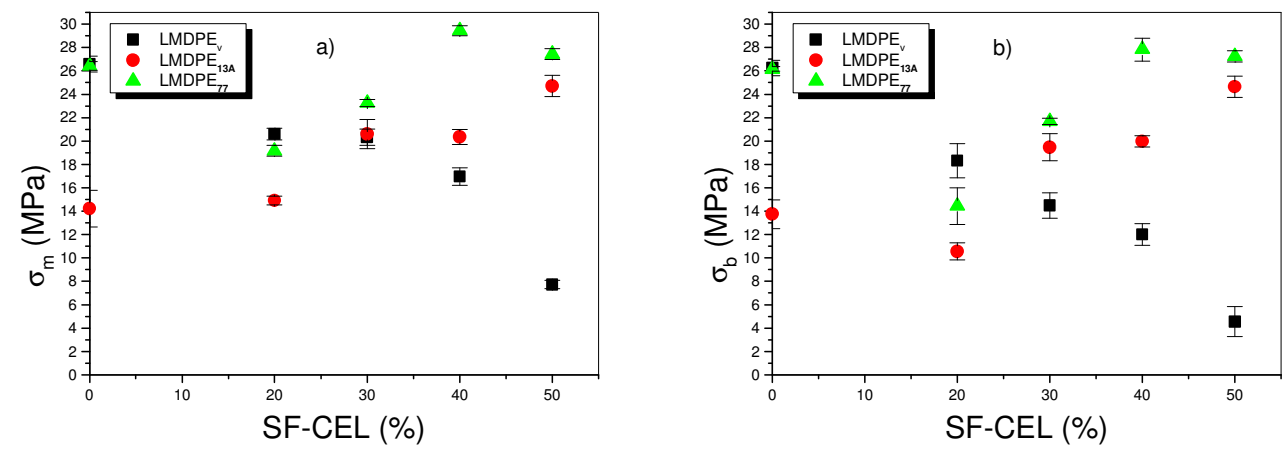

Figura 40 - (a) $\sigma_{m}$ em função da proporção da SF-CEL e (b) $\sigma_{b}$ em função da proporção da SF-CEL, usando LMDPE ${ }_{v}, L_{M D P E}$ e LMDPE $_{77}$.

Na Figura 41(a) é mostrado o E em função da proporção da SF-CEL e na Figura 41(b) é mostrada a $\varepsilon_{b}$ em função da proporção da SF-CEL, para os compósitos obtidos a partir das amostras do LMDPE $_{13 \mathrm{~A}}, \mathrm{LMDPE}_{77} \mathrm{e}$ LMDPE $_{\mathrm{v}}$. De modo geral, os valores de $\mathrm{E}$ aumentam com o aumento da proporção da SF-CEL. Para as proporções de SF-CEL entre 30\% e 50\%, os compósitos obtidos a partir do LMDPE $_{77}$ são os que apresentam os maiores valores de E. Porém, com 50\% de SF-CEL, o compósito obtido com LMDPE$_{25}$ apresenta o maior valor de $\mathrm{E}(1,10 \mathrm{GPa})$. Contudo, isso não está ilustrado na Figura 41(a). No caso da $\varepsilon_{b}$, há uma queda drástica dessa propriedade já com 20\% de SF-CEL. Mas, mesmo assim, é nítido que, dentre os compósitos, aqueles obtidos com LMDPE $_{77}$ são os que apresentam os maiores valores de $\varepsilon_{b}$, quando a proporção de SF-CEL varia de $20 \%$ a $50 \%$, exceto para o ensaio com $30 \%$ de SF-CEL. 

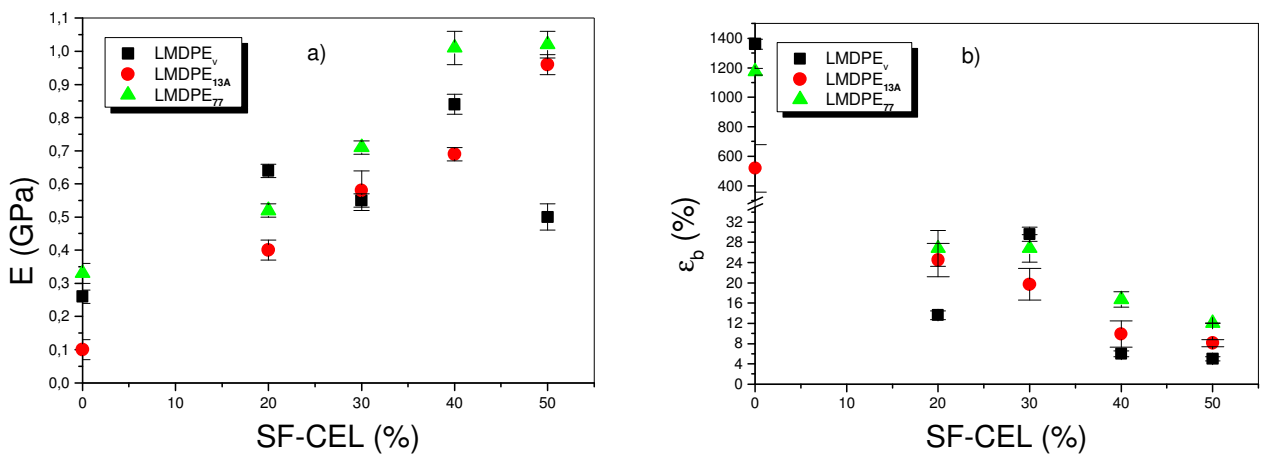

Figura 41 - (a) E em função da proporção da SF-CEL e (b) $\varepsilon_{b}$ em função da

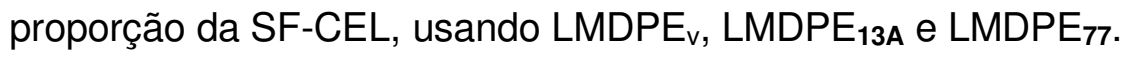

Para a $\varepsilon_{y}$, quando se comparam os valores observados para os compósitos obtidos com LMDPE virgem ou funcionalizado (Tabelas 14 e 15) com aqueles observados para o LMDPE virgem (Tabela 13), observa-se queda média de $\sim 80 \%$, quando a proporção da SF-CEL é $20 \%$. Dentre os compósitos, aqueles obtidos com LMDPE $_{77}$ foram os que apresentaram os maiores valores de $\varepsilon_{y}$, no intervalo entre $30 \%$ e $50 \%$ de SF-CEL.

A performance dos compósitos obtidos com $\operatorname{LMDPE}_{13 \mathrm{~A}}(\mathrm{GF}=0,74 \%$ ), aparentemente, foi sensivelmente afetada pela baixa resistência das amostras de partida do LMDPE $_{13 \mathrm{~A}}$ (ver na Tabela 13 os valores obtidos para o ensaio 13).

É digno de nota a performance exibida pelos compósitos (30\% a 50\% de SF-CEL) contendo LMDPE $_{77}$ nas suas formulações, apesar do valor de GF obtido para ele ser de apenas 0,28\%.

Aqui, vale a pena comentar a observação feita durante a obtenção dos filmes (a partir da amostra do ensaio 77) por "casting" (item 3.2.6) para a realização dos ensaios no FTIR, e subseqüente determinação do GF (item 3.2.7). Após a secagem (por $10 \mathrm{~min} a \sim 140^{\circ} \mathrm{C}$ ) do conjunto formado pela "placa de Petri (vidro) + filme" foi necessário deixar o filme em contato com 
água por até 10 dias, para poder remove-lo da placa, por causa da forte aderência do filme ao fundo da placa (de vidro). Indicando, assim, uma possível interação entre os grupos epóxidos inseridos nas cadeias poliméricas e os grupos silanóis do vidro. Comportamento similar foi observado também para o ensaio 13A. Normalmente, o tempo de contato do filme, de amostras funcionalizadas, com água, necessário para facilitar a sua remoção da placa, foi de $\sim 4 \mathrm{~h}$ a $8 \mathrm{~h}$ (em alguns casos isolados, de 1 a 2 dias). Já o do filme de amostras não funcionalizadas, de $\sim 2 \mathrm{~h}$.

\subsubsection{Compósitos obtidos com celuloses fibras média e longa}

Nesta investigação, a proporção dos polissacarídeos usada foi de $20 \%$. No entanto, também foram obtidos compósitos com 30\% de MF-CEL. Como matrizes poliméricas foram usadas as amostras do $\operatorname{LMDPE}_{13 \mathrm{~A}}(\mathrm{GF}=$ 0,74\%) e LMDPE 77 (GF = 0,28\%), bem como as do $\mathrm{LMDPE}_{\mathrm{v}}$, para servirem como controles. Como polissacarídeos foram usados a MF-CEL (comp. = 0,6 mm), LF-CEL (comp. = 1,5 mm) e ULF-CEL (comp. = 1,4 mm). O interesse aqui reside na avaliação das influências do comprimento da fibra e da presença de lignina (na celulose não-branqueada) na performance do compósito. Porém, é preciso ter em mente que as duas amostras de celulose fibra longa são de procedências distintas. As propriedades mecânicas obtidas para os compósitos preparados com SF-CEL (comp. = 0,13 mm), ver Tabelas 14 e 15, foram usadas para comparação.

Nas Tabelas 16 e 17 são mostrados os valores médios obtidos de resistência à tração, elongação e módulo de Young, junto com os respectivos desvios padrões das médias. 
Tabela 16 - Propriedades mecânicas dos compósitos obtidos com LMDPE $_{\mathrm{V}}$ e MF-CEL, LF-CEL ou ULF-CEL (controles).

\begin{tabular}{|c|c|c|c|c|c|c|}
\hline Ensaio & $\begin{array}{c}\boldsymbol{\sigma}_{\mathbf{y}} \\
(\mathrm{MPa})\end{array}$ & $\begin{array}{l}\varepsilon_{y} \\
(\%)\end{array}$ & $\begin{array}{c}\boldsymbol{\sigma}_{\mathbf{m}} \\
(\mathrm{MPa})\end{array}$ & $\begin{array}{c}\sigma_{\mathbf{b}} \\
(\mathrm{MPa})\end{array}$ & $\begin{array}{l}\varepsilon_{\mathrm{b}} \\
(\%)\end{array}$ & $\begin{array}{c}\mathbf{E} \\
(\mathrm{GPa})\end{array}$ \\
\hline 66 (80\%LMDPEv/20\%MF-CEL) & $17 \pm 1$ & $4,9 \pm 0,3$ & $19,8 \pm 0,4$ & $17,9 \pm 0,3$ & $25 \pm 3$ & $0,53 \pm 0,02$ \\
\hline 98 (70\%LMDPEV/30\%MF-CEL) & $17,6 \pm 0,9$ & $4,0 \pm 0,3$ & $20,5 \pm 0,8$ & $20,0 \pm 0,8$ & $10 \pm 1$ & $0,77 \pm 0,02$ \\
\hline 67 (80\%LMDPEV/20\%LF-CEL) & $19,2 \pm 0,1$ & $4,9 \pm 0,2$ & $20,1 \pm 0,3$ & $18,5 \pm 0,7$ & $23 \pm 6$ & $0,55 \pm 0,01$ \\
\hline 68 (80\%LMDPEV/20\%ULF-CEL) & $18,9 \pm 0,5$ & $5,1 \pm 0,3$ & $19,9 \pm 0,3$ & $18,6 \pm 0,8$ & $25 \pm 4$ & $0,55 \pm 0,01$ \\
\hline
\end{tabular}

onde $\sigma$ é a resistência à tração no ponto de escoamento $(\mathrm{y})$, máxima (m) e na ruptura (b); $\varepsilon$ é a elongação no ponto de escoamento (y) e na ruptura (b); E é o módulo de Young.

Tabela 17 - Propriedades mecânicas dos compósitos obtidos com LMDPE e MF-CEL, LF-CEL ou ULF-CEL.

\begin{tabular}{|c|c|c|c|c|c|c|}
\hline Ensaio & $\begin{array}{c}\sigma_{y} \\
(\mathrm{MPa})\end{array}$ & $\begin{array}{l}\varepsilon_{y} \\
(\%)\end{array}$ & $\begin{array}{c}\boldsymbol{\sigma}_{\mathbf{m}} \\
(\mathrm{MPa})\end{array}$ & $\begin{array}{c}\sigma_{\mathrm{b}} \\
(\mathrm{MPa})\end{array}$ & $\begin{array}{l}\varepsilon_{b} \\
(\%)\end{array}$ & $\begin{array}{c}\mathbf{E} \\
(\mathrm{GPa})\end{array}$ \\
\hline 87 (80\%LMDPE $\left.{ }_{13 A} / 20 \% M F-C E L\right)$ & $19 \pm 1$ & $5,5 \pm 0,2$ & $21 \pm 1$ & $20 \pm 1$ & $26 \pm 3$ & $0,56 \pm 0,03$ \\
\hline 96 (80\%LMDPE & $19,1 \pm 0,3$ & $5,5 \pm 0,2$ & $22,2 \pm 0,7$ & $19,8 \pm 0,8$ & $31 \pm 4$ & $0,58 \pm 0,03$ \\
\hline 97 (70\%LMDPE & $21,4 \pm 0,9$ & $4,3 \pm 0,4$ & $26,8 \pm 0,9$ & $27 \pm 1$ & $13 \pm 1$ & $0,81 \pm 0,02$ \\
\hline 88 (80\%LMDPE $E_{13 A} / 20 \%$ LF-CEL) & $17,6 \pm 0,2$ & $5,3 \pm 0,4$ & $19,2 \pm 0,4$ & $18,5 \pm 0,5$ & $23 \pm 3$ & $0,53 \pm 0,01$ \\
\hline 89 (80\%LMDPE ${ }_{13 \alpha} / 20 \%$ ULF-CEL) & $19,6 \pm 0,6$ & $5,5 \pm 0,3$ & $21 \pm 1$ & $20,8 \pm 0,7$ & $22 \pm 3$ & $0,58 \pm 0,05$ \\
\hline
\end{tabular}

onde $\sigma$ é a resistência à tração no ponto de escoamento $(\mathrm{y})$, máxima $(\mathrm{m})$ e na ruptura (b); $\varepsilon$ é a elongação no ponto de escoamento $(\mathrm{y})$ e na ruptura (b); E é o módulo de Young.

Para ilustração, na Figura 42 são mostradas as curvas de $\sigma$ em função de $\varepsilon$ para os ensaios 68, 89, 97 e 98. Os compósitos obtidos aqui também apresentam o mesmo comportamento à fratura que os obtidos com SF-CEL (Figura 38, item 4.4.2). 


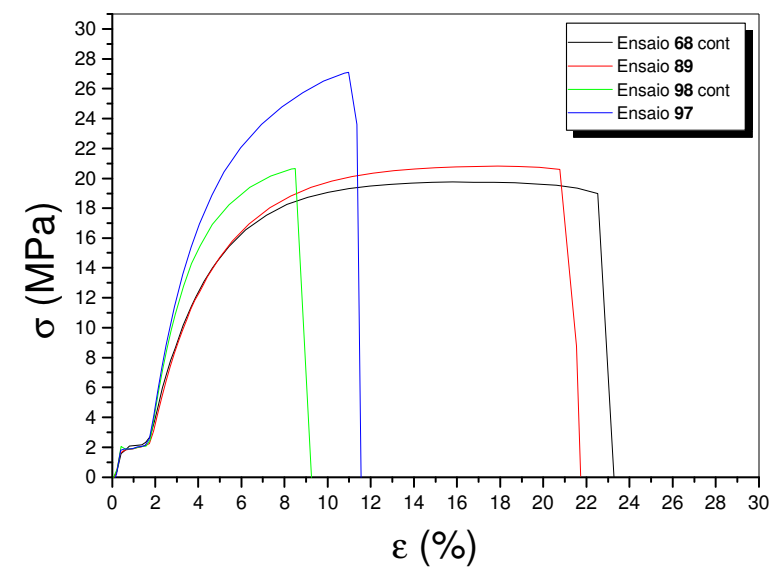

Figura 42 - Curvas da $\sigma$ em função da $\varepsilon$ para os ensaios 68, 89, 97 e 98.

Para a avaliar o efeito do comprimento da fibra e da lignina, do polissacarídeo, na performance do compósito, a Figura 43(a) mostra a $\sigma_{y}$ em função do comprimento da fibra, a Figura 43(b) mostra a $\sigma_{m}$ em função do comprimento da fibra e a Figura 43(c) mostra o E em função do comprimento da fibra. Os valores foram observados para os compósitos obtidos com

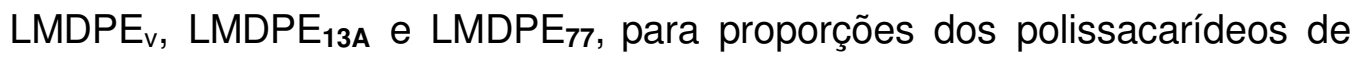
$20 \%$ e $30 \%$. 

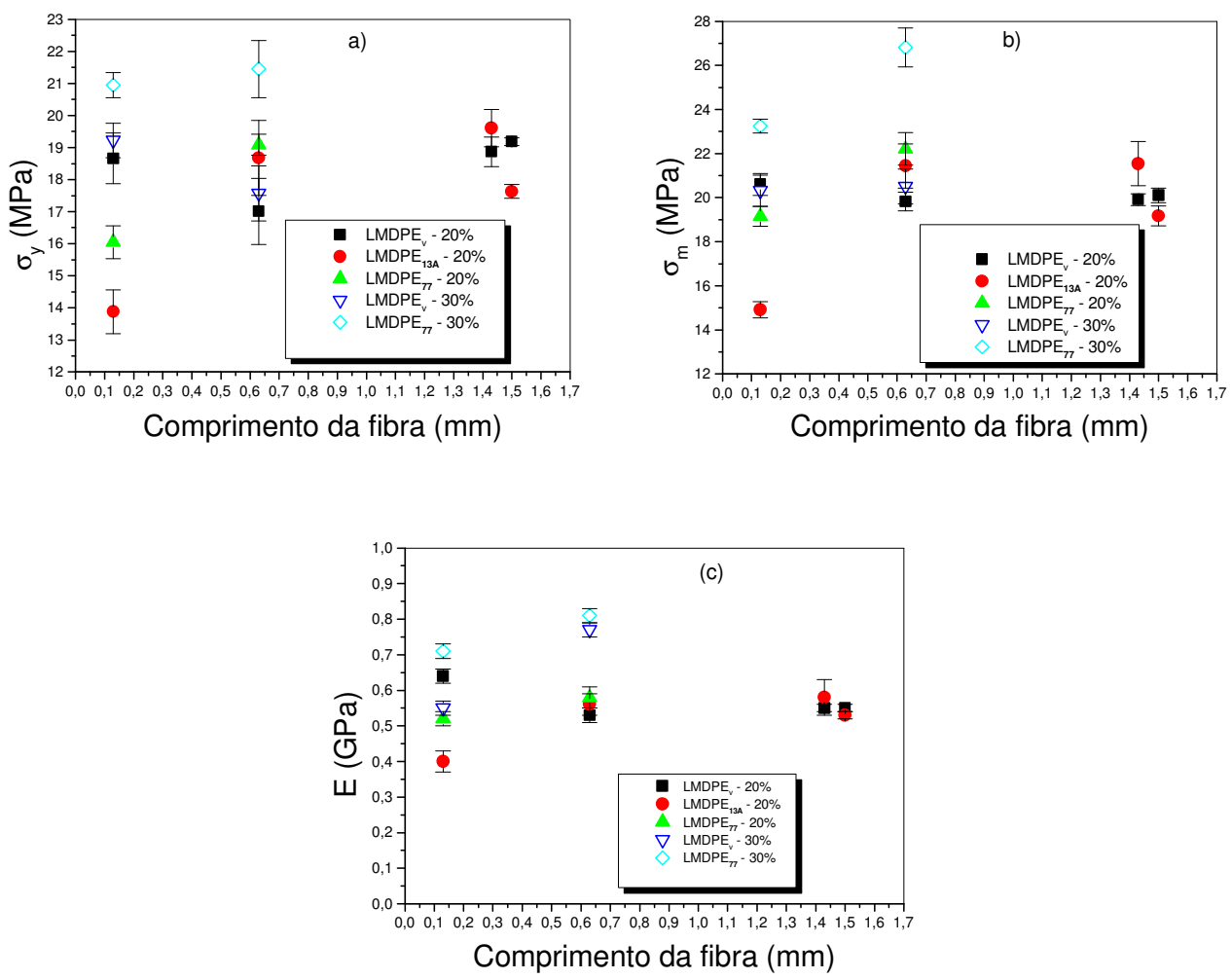

Figura 43 - (a) $\sigma_{y}$ em função do comprimento da fibra, (b) $\sigma_{m}$ em função do comprimento da fibra e (c) E em função do comprimento da fibra, para proporções dos polissacarídeos de $20 \%$ (símbolos fechados) e $30 \%$ (símbolos abertos).

Para os compósitos obtidos com LMDPE $\mathrm{v}_{\mathrm{v}}$, o $\sigma_{\mathrm{y}}$ e $\sigma_{\mathrm{m}}$, no geral, sofrem pequena influência do comprimento da fibra. Quanto aos obtidos com $L_{M D P E}{ }_{13 A}$ e $L_{M D P E}$, eles sofrem uma significativa influência do comprimento da fibra, porém atingindo um máximo quando o comprimento da fibra é de 0,6 mm (MF-CEL). É digno de nota o fato do valor obtido de $\sigma_{\mathrm{m}}$ para o compósito "70\%LMDPE ${ }_{77} / 30 \%$ MF-CEL" (ensaio 97, Tabela 17) ser de 26,8 MPa, além de ser maior que o do compósito "70\%LMDPE ${ }_{77} / 30 \%$ SFCEL", 23,2 MPa (ensaio 83, Tabela 15), é comparável ao valor obtido para a placa do LMDPE virgem, 26,6 MPa (Tabela 13), mas com valor de E bem maior, 0,81 GPa contra 0,26 GPa. 
Quando se comparam os compósitos obtidos com LF-CEL (comp. = 1,5 mm) com aqueles obtidos com ULF-CEL (comp. = 1,4 mm), em ambos usando LMDPE $E_{13 A}$, os valores observados de $\sigma_{y}, \sigma_{m}$ e $E$ são ligeiramente maiores para os compósitos obtidos com ULF-CEL. Assim, a presença de lignina, aparentemente, favorece de forma não significativa a performance do compósito (em termos de $\sigma_{\mathrm{y}}, \sigma_{\mathrm{m}}$ e E).

Neste estudo, o maior valor de E (0,81 GPa) é observado para o compósito obtido com LMDPE$_{77}$ e $30 \%$ de MF-CEL. Os valores de E são maiores para os compósitos obtidos com MF-CEL, em relação aos obtidos com SF-CEL, independentemente da matriz polimérica ser LMDPE $_{13 \mathrm{~A}}$ ou LMDPE$_{77}$.

\subsubsection{Blendas obtidas com acetato-butirato de celulose}

Aqui, a proporção de BUT-CEL (pó, com diâm. = 0,06 mm) usada foi de $20 \%$ e $40 \%$ e as amostras de LMDPE $_{12}$ (GF = 0,23\%), LMDPE 77 (GF = $0,28 \%$ ) e LMDPE $E_{v}$ foram usadas como matrizes poliméricas. Diferentemente dos compósitos obtidos com celulose, as blendas obtidas com BUT-CEL não apresentaram problemas com presença de bolhas. O BUT-CEL, provavelmente, é menos higroscópico que a celulose, por conter menos grupos hidroxilas livres.

Na Tabela 18 são mostrados os valores médios obtidos de resistência à tração, elongação e módulo de Young, bem como os respectivos desvios padrões das médias. 
Tabela 18 - Propriedades mecânicas das blendas obtidas com LMDPE

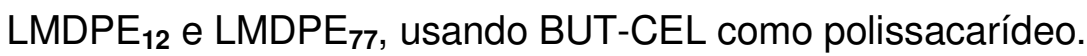

\begin{tabular}{|c|c|c|c|c|c|c|}
\hline Ensaio & $\begin{array}{c}\sigma_{\mathbf{y}} \\
(\mathrm{MPa})\end{array}$ & $\begin{array}{l}\varepsilon_{y} \\
(\%)\end{array}$ & $\begin{array}{c}\sigma_{\mathbf{m}} \\
(\mathrm{MPa})\end{array}$ & $\begin{array}{c}\boldsymbol{\sigma}_{\mathbf{b}} \\
(\mathrm{MPa})\end{array}$ & $\begin{array}{c}\varepsilon_{b} \\
(\%)\end{array}$ & $\begin{array}{c}\mathbf{E} \\
(\mathrm{GPa})\end{array}$ \\
\hline 73 (80\%LMDPEV/20\%BUT-CEL) & $13 \pm 2$ & $14,7 \pm 0,7$ & $13 \pm 2$ & $12 \pm 3$ & $676 \pm 312$ & $0,39 \pm 0,02$ \\
\hline 76 (80\%LMDPE & $12,6 \pm 0,2$ & $4,6 \pm 0,3$ & $12,9 \pm 0,4$ & $3 \pm 1$ & $18 \pm 3$ & $0,42 \pm 0,03$ \\
\hline 94 (60\%LMDPEV/40\%BUT-CEL) & $8 \pm 1$ & $3,6 \pm 0,4$ & $10 \pm 1$ & $4 \pm 2$ & $20 \pm 6$ & $0,38 \pm 0,03$ \\
\hline 92 (60\% LMDPE $_{12} / 40 \%$ BUT-CEL) & $18,1 \pm 0,7$ & $5,0 \pm 0,2$ & $19,9 \pm 0,7$ & $19,9 \pm 0,7$ & $7,5 \pm 0,5$ & $0,58 \pm 0,04$ \\
\hline
\end{tabular}

onde $\sigma$ é a resistência à tração no ponto de escoamento $(\mathrm{y})$, máxima $(\mathrm{m})$ e na ruptura (b); $\varepsilon$ é a elongação no ponto de escoamento (y) e na ruptura (b); E é o módulo de Young.

Na Figura 44 são mostradas as curvas da $\sigma$ em função da $\varepsilon$ para os ensaios 73, 76, 92 e 94 . O comportamento à fratura das blendas obtidas com BUT-CEL varia desde dúctil (com formação de pescoço, seguido de estiramento a frio, ensaio 73; com formação de pescoço, mas sem estiramento a frio, ensaios 76 e 94) até frágil (ensaio 92).

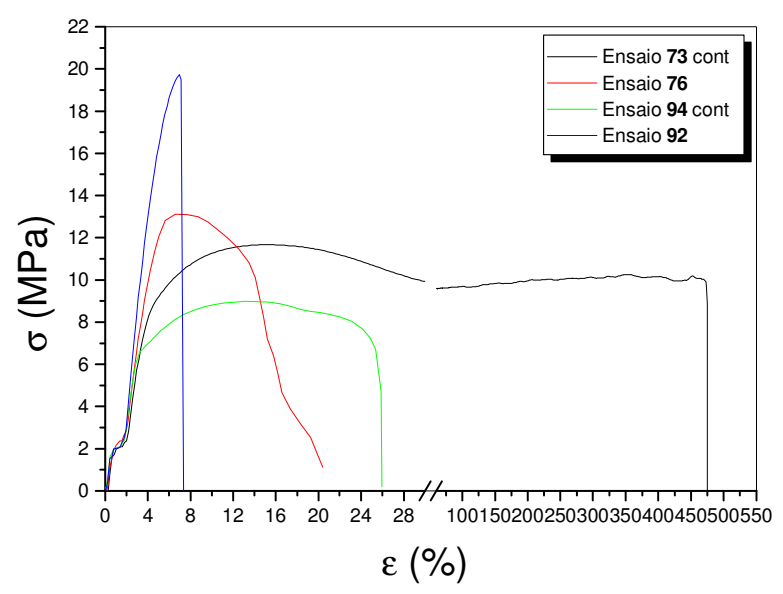

Figura 44 - Curvas da $\sigma$ em função da $\varepsilon$ para os ensaios 73, 76, 92 e 94. 
Pode-se notar que, quando a quantidade de BUT-CEL é aumentada de $20 \%$ para $40 \%$, os valores de $\sigma_{m}$ e $E$ da blenda obtida com LMDPE $_{12}$ também aumentam (Figuras 45a e 45b, respectivamente). O aumento de $\sigma$ e E com o aumento da proporção de polissacarídeo também foi visto nas investigações dos compósitos obtidos com celulose (SF-CEL e MF-CEL) e LMDPE funcionalizado. É digno de nota o valor bem baixo de $\varepsilon_{b}$ obtido no ensaio "80\%LMDPE $77 / 20 \% B U T-C E L "(18 \%)$, em relação àquele obtido para o ensaio "80\%LMDPE $/ 20 \%$ BUT-CEL" (676\%). Não obstante, este ter apresentado uma dispersão (da média) bem grande $( \pm 312 \%)$.
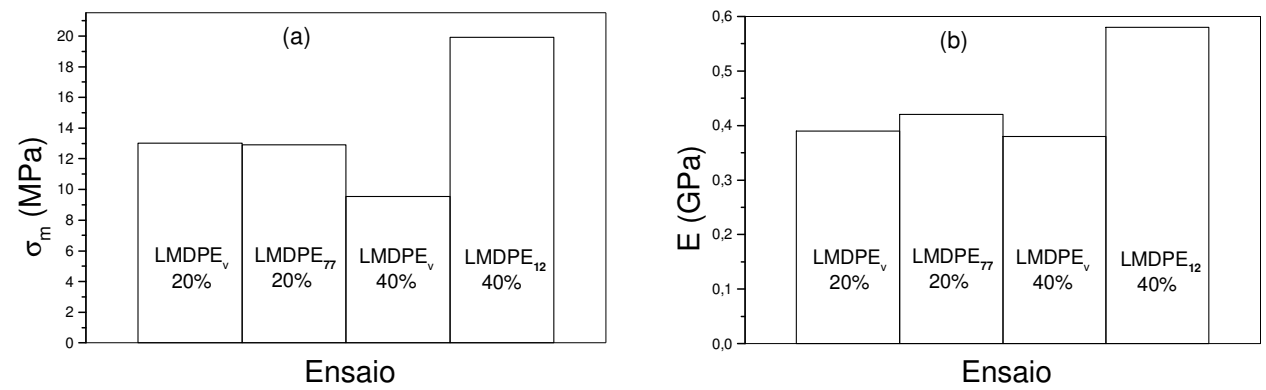

Figura $45-(a) \sigma_{m}$ e (b) E dos ensaios apresentados na Tabela 18.

\subsubsection{Caracterização por SEM}

Os compósitos e a blenda que apresentaram as melhores performances quanto à resistência à tração e módulo de Young foram selecionados para o estudo, por SEM, da interface matriz polimérica e polissacarídeo. O intuito é buscar mais evidência que corrobore a efetividade do LMDPE funcionalizado de melhorar a adesão entre as duas fases por meio da interação favorável dos grupos epóxidos inseridos nas cadeias poliméricas e os grupos hidroxilas presentes no polissacarídeo. 
Os compósitos selecionados foram os dos ensaios $\mathbf{6 4}$ (70\%LMDPE $/$ / $30 \%$ SF-CEL), controle, 83 (70\%LMDPE (60\%LMDPE ${ }_{77} / 40 \%$ SF-CEL), $\quad 95$ (50\%LMDPE $77 / 50 \%$ SF-CEL) $\quad$ e $\quad 97$ (70\%LMDPE $77 / 30 \%$ MF-CEL). A blenda selecionada foi a do ensaio 92 (60\%LMDPE $12 / 40 \%$ BUT-CEL).

As micrografias de SEM estão ilustradas na Figura 46. A boa adesão entre a matriz polimérica (LMDPE funcionalizado) e as fibras de celulose também é evidenciada por SEM, pois as fibras de celulose aparecem embebidas pela matriz polimérica, explicando a boa performance dos compósitos obtidos com LMDPE funcionalizado. A micrografia do ensaio 64 (controle), ver Figura 46(a), não mostra uma boa adesão entre as duas fases. A micrografia do ensaio 83 (Figura 46b) ilustra uma situação em que aparecem fibras completamente aderidas à matriz polimérica, e outra, em que aparecem parcialmente aderidas. Compreensível, em vista do valor de GF obtido para 0 ensaio $\mathrm{LMDPE}_{77}$ ter sido relativamente baixo (GF = 0,28\%). A micrografia do ensaio 92 (Figura 46f) mostra que a adesão interfacial entre a matriz e o BUT-CEL (na blenda) não é boa e que ocorreu coalescência das partículas de BUT-CEL. 

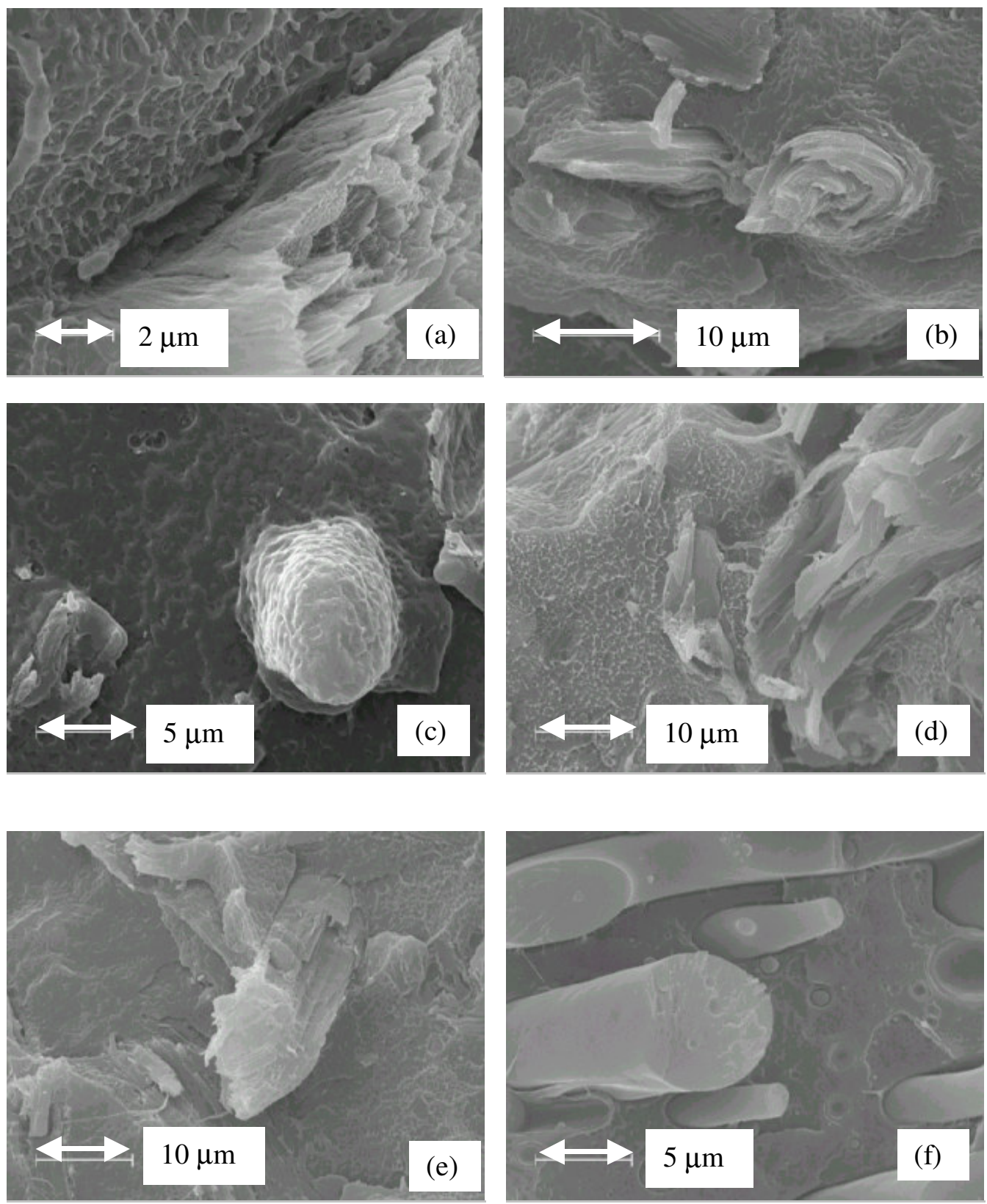

Figura 46 - Micrografias de SEM dos ensaios (a) 64, (b) 83, (c) 90, (d) 95, (e) 97 e (f) 92. 


\subsubsection{Extração em xileno sob refluxo}

A interação favorável entre os grupos epóxidos inseridos nas cadeias do LMDPE e os grupos hidroxilas presentes no polissacarídeo pode ser de natureza química e/ou física. Se for química, se deve à reação (típica) entre os grupos epóxidos e grupos hidroxilas, que ocasiona a abertura dos anéis epóxidos. Como resultado final, temos, então, a adição dos grupos hidroxila (da celulose) aos grupos epóxidos (inseridos nas cadeias do LMDPE). Se for física, é devido à formação de ligações de hidrogênio entre eles. Com o intuito de avaliar qual é a natureza dessas interações, quatro amostras de compósitos foram submetidas à extração em xileno sob refluxo. A partir das massas inicial e final (seca) a porcentagem de resíduo (material não extraído) foi determinada (Tabela 19). O LMDPE (virgem ou funcionalizado) é completamente solúvel em xileno quente, porém, a celulose é insolúvel. Caso a natureza da interação fosse química, então a porcentagem de resíduo teria que ser maior do que a proporção inicial de polissacarídeo, pois uma parte do LMDPE (funcionalizado) estaria ligada quimicamente à celulose e não seria extraída.

Tabela 19 - Quantidades de resíduos remanescentes após extração em xileno sob refluxo.

\begin{tabular}{|c|c|c|}
\hline Ensaio & $\begin{array}{c}\text { Duração da } \\
\text { extração (h) }\end{array}$ & $\begin{array}{c}\text { Quantidade de } \\
\text { resíduo (\%) }\end{array}$ \\
\hline $74\left(60 \% L_{M D P E} / 40 \% S F-C E L\right)$ - controle & 6,5 & 4,5 \\
\hline \multirow[t]{2}{*}{90 (60\%LMDPE $\left.{ }_{77} / 40 \% S F-C E L\right)$} & 6,5 & 27,8 \\
\hline & 6,5 & 42,9 \\
\hline \multirow[t]{3}{*}{98 (70\%LMDPE $\left.E_{\mathrm{v}} / 30 \% \mathrm{MF}-\mathrm{CEL}\right)$ - controle } & 13 & 25,7 \\
\hline & 19,5 & 7,4 \\
\hline & 13 & 50,7 \\
\hline \multirow[t]{2}{*}{97 (70\%LMDPE $\left.\mathrm{F}_{77} / 30 \% \mathrm{MF}-\mathrm{CEL}\right)$} & 19,5 & 40,6 \\
\hline & 26 & 24,2 \\
\hline
\end{tabular}

${ }^{\mathrm{a}} \mathrm{O}$ xileno foi trocado a cada $6,5 \mathrm{~h}$. 
Não foi possível obter as massas finais até massa constante, possivelmente porque a malha (de tamanho desconhecido) da tela de poliéster (comercial), usada para envolver as amostras durante a extração, não deve ser "fechada" o suficiente para impedir a passagem da celulose através dela. A quantidade de resíduo do controle obtido com celulose de maior comprimento das fibras (42,9\%) é maior do que aquela com celulose de menor comprimento (4,5\%), evidenciando a inadequabilidade da abertura da malha da tela usada. Assim, não foi possível distinguir a natureza da interação por esta metodologia. No entanto, ficou mais uma vez evidenciada a interação favorável entre os grupos epóxidos inseridos nas cadeias do LMDPE e os grupos hidroxilas presentes na SF-CEL e MF-CEL.

Na Figura 47 são mostrados os espectros no FTIR dos ensaios 74 (60\%LMDPE $/ \mathrm{v} / 40 \%$ SF-CEL) e 90 (60\%LMDPE $77 / 40 \%$ SF-CEL), da Tabela 19, junto com os do LMDPE virgem e da SF-CEL. Como pode ser observado, não há praticamente diferença entre os espectros dos ensaios 74 (controle) e 90. Os espectros dos ensaios 74 e 90, assim como o da SF-CEL, foram obtidos a partir da mistura da amostra com KBr. Já o do LMDPE virgem, a partir do filme. 


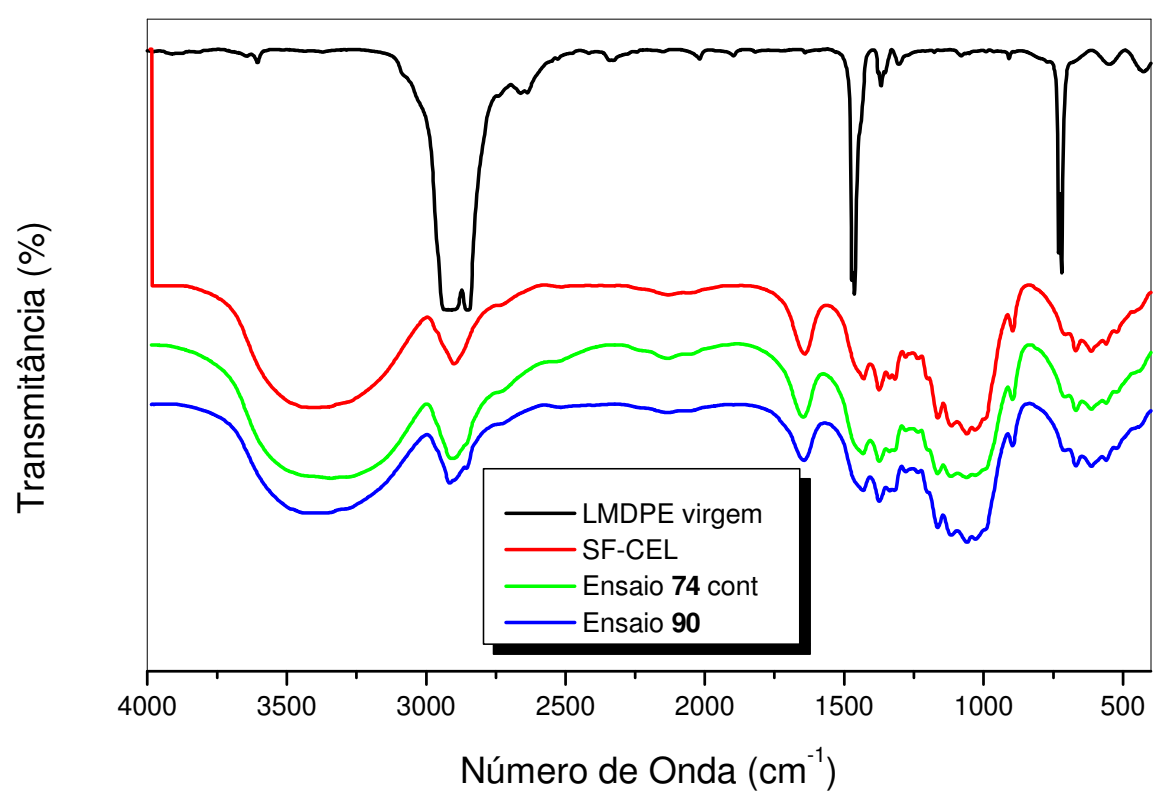

Figura 47 - FTIR do LMDPE virgem, da SF-CEL e dos resíduos remanescentes após extração em xileno sob refluxo (os ensaios 74 e 90, da Tabela 19). 


\section{CONCLUSÃO}

$\mathrm{Na}$ funcionalização em solução, a técnica por FTIR foi a única a ser empregada para evidenciar a ocorrência de funcionalização do LMDPE com AGE, na presença de BPO. Os valores de GF variaram de 0,21\% a 0,47\% e os de EF de 0,42\% a 0,94\%. O uso de um solvente (clorobenzeno) mau doador de átomos de hidrogênio favoreceu a funcionalização, independentemente da temperatura e tempo de reação, nas condições estudadas.

Na funcionalização superficial por radiação UV, houve uma redução relativa de $6^{0}$ no $\theta_{\text {avanço }}$ medido de uma placa de LMDPE tratada com THFAH e BPO. Tal redução é ligeiramente maior que o erro experimental global médio $\left(5^{0}\right)$, sugerindo que a evidência de que a funcionalização é fraca.

Na funcionalização por processamento reativo, a funcionalização do LMDPE com AGE, na presença de BPO, foi evidenciada por FTIR. Os valores de GF variaram de $0,23 \%$ a $0,74 \%$ e os de EF de $1,4 \%$ a 3,7\%. Os valores de GF (e EF) obtidos aqui, assim como aqueles obtidos na funcionalização em solução, são relativamente baixos, mostrando a dificuldade na funcionalização do LMDPE com o monômero AGE, consistente com a baixa reatividade apresentada pelos éteres alílicos. ${ }^{63-65} \mathrm{O}$ $\chi_{\mathrm{c}}$, determinado por DSC, diminuiu com o aumento do GF, indicando aumento do grau de desorganização das cadeias poliméricas atribuído à inserção fortuita de moléculas de AGE nas cadeias de LMDPE. Incrementos das quantidades de AGE e BPO favorecem o GF. No entanto, quando a quantidade de AGE (\%AGE/LMDPE) é $20 \%$ e a razão molar entre AGE e BPO é 10, como no caso do ensaio 13 (e 13A), há evidências (por diminuição relativa do torque e das propriedades mecânicas) de que tenham ocorrido fragmentação das cadeias do LMDPE. Os compósitos e blendas obtidos com LMDPE funcionalizado apresentaram valores de $\sigma$ e $E$ maiores 
do que aqueles obtidos com LMDPE virgem, podendo ser atribuído a um aumento na adesão entre a matriz polimérica modificada quimicamente e o polissacarídeo. No caso dos compósitos, esse aumento na adesão também pôde ser evidenciado por SEM e, de uma maneira qualitativa, pelas quantidades relativamente superiores dos resíduos que sobraram depois da extração em xileno sob refluxo. No geral, os valores de $\sigma$ e $E$ dos compósitos obtidos com LMDPE funcionalizado aumentam com 0 incremento da proporção de SF-CEL (de $30 \%$ para 50\%), incremento do comprimento da fibra de 0,13 $\mathrm{mm}$ (SF-CEL) para 0,6 mm (MF-CEL) e presença de lignina, porém, esta provoca aumentos discretos. Os valores de $\sigma$ e $E$ das blendas obtidas com LMDPE funcionalizado aumentam com 0 aumento da proporção de BUT-CEL. Comparando-se os valores de $\sigma_{y}, \sigma_{m}$ e E de dois compósitos "60\%LMDPE $77 / 40 \%$ SF-CEL" (Tabela 15, item 4.4.2) e "70\%LMDPE $77 / 30 \%$ MF-CEL" (Tabela 17, item 4.4.3), com aqueles obtidos para o $L_{M D P E}$ (Tabela 13, item 4.4.1), observam-se aumentos relativos de $68 \%\left(\sigma_{y}\right), 11 \%\left(\sigma_{m}\right)$ e $288 \%(E)$, para o primeiro, e $42 \%\left(\sigma_{y}\right), 1 \%\left(\sigma_{m}\right)$ e $212 \%$ (E), para o segundo. Salta aos olhos o aumento acentuado no E, sem contar o fato que para muitas aplicações, valores superiores de $\sigma_{y}$ são mais importantes que $\sigma_{\mathrm{m}}$. 


\section{REFERÊNCIAS BIBLIOGRÁFICAS}

(1) ROBERTS, G.A.F. Chitin Chemistry. The Macmillan Press Ltd, 1982.

(2) FROLliNI, E.; LEÃO, A.; MATTOSO, L.H.C. Natural Polymers and Agrofibers Based Composites. São Carlos: Embrapa Instrumentação Agropecuária, 2000.

(3) (a) KROSCHWITZ, J.I. (Ed.). Encyclopedia of Polymer Science and Engineering. 2. ed. New York: Wiley, 1985. v. 6, p. 383-513. (b) ibid., v. 3, p. 158-235. (c) ibid., v. 1, p. 476-486. (d) ibid., v. 4, p. 494-504. (e) ibid., v. 8, p. 69-92.

(4) WU, S. Polymer Interface and Adhesion. New York: Dekker, 1982.

(5) KARNANI, R.; KRISHNAN, M.; NARAYAN, R. Polym. Eng. Sci., 1997, 37,476 .

(6) QIU, W.; ZHANG, F.; ENDO, T.; HIROTSU, T. J. Appl. Polym. Sci., 2003, 87, 337.

(7) DE ROOVER, B.; SCLAVONS, M.; CARLIER, V.; DEVAUX, J.; LeGrAS, R.; MOMtAZ, A. J. Polym. Sci. Part A: Polym., Chem. 1995, 33, 829.

(8) MACHADO, A.V.; COVAS, J.A.; DUIN, M.V. Polymer, 2001, 42, 3649.

(9) MARCOVICH, N.E.; VILLAR, M.A. J. Appl. Polym. Sci., 2003, 90, 2775.

(10) BALASURIYA, P.W.; YE, L.; MAI, Y.W.; WU, J. J. Appl. Polym. Sci., 2002, 83, 2505.

(11) SCLAVONS, M.; FRANQUINET, P.; CARLIER, V.; VERFAILLIE, G.; FALLAIS, I.; LEGRAS, R.; LAURENT, M.; THYRION, F.C. Polymer, 2000, 41, 1989. 
(12) HUANG, H.L.; YAO, Z.H.; YANG, J.H.; WANG, Y.; SHI, D.A.; YIN, J.H. J. Appl. Polym. Sci., 2001, 80, 2538.

(13) OLIPHANT, K.E.; RUSSELL, K.E.; BAKER, W.E. Polymer, 1995, 36, 1597.

(14) PESETSKI, S.S.; JURKOWSKI, B.; KRIVOGUZ, Y.M.; KELAR, K. Polymer, 2001, 42, 469.

(15) GABOYARD, M.; ROBIN, J.J.; HERVAUD, Y.; BOUTEVIN, B. J. Appl. Polym. Sci., 2002, 86, 2011.

(16) CAMPOS, P.G.S.; FANTINI, M.C.A.; PETRI, D.F.S. J. Braz. Chem. Soc., 2004, 15, 532.

(17) HUANG, H.; LIU, N.C. J. Appl. Polym. Sci., 1998, 67, 1957.

(18) TORReS, N.; ROBIN, J.J.; BOUTEVIN, B. J. Appl. Polym. Sci., 2001, 81,581

(19) SUN, Y.J.; HU, G.H.; LAMBLA, M. Angew. Makromol. Chem., 1995, $229,1$.

(20) PAPKE, N.; KOCSIS, J.K. J. Appl. Polym. Sci., 1999, 74, 2616.

(21) SÈBE, G.; BROOK, M.A. Wood Sci. Technol., 2001, 35, 269.

(22) SOlPAN, D.; GÜVEN, O. J. Appl. Polym. Sci., 1999, 71, 1515.

(23) SUN, Y.J.; HU, G.H.; LAMBLA, M. Polymer, 1996, 37, 4119.

(24) CHEN, L.F.; WONG, B.; BAKER, W.E. Polym. Eng. Sci., 1996, 36, 1594.

(25) PESneAu, I.; CHAMPAGne, M.F.; HUneAUlt, M.A. J. Appl. Polym. Sci., 2004, 91, 3180. 
(26) (a) SAUNDERS, K.J. Organic Polymer Chemistry. 2.ed. Londres: Chapman and Hall, 1988. cap. 2, p. 48-60. (b) ibid., cap. 13, p. 307.

(27) BRYDSON, J.A. Plastic Materials. 6.ed. Boston: ButterworthHeinemann, 1995. cap. 10, p. 201-239.

(28) HAMIELEC, A.E.; SOARES, J.B.P. Prog. Polym. Sci., 1996, 21, 651.

(29) (a) LUCAS, E.F.; SOARES, B.G.; MONTEIRO, E.E.C. Caracterização de Polímeros. Rio de Janeiro: E-Papers, 2001. cap. 10, p. 247-285. (b) ibid., cap. 9, p. 217-245.

(30) SPERLING, L.H. Introduction to Physical Polymer Science. 2.ed. New York: Wiley, 1992. cap. 5, p. 122-177.

(31) ELIAS, H.G. An Introduction to polymer Science. New York: VCH, 1997. cap. 8 , p. $273-289$.

(32) (a) Celulose e Papel: tecnologia de fabricação de pasta celulósica. 2.ed. São Paulo: IPT, 1988. v. 1, cap. 2, p. 15-40. (b) ibid., cap. 11, p. 547. (c) ibid., cap. 3, p. 46. (d) ibid., cap. 3, p. 81-84. (e) ibid.,cap. 4, p. 113.

(33) GOMIDE, J.L. Polpa de Celulose: química dos processos alcalinos de polpação. Minas Gerais: Universidade Federal de Viçosa, 1979. v. 5, cap. 1, p. 1-2.

(34) (a) WHELAN, T. Polymer Technology Dictionary. New York: Chapman \& Hall, 1994. p. 67-68. (b) ibid., p. 43.

(35) TEDDER, J.M. Angew. Chem. Int. Ed. Engl., 1982, 21, 401. 
(36) (a) MARCH, J. Advanced Organic Chemistry: reactions, mechanisms and structure. 4.ed. New York: Wiley, 1992. cap. 14, p. 677-689. (b) ibid., cap. 5, p. 191. (c) ibid., cap. 7, p. 231-247.

(37) PRYOR, W.A. Introdução ao Estudo dos Radicais Livres. São Paulo: Edgard Blücher Ltda, 1970. p. 1-132.

(38) CAREY, F.A.; SUNDBERG, R.J. Advanced Organic Chemistry. Part A: structure and mechanism. 4.ed. New York: Kluwer Academic/Plenum Publishers, 2000. cap. 12, p. 663-742.

(39) (a) SKOOG, D.A.; HOLLER, F.J.; NIEMAN, T.A. Princípios de Análise Instrumental. 5.ed. Porto Alegre: Bookman, 2002. cap. 16, p. 342-362. (b) ibid., cap. 12, p. 252-272. (c) ibid., cap. 21, p. 476-499.

(40) SILVERSTEIN, R.M.; WEBSTER, F.X. Identificação Espectrométrica de Compostos Orgânicos. 6.ed. Rio de Janeiro: LTC, 2000. cap. 3, p. 67103.

(41) MCCLURE, G.L. Quantitative Analysis from the Infrared Spectrum. In: WILLIS, H.A.; van der MAAS, J.H.; MILLER, R.G.J., (Eds.). Laboratory Methods in Vibrational Spectroscopy. 3.ed. New York: Wiley, 1987. p. 148.

(42) COLLINS, C.H.; BRAGA, G.L.; BONATO, P.S. Introdução a Métodos Cromatográficos. 7.ed. Campinas: Unicamp, 1997. cap. 8, p. 141-181.

(43) CREWS, P.; RODRÍGUEZ, J.; JASPARS, M. Organic Structure Analysis. New York: Oxford University Press, 1998. cap. 6, p. 229-279.

(44) IONASHIRO, M.; GIOLITO, I. Cerâmica, 1980, 26, 17. 
(45) WILLARD, H.; MERRITT Jr., L.; DEAN, J. Análise Instrumental. 2.ed. Lisboa: Fundação Calouste Gulbenkian, 1979. cap. 17, p. 577-586.

(46) MILES, D.C.; BRISTON, J.H. Tecnologia dos Polímeros. São Paulo: Polígono, 1975. cap. 28, p. 548-549.

(47) (a) TIMMONS, C.O.; ZISMAN, W.A. J. Colloid Interface Sci., 1966, 22, 165. (b) BOUALI, B.; GANACHAUD, F.; CHAPEL, J.P.; PICHOT, C.; LANTERI, P. ibid., 1998, 208, 81.

(48) ADAMSON, A.W. Physical Chemistry of Surfaces. 5.ed. New York: Wiley, 1990. cap. 10, p. 392-396.

(49) http://www.fisica.ufc.br/raiosx-6.htm

(50) http://www.chemkeys.com/bra/md/ede_5/ddeq_2/raiosx_7/raiosx_7.htm

(51) BLOSS, F.D. Crystallography and Crystal Chemistry. Washington: Mineralogical Society of America, 1994. cap. 13, p. 467.

(52) (a) TSUJI, M. Electron Microscopy. In: Comprehensive Polymer Science: the synthesis, characterization, reactions and applications of polymers. New York: Pergamon Press, 1989. v. 1, cap. 34, p. 785-840. (b) KENNY, J.M.; NICOLAIS, L. Science and Technology of Polymer Composites. ibid. First Supplement, cap. 18, p. 476.

(53) GOLDSTEIN, J.I.; ROMIG, A.D. Jr.; NEWBURY, D.E; LYMAN, C.E.; ECHLIN, P.; FIORI, C.; JOY, D.C.; LIFSHIN, E. Scanning Electron Microscopy and X-Ray Microanalysis. 2.ed. New York: Plenum Press, 1992. cap. 12 , p. $635-639$.

(54) NAKANISHI, K.; SOLOMON, P.H. Infrared Absorption Spectroscopy. 2.ed. San Francisco: Holiden-Day, 1977. cap. 2, p. 31. 
(55) MCLAFFERTY, F.W.; STAUFFER, D.B. The Wiley/NBS Registry of Mass Spectral Data. New York: Wiley, 1989. p. 93.

(56) The Merck Index. 13.ed. New Jersey: Merck \& Co. Inc., 2001.

(57) (a) ODIAN, G. Principles of Polymerization. 2.ed. New York: Wiley, 1981. p. 196. (b) ibid., p. 216-219. (c) ibid., p. 205.

(58) MOAD, G. Prog. Polym. Sci., 1999, 24, 81.

(59) JANA, S.C.; PRIETO, A. J. Appl. Polym. Sci., 2002, 86, 2159.

(60) WUNDERLICH, B.; CORMIER, C.M. J. Polymer Sci. A-2, 1967, 5, 987.

(61) WARD, I.M.; HADLEY, D.W. An Introduction to the Mechanical Properties of Solid Polymers. New York: Wiley, 1997. cap. 11, p. 221.

(62) BUENO, W.A. Manual de Espectroscopia Vibracional. 2.ed. São Paulo: Mcgraw-Hill, 1989. p. 206.

(63) SOLPAN, D.; GÜVEN, O. Radiat. Phys. Chem., 2000, 57, 173.

(64) RASKULOVA, T.V.; VOLKOVA, L.I.; KNIZHNIK, A.V., KHALIULLIN, A.K. Polym. Sci., Ser. A, 2000, 42, 475.

(65) HAM, G.E. J. Macromol. Sci. - Chem., 1975, A9, 635.

(66) DETAR, D.F. J. Am. Chem. Soc., 1967, 89, 4058.

(67) DE VITO, G.; LANZETTA, N.; MAGLIO, G.; MALINCONICO, M.; MUSTO, P.; PAlUMBO, R. J. Polym. Sci., Polym. Chem. Ed., 1984, 22, 1335.

(68) SHECHTER, H.; BARKER, H.C. J. Org. Chem., 1956, 21, 1473.

(69) BICKFORD, W.G.; FISHER, G.S.; DOLLEAR, F.G.; SWIFT, C.E. J. Am. Oil Chem. Soc., 1948, 25, 251.

(70) FUHRMANN, I.; KOCSIS, J.K. J. Appl. Polym. Sci., 2003, 89, 1622. 
(71) RÅNBY, B. Polym. Eng. Sci., 1998, 38, 1229.

(72) TURRO, N.J. J. Chem. Educ., 1969, 46, 2.

(73) LEE, E.K.C.; LEWIS, R.S. Adv. Photochem., 1980, 12, 57.

(74) CORDELLA, C.D.; CARDOZO, N.S.M.; BAUMHARDT NETO, R.; MAULER, R.S. J. Appl. Polym. Sci., 2003, 87, 2074.

(75) ELIAS, G.H. An Introduction to Plastics. New York: VCH, 1993. cap. 2, p. $40-44$.

(76) GAYLORD, N.G; MEHTA, R.; KUMAR, V. J. Appl. Polym. Sci. 1989, 38, 359.

(77) QUIRK, R.P.; ALSAMARRAIE, M.A.A. Physical Constants of Poly(ethylene). In: BRANDRUP, J.; IMMERGUT, E.H., (Eds.). Polymer Handbook. 3.ed. New York: Wiley, 1989. p. v/19.

(78) ZHANG, F.; ENDO, T.; QIU, W.; YANG, L.; HIROTSU, T. J. Appl. Polym. Sci., 2002, 84, 1971. 


\section{CURRICULUM VITAE}

\section{Romeu Casarano}

Data de Nascimento: 04/03/63. Local: Osasco - SP

\section{Formação:}

Especialização: Administração Industrial - Fundação Vanzolini / USP Fev/1996 a Dez/1997.

Extensão Universitária: Obtenção de Celulose e Fabricação de Papel ABTCP / Faculdades Oswaldo Cruz - Ago/1989 a Dez/1989.

Aperfeiçoamento: Atribuições Tecnológicas (Monografia: Obtenção de Celulose e Fabricação de Papel) - Faculdades Oswaldo Cruz - Fev/1988 a Dez/1988.

Graduação: Bacharel e Licenciatura em Química - Faculdades Oswaldo Cruz - Fev/1982 a Dez/1985.

\section{Disciplinas cursadas na Pós-Gradução:}

Técnicas de Determinação Estrutural (QFL 5922-2) - 12/08/02 a 11/10/02 no de créditos 8 e conceito $A$.

Prática de Ensino de Química (QFL 5918-3) - 09/10/02 a 19/11/02 - ํo de créditos 2 e conceito $A$.

Mecanismos das Reações Orgânicas (QFL 5920-2) - 15/10/02 a 13/12/02 $\mathrm{n}^{\circ}$ de créditos 8 e conceito $A$.

Planejamento e Otimização de Experimentos (QFL 5912-2) - 12/03/03 a 11/06/03 - no de créditos 8 e conceito $A$.

Conceitos em Química Orgânica Avançada (QFL 5919-2) - 05/05/03 a 04/07/03 - no de créditos 8 e conceito $A$.

Introdução aos Métodos Termoanalíticos (FBF 5751) - 13/08/03 a 10/12/03 - no de créditos 10 e conceito $A$.

\section{Participação em Congressos:}

ISNAPOL: $5^{\text {th }}$ International Symposium on Natural Polymers and Composites - Set/2004. 